\title{
WestVirginiaUniversity
}

THE RESEARCH REPOSITORY @ WVU

Graduate Theses, Dissertations, and Problem Reports

2020

\section{Energy Forensics Analysis}

\author{
Rupa Das \\ West Virginia University, rd0040@mix.wvu.edu
}

Follow this and additional works at: https://researchrepository.wvu.edu/etd

Part of the Industrial Engineering Commons

\section{Recommended Citation}

Das, Rupa, "Energy Forensics Analysis" (2020). Graduate Theses, Dissertations, and Problem Reports.

7871.

https://researchrepository.wvu.edu/etd/7871

This Thesis is protected by copyright and/or related rights. It has been brought to you by the The Research Repository @ WVU with permission from the rights-holder(s). You are free to use this Thesis in any way that is permitted by the copyright and related rights legislation that applies to your use. For other uses you must obtain permission from the rights-holder(s) directly, unless additional rights are indicated by a Creative Commons license in the record and/ or on the work itself. This Thesis has been accepted for inclusion in WVU Graduate Theses, Dissertations, and Problem Reports collection by an authorized administrator of The Research Repository @ WVU. For more information, please contact researchrepository@mail.wvu.edu. 
WestVirginiaUniversity

THE RESEARCH REPOSITORY @ WVU

Graduate Theses, Dissertations, and Problem Reports

2020

Energy Forensics Analysis

Rupa Das

Follow this and additional works at: https://researchrepository.wvu.edu/etd

Part of the Industrial Engineering Commons 


\section{ENERGY FORENSICS ANALYSIS}

\section{Rupa Das}

Thesis submitted to the Benjamin M. Statler College of

Engineering and Mineral Resources at

West Virginia University in partial fulfillment

of the requirement for the degree of

\section{Master of Science \\ in \\ Industrial Engineering}

Bhaskaran Gopalakrishnan, Ph.D., P.E., Chair

Ashish Nimbarte, Ph.D.

Kenneth H. Means, Ph.D., P.E.

Department of Industrial and Management Systems Engineering

\section{Morgantown, West Virginia 2020}

Keywords: Utility bill, Energy, Simulation, Residential House

Copyright 2020 - Rupa Das 


\section{ABSTRACT \\ Energy Forensics Analysis \\ Rupa Das}

The energy consumed by a building can reveal information about the occupants and their activities inside the building. This could be utilized by industries and law enforcement agencies for commercial or legal purposes. Utility data from Smart Meter (SM) readings can reveal detailed information that could be mapped to foretell resident occupancy and type of appliance usage over desired time intervals. However, obtaining SM data in the United States is laborious and subjected to legal and procedural constraints. This research develops a user-driven simulation tool with realistic data options and assumptions of potential human behavior to determine energy usage patterns over time without any utility data. In this work, factors such as occupant number, the possibility of place being occupied, thermostat settings, building envelope, appliances used in households, appliance capacities, and the possibility of using each appliance, weather, and heatingcooling systems specifications are considered. For five specific benchmarked scenarios, the range of the random numbers is specified based on assumed potential human behavior for occupancy and energy-consuming appliances usage possibility, with respect to the time of the day, weekday, and weekends. The simulation is developed using the Visual Basic Application (VBA)® in Microsoft Excel®, based on the discrete-event Monte Carlo Simulation (MCS). This simulation generates energy usage patterns and electricity and natural gas costs over 30-minutes intervals for one year. The simulated energy usage and the cost are reflected in the sensitivity analysis by comparing factors such as occupancy, appliance type, and time of the week. This work is intended to facilitate the analysis of building occupants' activities by various stakeholders, subject to all legal provisions that apply. It is not intended for the general public to pursue these activities because legal ramifications might be involved. 


\section{Dedication}

This work is dedicated to my courageous mother and she is the inspiration of my life. To my Didivai and Dadavai, who have supported me through this journey. Finally, to my beloved husband, Rajib, who is my strength and encourages me to pursue my dream. 


\section{Acknowledgment}

I would like to express my sincerest gratitude to my research advisor and committee chair, Dr. Bhaskaran Gopalakrishnan, for his continuous support and motivation. He guided me through this whole process with his immense knowledge. Without his endless support, this research work was not possible to complete. I also wish to acknowledge my committee member Dr. Ashish Nimbarte, who always encouraged and supported me when I needed it most. I would also like to recognize my other committee member, Dr. Kenneth H. Means. I am grateful for their assistant, support and time throughout this research and besides, their expertise added value to this research. I would like to acknowledge Koushik Mandlem, whose previous work was an excellent reference for me.

I would like to acknowledge my friends, Bratatidi and Afrin, who were with me at my every step with their endless support since I moved to the USA. To my mother-in-law, father-in-law and bother-in-law, who were always beside me with their blessings. To my nieces Aratrika and Ariya, who are the source of my motivation. Above all, my husband who is beside me all the time when I need him. 


\section{Contents}

ABSTRACT

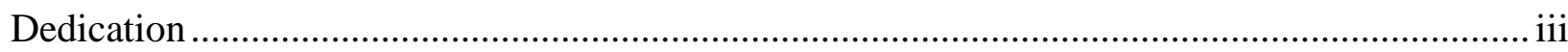

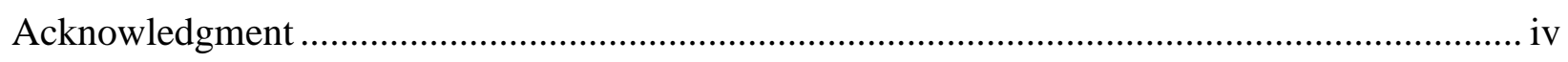

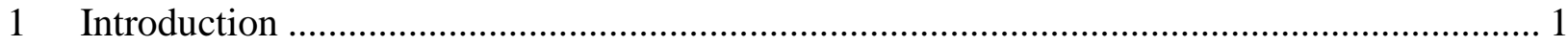

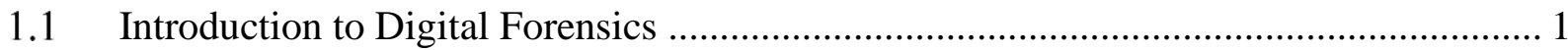

1.1.1 Data Analysis ............................................................................................ 2

1.2 Usage of Digital Data to Interpret Human Behavior...................................................... 3

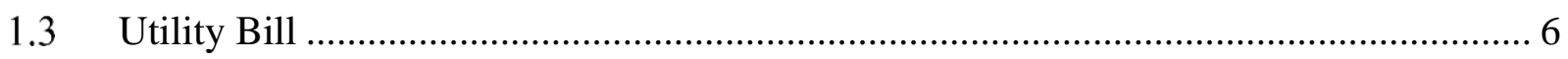

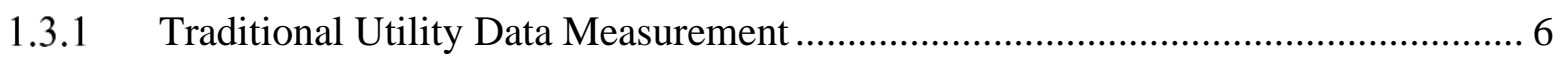

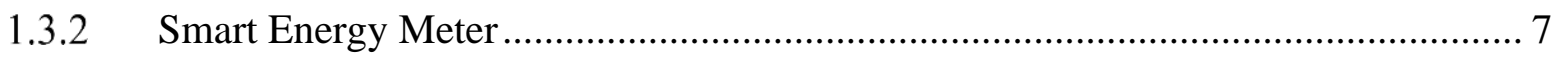

1.4 Resident Activity Related to Energy Consumption ..................................................... 8

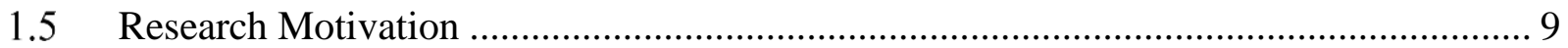

1.6 Research Approach and Objectives....................................................................... 10

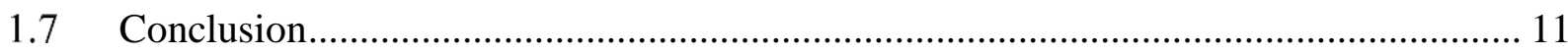

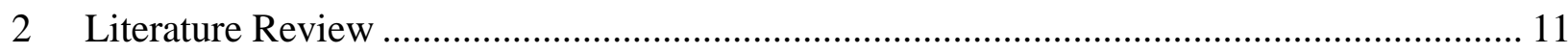

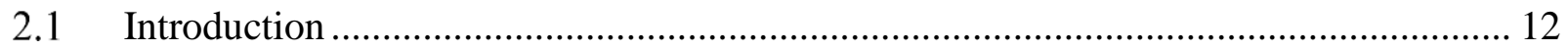

2.2 Traditional Electric Meter Energy Data Analysis for Residential House ...................... 12

2.2.1 Energy Consumption Models ........................................................................... 12

2.2.2 Cause of Energy Consumption Variation ............................................................ 15

2.2.3 Electricity Load Demand Model.................................................................. 16

2.3 Work-Based on SM Energy Data for the Analysis of Residential Energy Consumption 17

2.4 Work Based on the Benefits of SM Deployment ....................................................... 19

2.5 Obstacles of Using Smart Meter Data/ Research Gap ................................................ 20

2.6 Potential of this Research................................................................................... 22

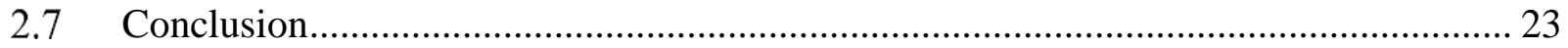

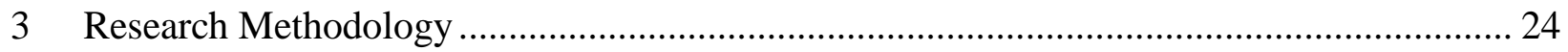

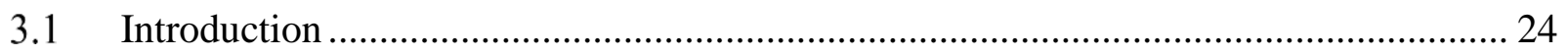

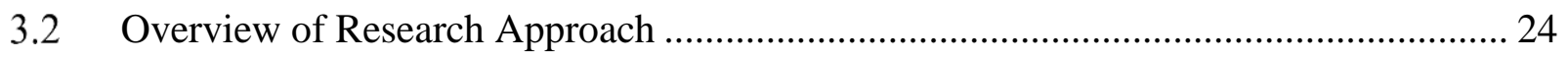

3.3 Case/Scenario Development ................................................................................. 26

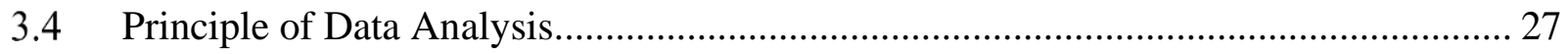

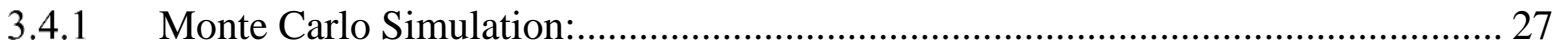




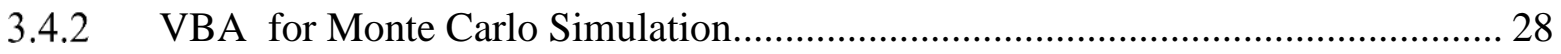

3.5 Summary of Energy Calculation Factors ……………………………………….... 28

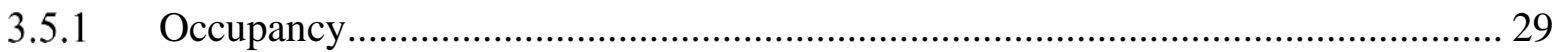

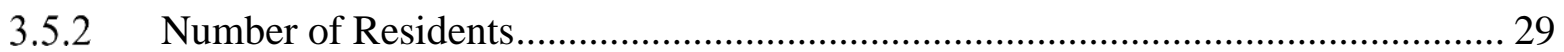

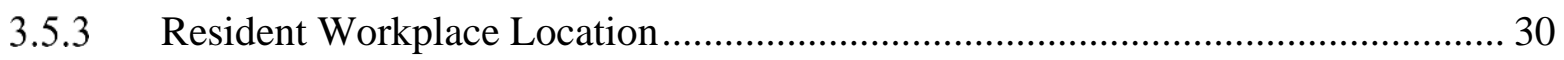

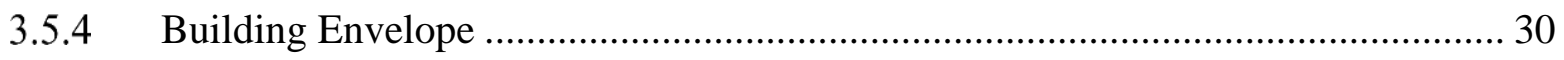

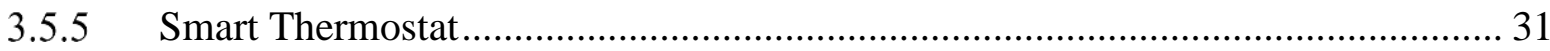

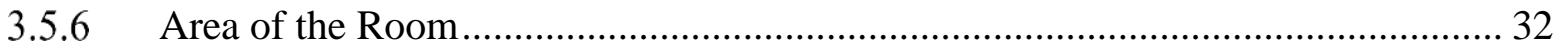

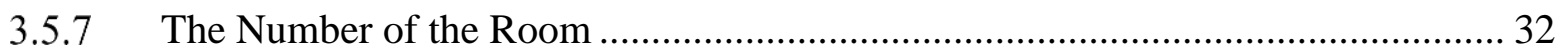

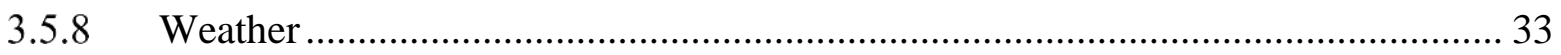

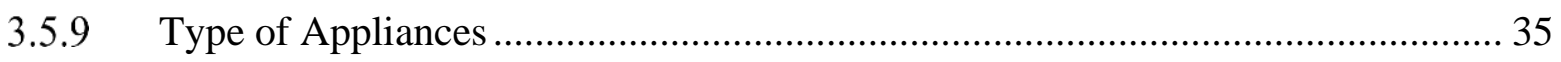

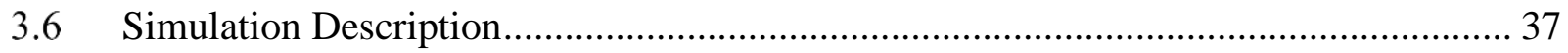

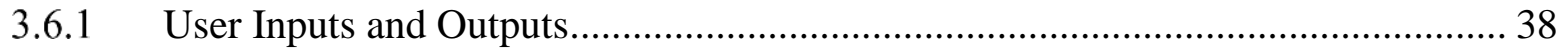

3.6.2 Description of Energy Consumption Calculation ............................................... 38

3.7 Assumption and Limitation ..................................................................................... 42

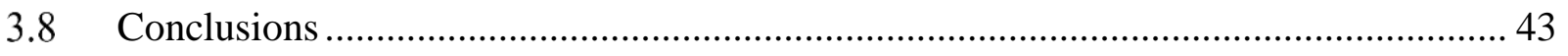

4 Simulation Tool Development...................................................................................... 44

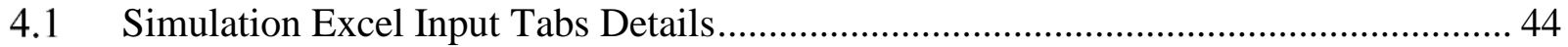

4.1.1 “User Manual” Worksheet .................................................................................. 44

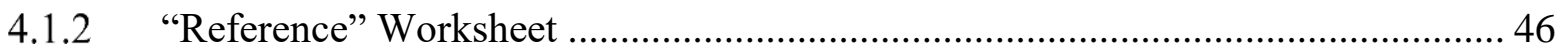

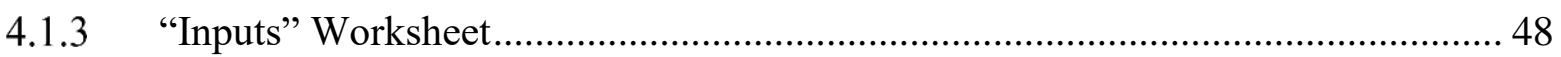

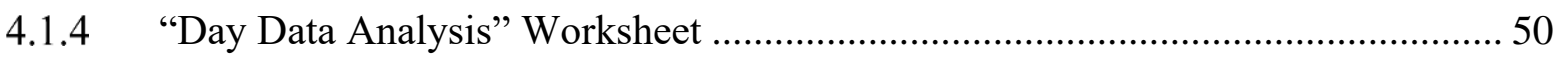

4.2 Developing Excel VBA Code …………….......................................................... 50

4.3 Simulation Demonstration with Case-1 Example ...................................................... 54

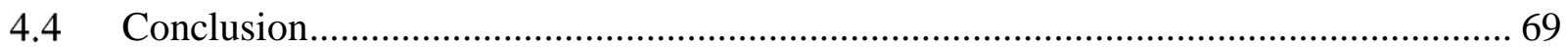

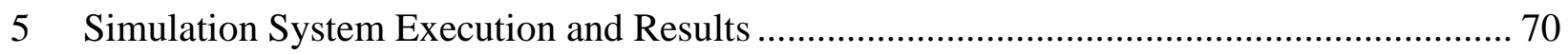

5.1 Realistic Data-Based Simulation Tool ...................................................................... 70

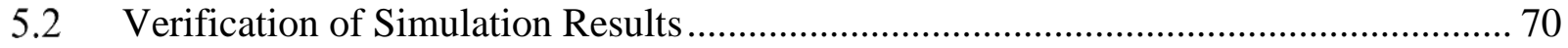

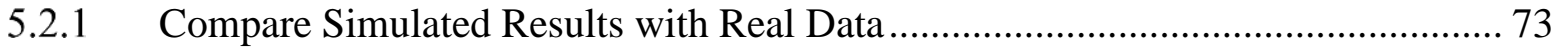

5.3 Research Work Relation with Forensics ................................................................. 74

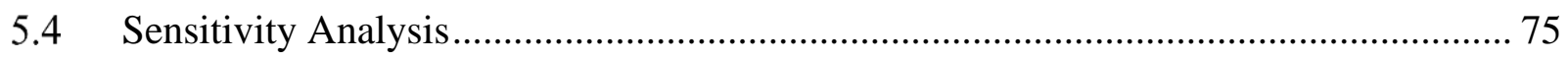

5.4.1 Different Occupancy Probability .................................................................. 75 
5.4.2 Probability of Appliances Usage ............................................................. 77

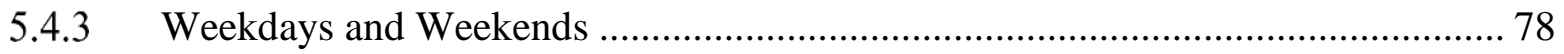

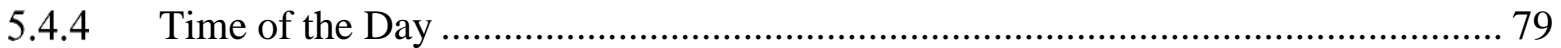

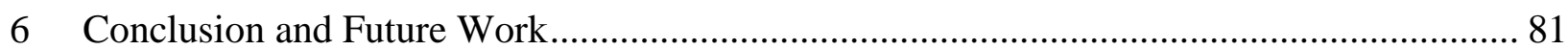

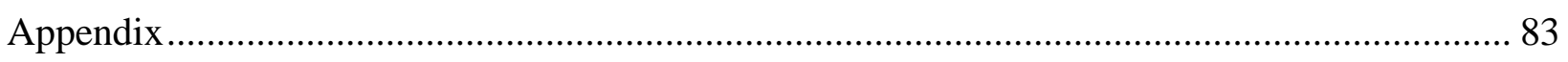

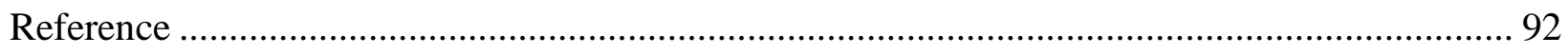




\section{List of Table}

Table 1.1: Types of electricity, heat, and gas meters [5] ..................................................... 6

Table 3.1: Building Envelope Regulation Chart [40] .............................................................. 31

Table 3.2: User Guidelines to determine the level for the thermostat [40]................................ 31

Table 3.3: Model Guidelines to determine the level for the thermostat [40] ............................... 31

Table 3.4: Standard Size of the room in Residential Building [41] ......................................... 32

Table 3.5: Probability chart to determine volume level [40] ...................................................... 32

Table 3.6: Details room number for each case ....................................................................... 33

Table 3.7: Rules to determine Whether Factor [40].............................................................. 33

Table 3.8: List of heating and cooling degree days for each climate zone ................................ 34

Table 3.9: Calculation of cooling ration for the South Atlantic region..................................... 35

Table 3.10: List of appliances for energy consumption. The specification of the appliances are taken from online resources [43]...................................................................................... 35

Table 3.11: The rules for using the light in the bedroom ....................................................... 37

Table 3.12: Load Factor Assignment [40] .............................................................................. 40

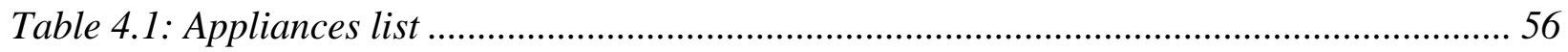

Table 4.2: Load Factor Assignment ...................................................................................... 59

Table 4.3: Appliances list with usage factor different than the default value of $100 \%$............... 61

Table 5.1: List of Used Appliance for Five Cases ................................................................... 70

Table 5.2: HVAC Specifications for five cases ...................................................................... 71

Table 5.3: Occupancy probability chart for five different cases ............................................ 75 


\section{List of Figure}

Figure 1-1: Nucleus of Digital Forensics Research. [1] .................................................... 1

Figure 3-1: Steps of Energy Forensics Analysis.................................................................... 25

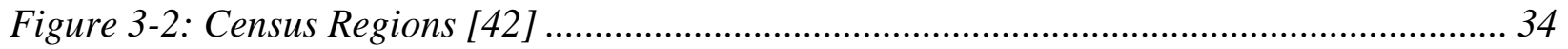

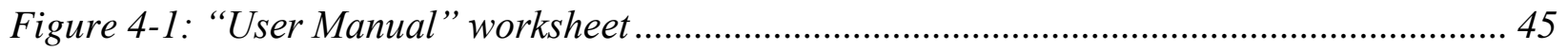

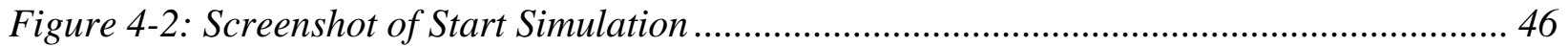

Figure 4-3: Occupancy Chart from "Reference" worksheet .................................................... 47

Figure 4-4: "Inputs" worksheet .......................................................................................... 49

Figure 4-5: Direction for considered factors value in "Inputs" worksheet ............................... 55

Figure 4-6: Pop-up input boxes for building construction and thermostat changing frequency 56

Figure 4-7: "Bedroom 1" sheet after Step 1 ............................................................................ 57

Figure 4-8: Average HVAC load factor in "Load factor" Worksheet ....................................... 58

Figure 4-9: Message boxes from "Step 5 ".......................................................................... 60

Figure 4-10: Selected Region Heating Degree Days (HDD) and Cooling Degree Days (CDD) at

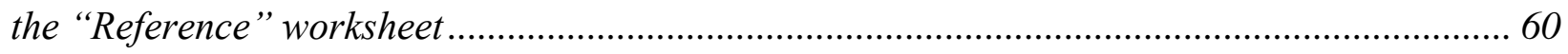

Figure 4-11: Total $\mathrm{kWh}$ and MMBtu consumption at 30 minutes interval for one year ............. 63

Figure 4-12: Total electricity cost and the cost of natural gas. ............................................. 63

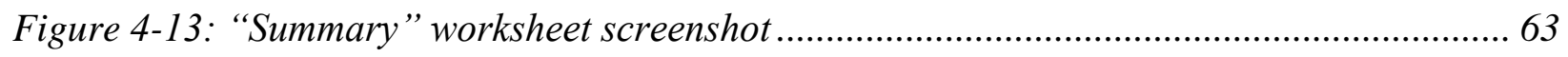

Figure 4-14: HVAC energy consumption summary of 12 months ........................................... 64

Figure 4-15: Appliances energy consumption summary for January .................................... 65

Figure 4-16: Total energy consumption pattern for $10^{\text {th }}$ July ............................................. 66

Figure 4-17: HVAC energy consumption pattern for $10^{\text {th }}$ July ................................................. 66

Figure 4-18: Low-capacity appliances energy consumption pattern of $10^{\text {th }}$ July ...................... 67

Figure 4-19: Medium-capacity appliances energy consumption pattern of $10^{\text {th }}$ July................ 67

Figure 4-20: Moderately high-capacity appliances energy consumption pattern of $10^{\text {th }} \mathrm{July}$.... 68

Figure 4-21: High-capacity appliances energy consumption pattern of $10^{\text {th }}$ July...................... 68

Figure 4-22: Stove and water heater energy consumption pattern of $10^{\text {th }}$ July ........................ 68

Figure 5-1: Building Specification in "Inputs" Sheet for Five Different Cases ......................... 71

Figure 5-2: Total energy consumption and cost for five different cases. The $k W h$ indicates electricity consumption, and the MMBtu indicates natural gas consumption............................ 72

Figure 5-3: One Year Energy consumption of HVAC for Five Different Cases ........................ 73

Figure 5-4: Simulated results vs. real data one-year electricity consumption comparison........ 74

Figure 5-5: One-year energy consumption and costs for five different cases ............................ 77

Figure 5-6: Energy consumption for case-1 with different appliances combination ................... 77

Figure 5-7: Energy consumption for case-5 with different appliances combinations in the living

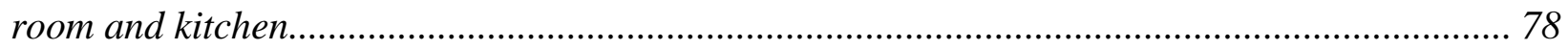

Figure 5-8: Energy consumption weekends Vs. weekdays ..................................................... 79

Figure 5-9: Energy consumption comparison for the same time of day for different case ......... 80 


\section{List of Nomenclature}

ANN - Artificial Neural Network

AMI - Advanced Metering Infrastructure

$\mathrm{COP}$ - Coefficient of Performance

EE - Energy Efficiency

EIA - Energy Information Administration

EUI - Energy Use Intensity

GHG - Green House Gas

HEMS - Home Energy Management systems

HVAC - Heating, ventilation, and Air Conditioning

IENs - Intelligent Energy Networks

IoT - Internet of Things

MCS - Monte Carlo Simulation

SEER - Seasonal Energy Efficiency Ratio

$\mathrm{SM}$ - Smart Meter

VBA - Visual Basic Application 


\section{Introduction}

\subsection{Introduction to Digital Forensics}

The rapid advantage in sensors, data collection monitoring systems and storage technology have generated enormous complex and multidimensional datasets. Our everyday life activities have been recorded while we are using digital technology such as credit cards, social media, telephone. All these recorded data are the potential source of valuable information and the primary input for digital forensics analysis. Digital forensics can be defined as the use of scientifically derived and proven methods toward the preservation, collection, validation, identification, analysis, interpretation, documentation, and presentation of digital data which is derived from digital sources to facilitate or further the reconstruction of events found to be criminal or helping to anticipate unauthorized actions shown to be disruptive to planned operations - DFRWS.[1]

The dependency on digital sources of information and computerized system and the network is a worldwide phenomenon that has been increasing day by day. Figure 1.1 illustrates the growing dependence for every sector on digital forensics research.

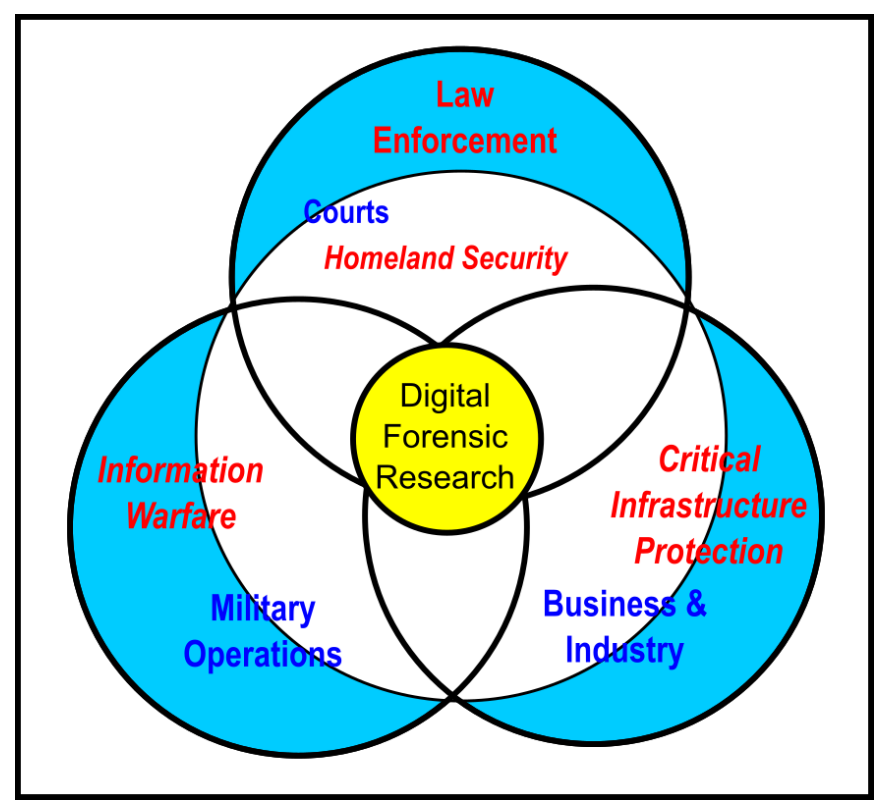

Figure 1-1: Nucleus of Digital Forensics Research. [1]

Energy Forensics: Recently, all information related to energy is available in digital format. Correspondingly, the improvement of the electronic sensor, data storage, and communication 
technologies in energy measurement provides enormous detailed information about energy usage, demand, supply, and systems performance. Energy data forensics relies on this digital information, networking, and data transmission systems. For analyzing all this information to get an insight into the detailed activities of energy users, different data analysis tools can be used, such as simulation, linear or nonlinear regression, least-squared method, decision tree analysis, clustering method. However, energy information is not publicly available. Even law enforcement personnel do not have access to detailed energy data such as energy supply, user information, appliance information, occupancy, which contributes substantial insight into evidence. So, the field of energy forensics is looking for an alternative solution. A simulation is an essential tool in the field of energy forensics. It is possible to simulate the energy usage pattern for different scenarios. After that, various data analysis techniques can be used for analyzing the simulation results.

\subsubsection{Data Analysis}

Data analysis plays an essential role in energy forensics for data processing and pattern development. Data mining and data visualization are the main two branches of data analysis. Both are an integral part of knowledge discovery in the database, converting raw data into useful information and allowing humans to interact with data and draw a conclusion. Data mining is the process of sorting out large data sets and extracting information out of them. Data mining deals with sophisticated mathematical algorithms. The core data mining techniques are regression analysis, decision tree, clustering, classification, and prediction. On the other hand, data visualization is the process of visualizing or displaying the data in the form of graphical and visual

formats. Data visualization can efficiently deal with highly homogeneous and noisy data with a higher degree of confidence. Besides, it does not require any complex mathematical and statistical algorithms. There are many visualization techniques such as geometrically transformed display, iconic display, dense pixel display, and stacked display.

The filtered information from the data analysis technique provides the opportunity for a better monitoring system in every sector. Nowadays, somehow every step of modern life is linked with an information networking system. Processing all this information through digital forensics analysis can portray the daily activities of a person in detail. 


\subsection{Usage of Digital Data to Interpret Human Behavior}

In this modern era, there are many ways people can leave electronic trails. It is easy to follow their digital footprint through these electronic trails. Generally, there are two types of digital footprint: active and passive. The passive footprint can define as interaction with infrastructure. For example, a mobile phone network, which produces entries in locational logs. The active footprint comes from the user when they expose location data in photos, messages, and sensor measurements. For example, we can trace the digital footprint of a person if we follow their daily routine. When a person uses a cell phone or any social media, then their location becomes traceable. When people go to the restaurant, they might add online reviews or upload photos that provide information about their site and activities. Even though they do not use any kind of apps, their position can be tracked by tracking their credit card usage. By chasing credit card usage, it is also possible to know about their shopping items in detail. When someone drives somewhere or take an Uber ride, their total traveling path can be tracked through google map, uber apps, and other location-sharing apps. Most of the place requires log entries, which also provide evidence about personnel location. In extreme cases, it is also possible to check their phone message and phone dial number in detail. Furthermore, the social media account is the projection of a person's view about different social incidents. At present, all the available sources of the digital footprint can detect a person's activities outside of his house.

In addition, the usage of Artificial Intelligence (AI) is gradually increasing in predicting human behavior. Two monitoring approaches are available for tracing human behavior: vision-based monitoring and sensor-based monitoring [2]. In vision-based monitoring systems, the video camera is commonly used to ensure outdoor and public places' security. Therefore, vision-based technology can be deployed for discovering human activities such as entertainment, home automation, security, and safety of the residents, Ambient-Assisted Living (AAL), advanced support, and care applications. AAL can provide different types of support regarding health and safety, mostly for the elderly or impaired people. AAL's intelligent monitoring system's main advantage over the traditional video surveillance systems recognizes a different set of behavior that can identify specific body activity, e.g., accurate fall detection. The leading information source for vision-based technology is the video camera because the video provides rich sensory information. This information can be utilized for providing services from automatic supervision to 
intelligent monitoring. Automatic supervision can help the elderly population to improve their daily life activities by promoting positive behavior changes and assist them with medication. For illustration, a vision-based health monitoring system learns the activity patterns of the elderly and detects anomalies or deviations, which can help to recognize the change of health status. There will be a predefined activity zones environment, where visitors will identify the activity. Usually, the event is logged when a subject stays in the activity zone for more than one second. To detect deviations from the learned activity pattern, it performs pattern analysis later. The system can detect a home emergency, such as the fall of a subject. Before the trigger, the alarm system tries confirming the fall detection with the involved person. As a next step, the system will contact the emergency personnel in charge. For communication, a video will be transmitted to the responsible person as a shadow form for maintaining a person's privacy. Finally, the monitoring person will check the subject person's state and take action as required. Moreover, under the obstruction, multiple people can be detected as well as their activities can be tracked. Nevertheless, continuous monitoring through the video camera violates privacy rights, so such systems frugally access the private area such as a home. Due to the obstacle of rules and regulations, the vision-based monitoring systems are not publicly available, and progress is slow.

Another known technique for monitoring human behavior is a sensor-based monitoring system. The sensor-based system uses deep learning architecture for modeling the inter-activity human behavior, which is based on classification concepts of human behavior. This classification develops an algorithm to automatically described inter-activity behavior. The algorithm creates a probabilistic model of user behavior by using Long-Short Term Memory Networks (LSTMs). This model predicts the next user action or detects unexpected behavior. For illustration, it can detect the over speed vehicle number plate, leaving a bag at the airport, removing an object from a store (theft), and exchange bag among two people.[3]

In general, the sensor-based system has two branches: data-driven and knowledge-driven approaches. Data mining and machine learning techniques have been used to learn about human behavior and activity in the data-driven approach. This system requires enormous sensor-based datasets about human activities to train different kinds of classifiers. Several training techniques are used, such as the Markova model, Bayes classifier, dynamic Bayesian network, support vector 
machine, and online classifier. Usually, all these techniques try to model human behavior while considering humans as devices with many internal mental states. Each mental state has its particular control behavior and interstate transition probabilities. Short-term and long-term behavior can be described by organizing the data in hierarchical order. In terms of a road-driving event, long-term behavior might be passing, turning, and following, and maintaining lane position and releasing break will be considered as short-term behavior. Another widespread usage is to manage people and object interaction by performing a shadow analysis of a person to protect body parts from the machine or avoid a car accident. [4]

The existing domain knowledge has been used for the training in the knowledge-driven approaches instead of labeled datasets. The significant task in an intelligent environment is to predict human behavior. The improvement of data science allows a model to scrutinize human daily life activities in detail. This facilitates the detection process of human behavior variation and the subject's needs. The different algorithm has been developed based on sequencing matching, compression, device usage pattern, user mobility pattern, and user activity prediction methods in the smart environment. Technically rich cities are trying to convert their cities into smart cities, where they are deploying deep learning architecture. The enormous amount of data improves the decision-making process and transforms the whole city into an intelligent environment. To ensure smart city residents' comfortlessness, a more in-depth analysis of the use of user behavior in intelligent environments is usually performed. Finally, it is possible to model and predict the inter-activity behavior with a detailed description by using action sequences from specific sensor technology. [2]

All the aforementioned human behavior prediction processes will help law enforcement to control illegal activities. Additionally, the improved vision-based and sensor-based monitoring system provide the facility to take more precaution. Law enforcement agencies can track a suspected person's activity through their financial actions, monitoring alliances with different groups, tracing their travel, and following them on social media. However, it is not easy to track a person's activity when they are inside the house. Due to the protection rules on citizen privacy rights, artificial intelligence cannot be deployed in a private place. In this situation, digital forensics of residential energy data can provide information about the resident activities and occupancy. Generally, all the appliances consume energy, and appliances' usage is directly related to the occupancy. The only 
way to get detailed energy consumption information is the utility bill. So, in this study, the utility bill is an integral part of energy forensics analysis.

\subsection{Utility Bill}

The utility bill is the primary source of energy data for the residential area. The utility bill of the residential area consists of administrative/customer charge and energy charge. In general, the energy charge includes the cost of the actual energy expenses, implicit demand charge, and fuel adjustment charge. Electricity and natural gas are usually included in this energy. Utility bill varies depending on the amount of usage. In general, the Demand charge does not apply to the residential area because individual demand is relatively inconsequential and expensive to a meter. Residential rate schedules are diverse for different residential users and regions. The most efficient way to understand the utility bill is to analyze the energy consumption for each equipment.

\subsubsection{Traditional Utility Data Measurement}

There are a variety of energy meters available. Depending on the type of energy, the most common measuring equipment are electricity meter, heat meter, and gas meter are shown in table 1.1. The most typical electricity meter is known as the electromechanical meter. The electromechanical meter is equipped with a non-magnetic, electrically conductive metal disc where rotational speed is proportional to the power which is passing through the meter. Usually, the meter is manual and read by the power company representative or customer. Digital microtechnology (DMT) promotes the development of electronic meters, where the meter does not need to depend on moving parts. The electronic meter consists of several parts, such as an LCD monitor, a metering engine, a processor, and a communication engine. Besides measuring the energy use, it can record another

parameter such as usage demands, voltages, power factor, reactive factor. In addition to help consumers and utility companies, it can transmit the reading to a remote place. [5]

Table 1.1: Types of electricity, heat, and gas meters [5] 


\begin{tabular}{|c|c|c|c|c|}
\hline \multicolumn{3}{|c|}{ Type Of Meter } & Advantages & Disadvantages \\
\hline \multirow[b]{2}{*}{$\begin{array}{l}\text { Electricity } \\
\text { Meter }\end{array}$} & \multicolumn{2}{|c|}{ Electro-mechanical } & - $\quad$ Reliable measurement & $\begin{array}{ll}\text { - } & \text { Manually Reading } \\
\text { - } & \text { Electricity consumed by } \\
\text { current coil is also registered } \\
\text { on the meter } \\
\text { - } & \text { Creep phenomenon } \\
\end{array}$ \\
\hline & \multicolumn{2}{|c|}{ Electronic } & $\begin{array}{l}\text { - Measure more parameters besides } \\
\text { energy consumption } \\
\text { - LCD/LED display } \\
\text { - Two-way communication } \\
\text { - Other functions of smart control }\end{array}$ & $\begin{array}{ll}\text { - } & \text { Complex communication } \\
\text { infrastructure required } \\
\text { - } & \text { Periodic calibration routines } \\
\text { are required } \\
\text { - } & \text { Security issues with } \\
\text { unencrypted communication }\end{array}$ \\
\hline \multirow{4}{*}{ Heat Meter } & \multirow[b]{2}{*}{$\begin{array}{l}\text { Dynamic } \\
\text { Meter }\end{array}$} & $\begin{array}{l}\text { Impeller } \\
\text { Meter }\end{array}$ & $\begin{array}{l}\text { - Suitable for small-(single jet) and } \\
\text { medium-size (MultiJet) buildings }\end{array}$ & - $\quad$ Sensitive to impurities \\
\hline & & $\begin{array}{l}\text { Turbine } \\
\text { Meter }\end{array}$ & - $\quad$ Suitable for large flows & $\begin{array}{l}\text { - } \quad \text { High start-up threshold } \\
\text { - } \text { Rapid wearing of bearings at } \\
\text { high loads and/or in dirty } \\
\text { water }\end{array}$ \\
\hline & \multirow{2}{*}{$\begin{array}{l}\text { Static } \\
\text { Meter }\end{array}$} & $\begin{array}{l}\text { Magnetic } \\
\text { Induction }\end{array}$ & - $\quad$ Accurate & $\begin{array}{ll}- & \text { Initial costs are higher than } \\
\text { dynamic meters }\end{array}$ \\
\hline & & Ultrasonic & $\begin{array}{l}\text { - Accurate and cost-effective for large } \\
\text { flows }\end{array}$ & $\begin{array}{l}\text { - Less accurate than magnetic } \\
\text { meters }\end{array}$ \\
\hline \multirow{6}{*}{ Gas Meter } & \multicolumn{2}{|c|}{ Diaphragm Meter } & - Widely adopted & $\begin{array}{l}\text { - Cannot handle large flows or } \\
\text { high pressure }\end{array}$ \\
\hline & \multicolumn{2}{|c|}{ Rotary Meter } & $\begin{array}{l}\text { - Accurate } \\
\text { - Capable of handling large flows and } \\
\text { high pressure }\end{array}$ & $\begin{array}{l}\text { - } \quad \text { More maintenance is needed } \\
\text { Relatively expensive for large } \\
\text { sizes } \\
\text { Possible corrosion 'erosion } \\
\text { due to abrasive materials }\end{array}$ \\
\hline & \multicolumn{2}{|c|}{ Turbine Gas Meter } & 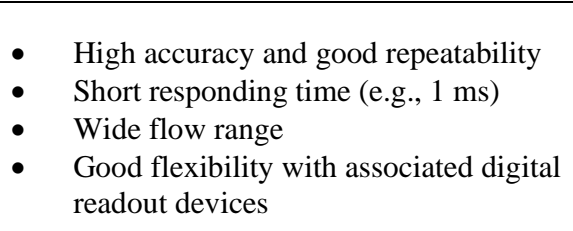 & $\begin{array}{ll}- & \text { Requires good flow condition } \\
\text { - } & \text { Problematic when measuring } \\
\text { lower flow rate } \\
\text { - } \quad \text { Particulates can cause line } \\
\text { blockage }\end{array}$ \\
\hline & \multicolumn{2}{|c|}{ Orifice Gas Meter } & $\begin{array}{l}\text { Acceptable in industrial applications, } \\
\text { because 1) easy to field-service and ) } \\
\text { no moving parts }\end{array}$ & - Cannot handle large flows \\
\hline & \multicolumn{2}{|c|}{ Ultrasonic Flow Meter } & $\begin{array}{ll}\text { - } & \text { Works best in no-liquid condition } \\
\text { - } & \text { Great accuracy } \\
\text { - } & \text { Wide flow range } \\
\text { - } & \text { Applicable to almost any dry gas }\end{array}$ & 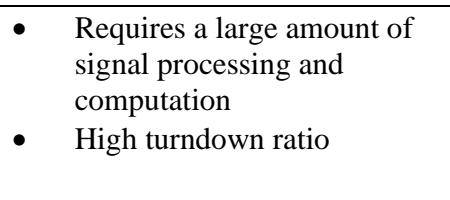 \\
\hline & \multicolumn{2}{|c|}{ Coriolis Meter } & $\begin{array}{ll}\text { - } & \text { Wide flow range } \\
\text { - } & \text { Most accurate } \\
\text { - Can infer gas flow rate in flowing } \\
\text { condition }\end{array}$ & $\begin{array}{l}\text { - Requires additional elements } \\
\text { to function }\end{array}$ \\
\hline
\end{tabular}

\subsubsection{Smart Energy Meter}


Utilizing communication and data storage technology, utility companies introduce new energy consumption measuring devices, known as Smart Meter (SM). The most crucial feature of SM is the two-way communication capability. SM measure the energy consumption and display it on an analog counter. SM directly sends the bill and energy status to utility companies and customers. The first-generation SM was equipped with Automated Meter Reading (AMR) and Remote Meter Reading (RMR) while it operates at one-way communication. SM provides access of long distances meter reading to the utility company. After the development of Advanced Metering Infrastructure (AMI) and Intelligent Energy Networks (IENs), SM could afford two-way end-toend communication, appliance monitoring, and control, detection and diagnosis of faulty systems, data storage and management, demand-side management, detection of electricity theft, enhancement of system security, load management, and emission control, and development of smart urban cities. [6], [7] The functions of SM are;

- Data Recording and Alarming

- Two-Way Communication

- Demand-Side Management

- Detection of Electricity Theft and Enhancing System Security

\subsection{Resident Activity Related to Energy Consumption}

With the ability of the functions mentioned above, details energy consumption data can be utilized to predict human behavior. Even though constructing a load pattern for residential end-users is a highly complex task, it can be achieved through the usage of smart meter data to understand the behavior of the residents.

- Occupied or Unoccupied: Electricity consumption pattern at various time intervals of the day shows people's presence in that specific house. Any appliance usage directly depends on the occupancy except few appliances such as freezer, refrigerator.

- Number of Residents: It is also possible to get an idea about the number of residents who are staying at that specific house. Based on the number of residents, the energy consumption quantity will vary. An extra number of residents will consume excess energy.

- Residents Occupation: Depends on the occupation, resident occupancy will vary. So, the energy consumption data can assist in getting an idea about the resident job schedule. For 
example, the energy consumption of a person working from home will be higher than that of a person who has to go outside for work.

- Home-activities: Daily activities of the current time are related to electric appliances. For example, people usually will wake up at 7 am to make breakfast and this means electricity consumption of the kitchen will be high in the morning. Afterward, people will leave for the office or will work at home. In the evening, electricity consumption in the kitchen will usually be high due to preparations for dinner. Finally, it is quite evident that every apartment has its signature electricity consumption pattern.

- Appliance: As we mentioned earlier, it is possible to get an idea about the used appliance type by scrutinizing the utility consumption pattern.

Finally, it can be concluded that electricity consumption data tells us a story about the house's resident number and their activities. Also, the scrutinize analysis of the electricity consumption pattern illustrates the type of appliances that have been used.

\subsection{Research Motivation}

It is entirely feasible that the detailed utility data analytics associated with facility annual energy consumption can provide insight into human activities within the building. The investigation of the utility data will deliver knowledge about the resident number, occupancy, and activities. Utility data can be obtained from the AMR or SM reading. SM reading contains detailed information about the occupancy and appliance usage within a small-time interval intersection.

There are some obstacles to get access to utility data. Foremost, any kind of utility data is very confidential, and it is not available to the public. Subsequently, the SM's deployment in the USA is a little bit slow even though it is expected that 1000 million SM will be installed worldwide by 2022.[8] There are mainly two reasons for the slow penetration of SM at households in the US. First, the presently installed meter can do one-way communication, and second, the less awareness of customers about the SM. Besides, state regulation and legislation for the variation of SM deployment in a different state. So, in the current situation, SM data to analyze resident behavior by using artificial intelligence or machine learning cannot be feasible most of the time. Moreover, legal constraints also prevent law enforcement agencies from quickly obtaining utility information of a building. However, an easier alternative for getting an idea about the number of residents and 
their activities is to develop electricity consumption patterns without knowing the utility bill. This pattern will present the energy consumption rate within short time intervals, over a whole year or any specific day of the year. From the pattern, it can indicate when the place was occupied by analyzing the types of appliances that were being used.

\subsection{Research Approach and Objectives}

This research aims to develop a user-driven simulation tool with realistic input options for the users. The input options are based on human occupancy, thermostat settings, building envelope, appliances used and their energy capacities, occupancy, weather, HVAC systems specifications, fuel type, and fuel cost. Each of these parameters will either be linked with the user-provided information or values for random variables acquired from uniform distributions. Based on the number of residents and their occupation location, five different scenarios are considered. For specific benchmarked scenarios, the range of the random numbers will be specified based on assumed potential human behavior in terms of occupancy, use of energy-consuming appliances, building envelopes, weather, and setting of thermostats, all with respect to time and pertinent weather-related aspects. The simulation will be developed in Microsoft Excel@ based on the discrete event Monte Carlo Simulation (MCS) using the Visual Basic Application (VBA)®.

The Monte-Carlo simulation methodology will then generate energy consumption pattern for electricity and natural gas over 30 minute time intervals for one year for each benchmarked scenario. For a commercial enterprise, the knowledge of such human activities within building spaces is invaluable information for understanding the market condition and developing a new product. This information also can be used for legal purposes by law enforcement people to avoid undesirable societal elements. The objectives of this research are:

1. Pave the way to analyze residents' behavior and activities inside a building space for commercial and legal reasons.

2. Develop cases for calculating energy consumption (electricity and natural gas) based on a different scenario.

3. Develop a Microsoft Excel® based (Visual Basic Application (VBA)®) Monte Carlo simulation, which can forecast the occupancy level at the day's different time frames. 
4. Identify the usage of appliance based on the occupancy for that specific time frame of the day.

5. Develop a user-interactive simulation where the users will be able to change the parameters value

\subsection{Conclusion}

To understand the present market demand and get the idea about the new product, resident behavior analysis data provide crucial information to the commercial group. Simultaneously, resident activity data can be used for the legal resolution by law enforcement personnel to prevent any unlawful situation. However, this process should preserve people's privacy and maintain confidentiality about a citizen's private life. However, monitoring activity and maintaining privacy can be contradictory to each other. This simulated energy consumption pattern will support the commercial enterprise and law enforcement agencies as a primary step in resident activities analysis to avoid this conflicting situation. Here, the Monte Carlo Simulation has been used to simulate the behavior of the resident by generating random numbers. Also, a generated pattern shows appliance usage history. This simulation's performance can be accessed by drawing many random numbers and comparing every simulation result with the previously known energy consumption data. Therefore, this model would be beneficial for commercial and law enforcement purposes for better product development and creating a safer world. It is to be noted that this work is intended to facilitate the analysis of building occupants' activities, subject to all legal provisions that apply. It is not intended for the general public to pursue these activities because legal ramifications might be involved.

\section{Literature Review}




\subsection{Introduction}

Energy consumption in residential buildings requires special monitoring for supply-demand management, policymaking, and price setting. Therefore, research attention must be provided for the improvement in electricity consumption. The prediction and modeling of a residential electric load profile can be very cost-effective for a utility company. Researchers used different statistical tools such as regression, clustering method, a least-squared method to model residential energy consumption, to simulate residential energy consumption. More recently, with the development of modern electricity measuring equipment and data storage technologies, a significant amount of data on energy usage in residential buildings has become available. The increased knowledge about utility data through the implementation of smart meters could be utilized to forecast the electric load, demand pattern, and types of appliances used. Different groups of researchers have been developing various models for calculating energy consumption based on data from both traditional and smart meter.

\subsection{Traditional Electric Meter Energy Data Analysis for Residential House}

The traditionally used electric meter can calculate the total energy consumption in $\mathrm{kWh}$ and voltage. In some cases, the electric meter also measures the demand in $\mathrm{kW}$. In the same way, the gas meter also measures the total usage gas amount. Usually, new electronic meter and gas meter are equipped with automated meter reading(AMR) and remote meter reading (RMR), which can send the meter reading directly to the utility company. The different research groups used these publicly available data to develop a prediction model for energy consumption calculation.

\subsubsection{Energy Consumption Models}

From a research point of view, if measured and observed data is available, then a statistical approach is a reasonable way to model energy consumption. In some particular circumstances, if the researchers have access to some historical utility data, they can fabricate synthetic utility data for further analysis. Analyzing the historical or synthetic data, various statistical methods were employed to develop different types of energy consumption models with different factors such as time, location, building envelope, heating type, and residents' socioeconomic condition. 
For predicting the residential electricity consumption with respect to time, Fumo and Biswas [9] utilized Simple linear regression analysis along with quadratic regression analysis. Here, they also consider time as a relevant factor that defines the quality of the model. Also, multiple regression analysis was used to compare the results with simple linear regression. For the regression analysis, they used recorded data from the TxAIRE research and demonstration house while the house was unoccupied, and all activities were academic nature. Their regression model found that an increased time interval will decrease the quality of the model, and the simple quadratic model has better quality than the simple linear model. When the electricity data was recorded every 5 minutes, the weather data was also recorded in the same interval. The researchers found that multiple linear models provide a better-quality model when compared to a simple linear model.

In this study, Min et al. [10] developed a nonlinear regression-based model to estimate residential energy consumption in the United States (US) based on the zip-code level. The residential energy consumption data from the US Energy Information Administration was used to develop the model, and the model was tested with US census 2000 data. Here, the predictor variable was energy price, household characteristics, housing unit characteristics, regional fixed effects, and heating/cooling degree-days, which were used to develop linear and nonlinear models for heating, cooling, water heating, and appliances.

Yu et al. [11] developed a method to assess building energy performance by using a decision tree method and ANN. This decision tree method generated an accurate predictive model with a visible flow chart. Moreover, they also modeled building energy use intensity (EUI) to enhance their model's applicability. Ten parameters (or attributes) were considered as input for the model, such as average temperature, house type, type of construction, space, heat loss coefficient, leakage area, number of occupants, space heating, water heating equipment, and kitchen oven type. This model was applied in the Japanese residential area and it was able to predict the building energy demand accurately ( $93 \%$ for training data and $92 \%$ for the test data). In their opinion, this model's results can be used by the building designer, architecture, and building owners to manage the operations.

To simulate the energy consumption profile for single-family houses in Florida, researcher Hoşgör and Fischbeck [12] collected data from 7091 houses and used the Princeton Scorekeeping Method (PRISM). Historical weather data and publicly available monthly utility consumption data were used as input in this research. The motivation of this work was to use publicly available data to 
understand energy efficiency. The simulation software like PRISM can help to understand building baselines and energy efficiency profiles. PRISM uses the regression method to calculate the following three energy efficiency parameters: baseload consumption (lighting, refrigerator, water heater), heating/cooling slope depending on the building insulation and the equipment efficiency, and reference temperature, which heating or cooling systems start to work. Finally, the authors showed that the regression model draws an energy efficiency "reservoir maps" while reducing the information barrier to energy efficiency adoption.

Several works have been done to develop a model for calculating the heating energy consumption of residential buildings from historical utility data. For example, Westergren et al. [13] and Catalina et al.[14] utilized simple and multiple regression models to estimate the heating energy consumption per unit of time (hour). Westergren et al. collected data from the sample houses and closed weather station. The simple linear model was able to predict energy consumption, with a 9.0\% error and multiple models were able to predict energy consumption, with less error of $2.5 \%$. Catalina et al. considered four predictor variables: shape factor, envelope U-value, window to floor area ratio, building time constant, and climate coefficient. They also used building simulation software TRNSYSs to get the synthetic data. In their opinion, the best model is polynomial, which predicts the synthetic data within $1.2-5.2 \%$ for the 270 - scenario. Finally, they concluded by mentioning that there is a strong relationship between the shape of a building and energy consumption. Soldo et al. [15] also presented a simple linear regression model to verify the impact of solar radiation on gas consumption for heating in the sample house. In their linear model, they used an artificial neural network. Their model house was designed with a central heating system by the boiler, and other parameters were controlled. Hourly recorded data was used with past gas consumption data to formulate the problem. The authors found that the use of solar radiation improves the accuracy of natural gas consumption.

Compare the efficiency of different heating systems. Elsawaf et al. [16] used a linear least squared regression method. They studied different combinations of heating, such as heat pump, gas heating, and an electric heater, to model their efficiency. The data were analyzed for four cities of eastern Northern California (USA). The researchers considered seven variables -house size, number of occupants, number of stories, years since construction, house orientation, heating temperature, and 
a dummy variable (value of 0 or 1 ) to indicate if the home relies on heat pumps. The authors found that the usages of the heat pump are more energy-efficient than other heating methods.

\subsubsection{Cause of Energy Consumption Variation}

To find the cause of increased energy consumption in China from 2002 to 2010, Nie and Kemp [17] used a regression-based prediction model. The available data from china statistical yearbook 2011 and china statistical energy yearbook has been used in this work. They have found that the change of appliance has a great impact, and the second significant cause is floor space per capita. The model has been developed to predict electricity usage by investigating a relationship between electricity consumption and ownership of appliances. In another example, Bianco et al. [18] developed a simple and multiple regression model to forecast the energy consumption for the residential and non-residential areas in Italy over the period of 1970-2007. In their study, they prove that the gross domestic product (GDP) has a strong relationship with electricity consumption.

Similarly, Chen et al. [19] implemented a multivariate regression analysis to find a correlation between household variables, energy consumption, socioeconomic conditions, and resident behavioral variability in China. The data was gathered from 642 households during the wintertime and 838 households during the summer. The researchers concluded that the socio-economic parameter explains $26.3 \%$ of the energy consumption variation with the defined condition. When the behavioral variability was included, the variation increased up to $28.8 \%$. Also, based on the income level, variation in energy consumption for the air conditioner was $18 \%$. When the floor area was incorporated, it raises to 44\%. In this research, Gans et al. [20] also worked with realtime energy usage information while they were trying to find the impact of dwelling, health, education, employment, and welfare payments on electrical energy consumption for a residential area in Northern Ireland.

Some researchers tried to measure energy consumption, aimed to find opportunities to improve energy efficiency. For example, Raffio et al. [21], Mattinen et al. [22] and Mastrucci et al. [23] investigated the building envelope effect on energy consumption. Different methods were used by the researchers such as multiple linear regression, and bottom-up approach. Raffio et al. identified the following characteristic of the house, such as high hot water temperature setpoints, low- 
efficiency hot water heaters, no nighttime setbacks, a high rate of infiltration, and low furnace efficiency are the cause of high energy consumption. Mattinen et al. concluded that single-family houses have lower energy intensity than apartment buildings. Finally, they found a distinct difference in the emission intensities between the apartment and single-family houses, which is caused by the apartment heating systems. Mastrucci et al. suggested that the possibility of energy savings in the range of 41-68\% and 5-12\% for the household built respectively before 1964 and between 1992 and 2005. For developing the model, they used a bottom-up statistical approach. This model estimated the natural gas and electricity consumption in the city of Rotterdam, Netherlands.

In addition, Schleich et al. [24] in his study examine the impact of customer feedback provided to the customers on energy consumption. The obtained data was from 1500 households, where half of the households received the feedback and were considered as pilot groups. The rest of the households did not have that feedback and were considered as control groups. The regression results revealed that the feedback helped to reduce the energy savings by $4.5 \%$.

\subsubsection{Electricity Load Demand Model}

The demand load for residential houses is an important factor. One researcher group, Ndiaye and Gabriel [25], completed a conditional demand analysis with 59 predictor variables to develop a regression model for the housing units in Oshawa (Ontario, Canada). They have found that the coefficient of determination is $\mathbf{0 . 7 8 4}$, only for nine predictor variables. There were three methods for collecting the data: survey, site audits, and audit of smart meters information. In another study, Capasso et al. [36] proposed modeling of residential electricity load based on the bottom-up approach. They tried to find a relationship between the demand and psychological and behavioral factors of the household. They implemented the Monte Carlo Simulation (MCS) method and conducted a mail-survey to collect real energy consumption data. In their model, they considered the following characteristics: household profiles and individual appliance. In addition, to predict the residents' psychology, they considered the socio-economic condition of the residents and utilized the MCS method to account for the high random variability of human behavior. To validate their results, they compared their simulation model with the survey data. 
In this paper, Bartels et al. [26] discussed a simulation model called DELMOD. This model was used to forecast and simulate the residential electricity load curve in Australia. The model generated the load curves for working and non-working days based on the user's input scenario. In this paper, the authors described the estimation procedure and the range of scenarios of the user. DELMOND consisted of two modules - the base module and the weather module are respectively referred to as DELMOND-B and DELMOND-W. DELMOND-B was concerned with average working days in one month to estimate the residential load profiles. DELMOND-W presented an equation to calculate the load profile based on the temperature during the observation period. DELMOND could be effectively implemented for estimating the end-use gas and water loads.

\subsection{Work-Based on SM Energy Data for the Analysis of Residential Energy Consumption}

SM data is usually used to forecast, cluster, classify, and optimize electricity consumption. There are different clustering techniques such as hierarchical clustering, fuzzy k-means, fuzzy c-means, that are popular for analyzing SM data. Chicco [27] reviewed different clustering techniques used to group the customer based on the electricity consumption pattern. At first, they discussed hierarchical clustering, which is used to cluster the load patterns. The second and third techniques were k-means and fuzzy k-means. The fourth technique was to Follow the Leader (FDL), where the algorithm does not require the number of clusters as an input. Instead of the predefined cluster number, it used an internal distance threshold among the cluster centroids. This algorithm was relatively fast, which led the researchers to successfully run it a more significant number of times. SOM is another method that represents results as a bi-dimensional map. It requires a postprocessing stage to develop the cluster with arbitrary assumptions. SOM is a simple and effective clustering visualization techniques. The authors also discussed Probabilistic Neural Networks (PNN), which is based on analyzing each load pattern separately and find the maximum probability of being the right one and use a Weighted Evidence Accumulation Clustering Approach (WEACS).

Rhodes et al. [28] investigated residential houses' demand profile within their respective seasons. In this work, they used the k-means cluster method to cluster similar hourly electricity use patterns based on the smart meter data and survey data from 103 homes in Texas, Austin. The average curve was created for each home for the season to put them into a group via k-means clustering analysis. The focus was to find the temporal variation in electricity use rather than magnitude. 
After creating the cluster profile, survey data were utilized to find a correlation between survey response and cluster identification. The researchers showed two main groups of temporal profiles in each season, where one group demands more power during higher wholesale electricity prices than other times. This information can allow both the utility company and the homeowner to reduce electricity use during peak times.

Al-Wakeel [29] also used the k-means clustering algorithm to develop a clustering method. For the validation of their model, they used individual or aggregated smart meter based residential daily and segmented load profiles data from 100 residential smart meters. They separately clustered and then re-clustered the daily and segmented profiles of individual and aggregated smart meters. The author aimed to show a relationship between the clustering ratio and segmentation time. The simulation results showed that the minimum clustering ratio is obtained for the shortest time window of segmentation and a small number of clusters is recommended for highly correlated load profiles.

Zhou et al. [30] developed a fuzzy c-means clustering model for households' monthly electricity consumption pattern mining. In this experiment, the SM data was collected from 1200 households in China for one month. The author claimed that c-means fuzzy clustering is superior in electricity consumption data analysis compared with hard clustering methods.

For example, Gouveia and Seixas [31] used this method in their study. The obtained data was from the high-resolution smart meter data and surveys for the 265 sampled households in a Southwest European city of Portugal. Hierarchical clustering has been used for trimming the electricity data over 2011-2014, for each day. The authors also used the analysis of variance approach for measuring the distance between clusters. They introduced 10 cluster options with similar means and standard deviations for profile analysis. From the survey data, they incorporated the following information as the variable: location, dwelling type, and age, floor area, type of glazing and windows framing, bearing structure and external walls, number of occupants, education level of head of household, household income, employment status. The cluster analysis showed a correlation that presented a strong relationship between electricity consumption and the use of cooling and heating systems. 
Yang [32] also utilized a hierarchical clustering method to identify electricity consumption patterns and abnormal users in China. They used electricity consumption data of 300 residential users for one month. From their research, they were successfully able to find the nine abnormal users and four types of monthly electricity consumption patterns. The author concluded that a $19 \%$ observed deviation from the regular pattern had a significant effect in planning, policy formulation, and decision-making of the smart grid.

\subsection{Work Based on the Benefits of SM Deployment}

SM data can be used in demand control, appliance control, electricity theft reduction, and highfrequency data recording. The consequences of the deployment of SM data are both positive and negative.

Beaudin and Zareipour [33] present the positive side of SM deployment. They discussed the Home Energy Management Systems (HEMS) and several optimization methods based on the HEMS information. The recent improvement of smart meter and smart grids provides opportunities to develop some tools for reducing the demand response and electricity consumption. HEMS are demand response tool which provides information about the demand load to the customer, aiming to shift and curtail demand to improve energy consumption. HEMS can communicate with the household device and utility company for evaluating the uncertainties of prices, demand, and external variables. Based on the collected information, the HEMS plan is an appropriate response without intervention by using a different scheduling algorithm. Beaudin and Zareipour [33]also reviewed mathematical optimization, predictive control, and heuristic control of HEMS. It was recommended that a baseline is needed to be created for evaluating the HEMS more effectively, and complexity and tractability measurement should be considered to provide a fair comparison of the trade-offs between optimal scheduling and computational considerations. Vega et al. [HEMS] also reviewed previous work based on HEMS with similar findings.

Author Yildiz et al. [34] reviewed the recent methods and techniques for analyzing SM data. They discussed the techniques for the development of a Smart Meter Based Model (SMBM). They recommended Demand Response (DR) tools and Home Energy Management Systems (HEMS) to improve their electricity consumption management. Among various smart meter data applications, they focused on end-use applications from two main stockholders' perspectives: homeowners and 
utilities. They found forecasting the demand load for the residential area is more challenging compared to the commercial building. Finally, they conclude that potential enhancement can be achieved in forecasting the electric load and improving efficiency by using machine learning and deep learning compared to the probabilities and time series models.

A pilot project called "Latvenergo" was introduced in Latvia, where smart meters were installed in 500 Latvian households at the beginning of 2013 to promote households' energy efficiency using smart technologies. One research group, Poznaka [35], investigated the "Latvenergo" pilot project and revealed that electricity consumption decreased by $23 \%$ for the target group. To enlighten the results, the researchers were looking for the answer to the following questions: 1) Influential behavioral and motivational factors which helped them to change in electricity consumption, and 2) the magnitude changed in electricity consumption were affected by smart meters. They used three multiple linear regression models to analyze the data from 430 households. They also conducted a resurvey at 8 selected houses in March-April 2014. The results demonstrated that the reason for decreased electricity consumption is not only technical support; psychological aspects like the subconscious and belonging to a social group is also one reason.

\subsection{Obstacles of Using Smart Meter Data/ Research Gap}

The increased access of Smart grid and Advanced Metering Infrastructure (AMI) systems into households indulge the huge data collection process with low cost and reduce the cost of power generations. However, besides these advantages, new technology increases the risk of exposing citizen private information and security.

In one example, Lisovich et al. [36] claimed that it is possible to reveal and exploit personallyidentifying information through AMI information. The authors explored the technical aspects by focusing on an algorithm that is used to extrapolate the activity information from energy consumption information. Non-intrusive load monitoring (NILM) and Camera data have been utilized to prove their claim. The collected electricity consumption data was passed to the behavioral-extraction algorithm (NILM) through a bridge program. In addition, video data was analyzed manually and processed into the activity log. The experimental data were divided into three sets: a three-day training set and a larger seven-day experimental set. The results showed that the algorithm was able to determine the presence and sleep cycle of more than 90 percent of the 
total interval time for both training and experimental data. They proved that residential privacy could be violated using the power consumption data with simple data mining and pattern matching tools. So, they suggest that policymakers need to be more careful about protecting the smart meter data.

Additionally, Lerner and Mulligan [37] discussed the Fourth Amendment: The used energy information and emitted heat signatures of the resident can provide significant information about their personal life. Nowadays, smart meter data becomes more sophisticated and detailed, revealing information about the resident's activities, occupation, habits, socioeconomic status, and availability at home. But this information is not publicly available. The Fourth Amendment of the U.S. Constitution and the California Constitution both protect against unreasonable government intrusions into the home. Therefore, law enforcement agencies need special warrants to get access to smart meter data. Moreover, in 2001, to increase the protection of home privacy, the Supreme Court prohibited the use of a thermal imager to gather detailed information about the home that would have been previously inaccessible without a physical trespass. This decision was also vigorously motivated by the Fourth Amendment. Lerner and Mulligan [37]mainly focused on the Fourth Amendment issues, which were raised by improving the quality and quantity of the utility data. Following three cases Kyllo, Smith, and Miller were discussed in detail to resolve these issues. By judging all the pros and cons of the Fourth Amendment and the new technology feasibility, they conclude with following statement that " to protect the citizens private act the law enforcement agents must obtain a warrant or receive permission to enter the home not only physically also to obtain any information through $3^{\text {rd }}$ party or with the help of any technology. Any data inside the home which are related to personal behavior, habits, or energy usage is customarily afforded the same high level of privacy protection against both private party and government instructions.

In another example, McKenna et al. [38] described the smart meter's negative effect in terms of violating citizen's privacy. Smart meter data can be classified as personal data and system-related data. This paper investigated the possibility of avoiding personal data while using the system data aimed to improve demand control, distribution network operation, and planning. Even though EU policy tried to protect the personal data through existing data protection activities, a Dutch senator in 2009 argued that smart meter violates the citizens' rights. As a result, currently, the smart meter 
is being installed on a volunteer basis in the Netherland, which reduced smart meter deployment. Installed smart meter can record data within 15 minutes and provide a strong indication of occupancy and individual appliance usage. They examined several usage options of smart meter and suggested some ways to protect personal information. For example, a utility company can use low-resolution data for the system balancing and transmission network power flow and demand reduction. For calculating the utility bill, there is no need to send the price information to the meter, rather switch the time of the meter registration that is adjusted automatically. Finally, the authors concluded that the smart meter's current resolution indicates strong evidence of occupancy but is not high enough to reveal the individual appliance usage information. However, this personal information could be serious security threaten for people.

\subsection{Potential of this Research}

All the above-mentioned research work requires a detailed utility bill, which is not publicly available. Providing all this information to anyone, without the permission of the users, violates citizens' rights. The reason is if a criminal can get access to smart meter data, he can utilize the occupancy information for illegal activities such as robbery, kidnapping, or murder. It is also a citizen's moral right that nobody can monitor their activities in their home. As a result, the policymakers made rules that the smart meter data will not be available to people. Due to these rules, even law enforcement personnel need warrants for investigating these data.

In this research work to resolve this problem, a pattern generating simulation process will be developed for the energy consumption of residential apartment houses. This detailed pattern will identify occupancy and activities. Using Monte Carlo Simulation, this process will generate an electricity consumption pattern at a 30-minute time interval. The main advantage of this work is that the simulation does not demand any previous detailed utility data. Suppose R\&D or marketing department of commercial group or low enforcement personnel need to know about the resident's activities at a specific time of a month. In that case, they can run the simulation and generate the energy consumption pattern. From the pattern, place occupancy and the type of appliance was used in that specific time interval can be identified. This finding can help the commercial group develop new and efficient products. Also, this finding can be presented in the court as evidence to get access to detailed utility data. This pattern generating simulation can help expedite the warrant 
issuing time, and consequently, becoming beneficial for controlling illegal activities. Moreover, this pattern generating simulation is also applicable where smart meter facilities are not available.

\subsection{Conclusion}

This literature review explored various analysis techniques and usage of utility bill information. With the development of new technologies, smart meter and smart grid are being employed at a very fast rate. SM can record utility data at a very high time resolution. The high resolution of smart meter data can reveal detailed information about energy usage and occupancy and appliance usage. Several statistical and data analysis tools have been used to analyze the utility data and develop a model for energy efficiency. Obtained results from the model can be used to reduce energy consumption, optimize power supply systems, and demand control. In addition, some model guide to improving the efficiency of the appliances. The primary obstacle to using utility data is publicly unavailability. To get the access to the SM data, court permission is required due to potential privacy violation concerns. Aiming to provide an alternative and facile solution, this simulation will develop energy consumption patterns for the residential area without any utility data. 


\section{Research Methodology}

\subsection{Introduction}

The smart meter (SM) recent deployment has allowed high-resolution utility data collection, which is not publicly available. There are methods such as regression, clustering, neural networking, which can be used to reveal information about occupancy, resident habits, activities, and used appliance type by using this high-resolution data. Therefore, this data might be misused if they become available. For example, people with criminal intentions can use this data to determine the residents' existence and activities. On the other hand, the landlord or the employers can engage in unlawful spying on their tenants or their employees, respectively. All these activities endanger public safety and violate privacy. As a result, policymakers are introducing stricter rules to protect the privacy of the citizens. However, knowledge of residents' activities sometimes can be useful for commercial entities to develop new products and for law enforcement personnel to protect citizens efficiently. To avoid this contradictory situation, the pattern developing simulation work can determine the occupancy level and residents' activities for the target apartment without requiring the SM data. The resulted pattern can be used to compare with the targeted house general utility bill to get an idea about the resident activities.

\subsection{Overview of Research Approach}

This work involves the determination of the activities in resident apartments by simulating the energy consumption pattern. The simulation takes information about the resident number, information about apartment envelope and location, and the home appliances' number and capacity as input factors. The simulation workflow can be segmented into steps, as shown in the flow chart (Figure:3.1) and described in the subsequent text. Step-1: Define occupancy scenarios based on the number of residents, age of residents (i.e., adult or child), work location (i.e., work from home or outside), and the number of rooms in the apartment. Step-2: Define probability charts for occupancy (i.e., occupied or unoccupied), room size, thermostat settings, weather condition, and usage status of the appliance (i.e., being used or unused), based on the time of the day and the day of the week. Step-3: Define factors necessary for energy calculation, such as the size of the rooms, building envelope, thermostat settings, future of building construction, heating $\&$ cooling systems capacity, appliance capacity, USA weather data, energy source, and energy unit cost. 


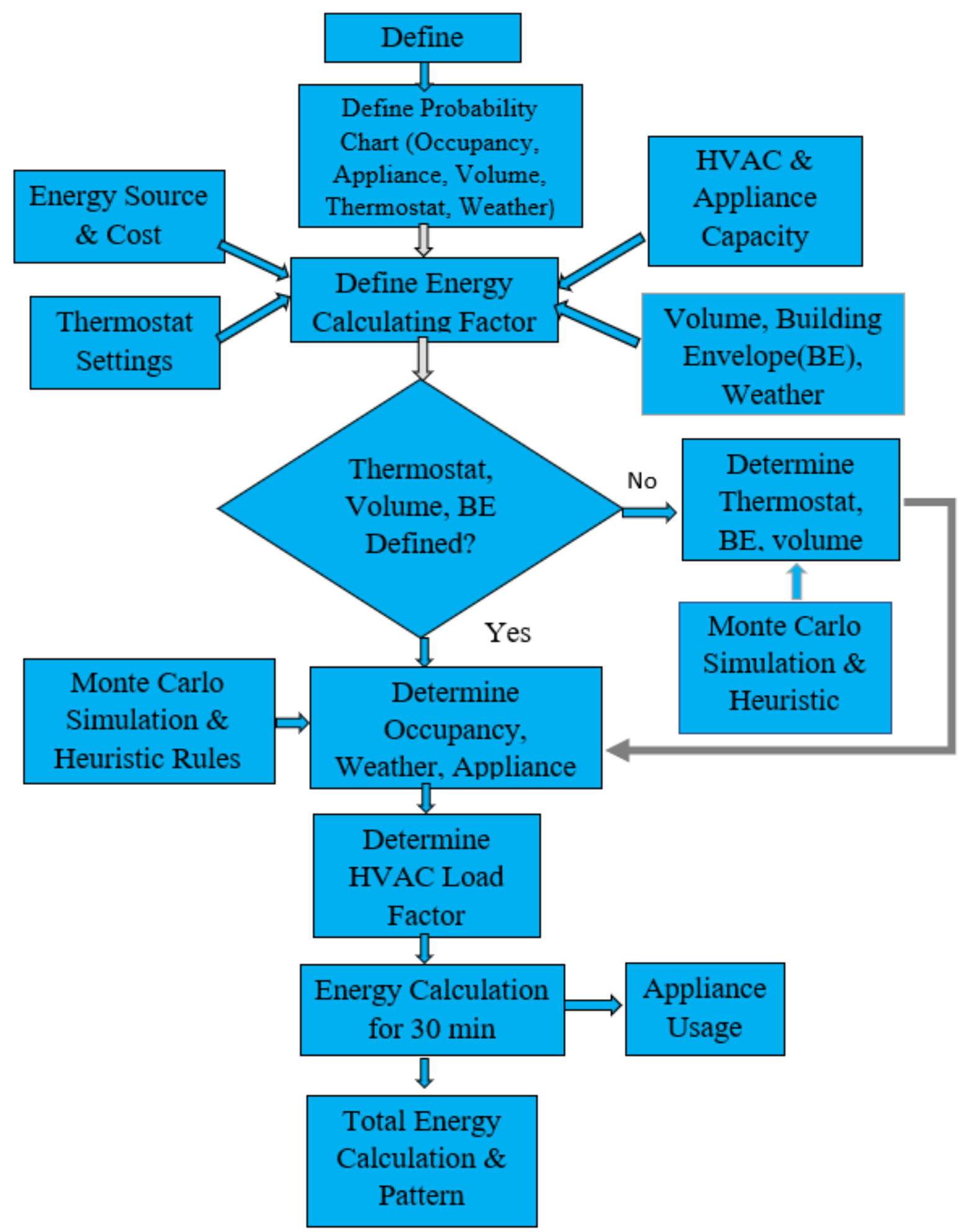

Figure 3-1: Steps of Energy Forensics Analysis

Step-4: Define the value for thermostat settings, room volume from the user. Step-5: If the user misses the input value, then the system will determine the status of the room volume and thermostat 
settings by Monte Carlo Simulation and Heuristic Rules. Step-6: If at step 4, the user assigns the value for room volume and thermostat, then the system will Determine the occupancy, weather, and the status of the appliance by Monte-Carlo simulation. The Monte-Carlo simulation works by comparing random numbers with the probability chart (from Step-2) to randomly define the occupancy, weather condition, and appliance usage status. Step-7: Assign load factors for the HVAC system for various combinations of occupancy, building envelope, room-size, thermostat settings, and weather. The detail load factor is defined only for HVAC, as this is the most energyconsuming component that runs at variable load based on various user comfort. For simplification,

most of the energy-consuming parts are assumed to be run at full load capacity. Step-8: Calculate energy consumption for every 30 mins - for one year and specific scenario from Step-1. Besides, the total energy consumption is calculated for all appliances. Step-9: Finally, individual equipment's total energy consumption pattern is developed for a particular day and one year.

\subsection{Case/Scenario Development}

For this study, five cases are described to increase the versatility of this pattern generating simulation. These cases portrait the common scenarios about the resident's activity and occupancy in the apartment houses. The cases are described below:

Case I: One-bedroom apartment house for an adult couple without a kid: Both adults work outside with the same working hours. So, there is a low chance that the place will be occupied from 9:00 am to 5:00 $\mathrm{pm}$. The probability of the area to be occupied is varying on the weekdays and weekends.

Case II: One-bedroom apartment without a kid and one person works from home and another person works outside: Now, the daytime occupancy will be different because one person will be home most of the time. At the same time, appliances usage probability will be different from Case I. So, electricity consumption patterns will be different.

Case III: Two-bedroom apartment house for an adult couple with children: Children could be toddlers or school going kids, and both adults are working outside at the same time with regular work hours. In this case, the occupancy and the usage probability of the appliances will be different. So, the load factor and electricity consumption will be different, which depicts the difference in the resident's activities due to the kid's presence. 
Case IV: two-bedroom apartment with children's where one adult works from home and other works outside: In this case, the kids and one adult will stay at home and the place will be occupied all the time. Consequently, the probability of usage will be different, resulting in different electricity consumption patterns.

Case V: Three-bedroom apartment for student housing: Student's behavior is very capricious based on their schedule. So, the occupancy level will be different because of the student's volatile schedule. Also, the home appliances will be distinct from the family apartment. All these will show a different result in pattern generations.

\subsection{Principle of Data Analysis}

For the pattern generating simulation, the system requires some input. In this simulation, the user has the flexibility to choose the building envelope, thermostat settings, room volume, building construction time, the geographical position, heating and cooling systems specification, fuel type, fuel cost, type of home appliances related to each room, and appliances capacity. All these factors have been accounted for as input data. This simulation is interactive, which allows its user to change the value of the variables. All these variables are explained in detail in the next chapter. The simulation is done in Microsoft Excel® based on the discrete event Monte Carlo Simulation (MCS) using the Visual Basic Application (VBA)®. The uniformly distributed random number will be generated in the excel. The heuristic rules are applied to compare the automatic generated random number and value from the probability chart to determine the occupancy. Similarly, heuristic rules are used to determine the appliance usage status, weather conditions and thermostat settings.

\subsubsection{Monte Carlo Simulation:}

The Monte Carlo Simulation (MCS) method is a powerful modeling tool. It is used to analyze complex mathematical and statistical problems due to its outstanding capability of achieving a closer observance of reality.[39] By generating random numbers, it obtains the estimation the solution of complex multi-dimensional mathematical problems. So, it is defined as a methodology of generating random numbers and understanding the impact of a specific system's risk and uncertainty. Before the development of the affordable and powerful computer, as we have now, a random sampling number was used by skillful scientists. With the development of faster 
processors, MCS was exclusively being used for three decades to solve a complex problem in theoretical physics. As faster computers became more accessible, the application of MCS methods becomes more and more feasible and practical for the various fields. In a simulation process, the system's performance can be studied by drawing many random samples and then analyzing their behavior. In this study, many factors simultaneously affect the calculation. Even though all the factor information is pre-defined, but it is difficult to predict the exact scenario. However, with MCS, it is possible to generate several different possible outcomes, which guide us to choose better decisions under uncertainty. Here, MCS is used to simulate desired parameters, i.e., total energy consumption and energy usage by appliances, at different time slots of a day, based on uniform distribution uncertainty and the weighted probability of occupancy and appliance status. The results are recorded, and the calculation is repeated for other days to acquire a cumulative outcome over several days.

\subsubsection{VBA for Monte Carlo Simulation}

VBA is an interpreted representation programming language performs the instruction and proceed to the next level step by step, making it very fast. VBA is an implementation of Microsoft's event driving programming language, which is very simple and efficient to use, and available built-in with Microsoft Office software. Using VBA, it is possible to build user-defined functions (UDFSs), automatic processes and accessing Windows API (Application Programming Interfaces). The usage of VBA in the proposed research will require access to Microsoft Office software, which may limit its utility. However, the Microsoft Office is widely available and run efficiently on usual work computers. Hence the VBA was chosen for our research work. Furthermore, using VBA allows easy development of a program with a graphical interface.

\subsection{Summary of Energy Calculation Factors}

All the energy calculation factors can be divided into two categories- major factors and minor factors. Major factors are those who have a direct impact on energy accounting and are related to the designed case. Major factors are Occupancy, number of residents and residents' workplace position. On the other hand, the minor factors are the ones which are present in all different scenarios, such as building envelope, thermostat level, area of the room, number of rooms, weather, appliances. 


\subsubsection{Occupancy}

In this work, the most crucial factor is occupancy as all appliances' usage depends on the occupancy. For example, when people are at home, heating or cooling will run at a set temperature to fulfill residents' comfort. Essentially, electricity consumption for every appliance, with a few exceptions such as refrigerators and freezers, directly depends on occupancy. To detect a person's occupancy in a room occupant's schedule based on their occupation and heuristic rules are used. Besides, occupancy will vary based on weekday or weekends, the number of residents, and their age. The higher the occupancy probability value, the more likely the room is occupied during that time interval.

The VBA code containing the Microsoft Excel program will generate a random number for every 30 minutes to simulate the occupancy. The generated random number will be compared against the occupancy probability listed in the "Reference" worksheet of the excel file using a logicformula, and it will be decided if the place is occupied or unoccupied. Using the VBA programming makes the model flexible, such that the user can change the occupancy probability relatively quickly in the predefined reference tables if desires.

\subsubsection{Number of Residents}

This work's target includes developing electricity consumption patterns based on the number of residents living in a designed case. For example, in case 1, the number of residents is only two adults who live in the one-bedroom apartment, and the numbers of residents are different in other cases. The usage factor of appliances directly related to the number of residents. There are usage probability charts for each appliance for a chosen occupancy case, corresponding to that specific case. These probability values of using the appliance in this chart are determined based on the number of residents. For example, an apartment with a kid usually has a more occupied living room or TV used more frequently than an apartment with no kid present. The program will require the users to select a specific case, and consequently, directly relate the number of residents to the electricity consumption. 


\subsubsection{Resident Workplace Location}

Another critical factor is the residents' workplace location. Occupancy level and appliance usage are related to the resident occupation. This means if the residents work from home house will be more occupied, or if they work outside the house will be less occupied. Thus, the resident occupation affects the occupancy, which is directly connected with electricity consumption. For example, in case 2, one of the residents works outside the home and another resident stays at home, leading to a higher probability of occupying the living room during the daytime, compared to case 1. Suppose the apartment is occupied with college-going students, as specified in case-5. In that case, their occupancy level and the usage of electronic devices will be different due to the possible use of computers and late-night studies.

\subsubsection{Building Envelope}

Whenever a temperature difference occurs between two areas (indoor-outdoor), heat flows from the warmer area to the colder area. The heat transfer takes place by three methods - conduction, convection, and radiation. Conduction refers to heat transfer through solid such as wall, window, roof. Convection transfers heat by the movement of liquids and gases (air). The radiation method transfers heat by the wave, such as sunlight. Transferred heat through these methods can have a significant effect on the load factor of HVAC. This outside cold air and sunlight heat by mixing with conditioned air increase the energy requirement for conditioning the room at a comfortable temperature. Controlled outdoor air is needed to maintain proper $\mathrm{CO}_{2}, \mathrm{O}_{2}$ and humidity levels at the building air for providing comfort for occupants. However, uncontrolled outside heat transfer through the building wall, cracks, unintentional openings, roof, window, door entrance and egress, known as infiltration, and indoor air leakage out of the building known as exfiltration, also may occur. All these heat transfer processes depend on the building's physical structure, often called by Building Envelope. Thus, in HVAC calculation, the building envelope is considered one of the critical parameters to determine the load factor. In this proposal, two levels for building envelope have been considered - level 1 as good and level 2 as poor (Table 3.1). The program, by default, has a building envelope as user input. However, if the user skips this input, the program will randomly assign one of the two levels with equal probability. Before the up-gradation date, the building envelope will be assigned as level 2 (poor), which will change to level 1 (good) after upgradation. 
Table 3.1: Building Envelope Regulation Chart [40]

\begin{tabular}{|l|c|c|}
\hline & Level 1 & Level 2 \\
\hline Building Envelope & Good (0-0.5) & Poor (0.51-1) \\
\hline
\end{tabular}

\subsubsection{Smart Thermostat}

The comfort levels of residents can vary from person to person, as one person may prefer a warmer room and the others might prefer a colder room. In this work, it has been assumed that each room has a smart thermostat to ensure the occupants' comfort. The smart thermostat's primary purpose is to adjust the temperature with the occupancy level and control the HVAC timer remotely using any internet-connected device to get a comfortable temperature. In this simulation, there are two user input options for thermostat settings levels- level 1 for low comfort and level 2 for high comfort (Table 3.2). If the user skips the thermostat level's input value, the program will randomly assign one of the two thermostat setting levels at the probability listed in table 3.3.

Table 3.2: User Guidelines to determine the level for the thermostat [40]

\begin{tabular}{|c|c|c|}
\hline & Level 1 & Level 2 \\
\hline Summer & $70-80^{\circ} \mathrm{F}$ & $60-70^{\circ} \mathrm{F}$ \\
\hline Winter & $60-70^{\circ} \mathrm{F}$ & $70-80^{\circ} \mathrm{F}$ \\
\hline
\end{tabular}

Table 3.3: Model Guidelines to determine the level for the thermostat [40]

\begin{tabular}{|c|c|c|}
\hline Number of Days & Level 1 & Level 2 \\
\hline $1-120$ (Summer) & $0-0.68$ & $0.69-1$ \\
\hline $121-272$ (Winter) & $0-0.37$ & $0.38-1$ \\
\hline $272-273$ (Summer) & $0-0.68$ & $0.69-1$ \\
\hline
\end{tabular}

In addition, there will be another option for the user to define the number of times the thermostat level will change throughout the year. So, the thermostat settings will change after the number of days calculated by dividing the total number of days in the year by the number of changes per year (i.e., 365/number of changes per year). However, if there are no changes to the thermostat, the user's initial input will be used for the calculations.

It has been assumed that the zoning system is employed at the apartment house. Even though zoning does not help with efficiency but eliminates the problem with overheating and overcooling 
the furnace or air conditioner. A zoning system will reduce overall energy consumption by maintaining the zone temperature at the occupant's desired level and shutting off the systems after reaching the target temperature. The main components for HVAC zoning are the central control system, thermostat, zone damper and bypass damper.

\subsubsection{Area of the Room}

To control the room temperature, the HVAC system needs to provide or remove heat from the room air. So, the energy required to cool down the air or heat the air depends on room air quantity; consequently, it depends on the room size. Also, the level of lighting varies based on the size of the room. Thus, the room volume has a significant influence on electricity consumption. In this simulation, three levels are considered for the room's volume - level 1 as small, level 2 as a medium, and level 3 as large. This user-interactive program will allow the user to decide the room size. If the user skips the choice of room size, the program will randomly assign one of the three levels at equal probability for all three levels. Table 3.4 presents the room volume information in terms of level and table 3.5 shows the probability to determine the room volume.

Table 3.4: Standard Size of the room in Residential Building [41]

\begin{tabular}{|c|c|c|c|c|}
\hline \multicolumn{5}{|c|}{ Floor Area (Sq.ft) } \\
\hline Level & Bedrooms & Bathroom & Living Room & Kitchen \\
\hline 1 & 144 & 54 & 216 & 50 \\
\hline 2 & 250 & 70 & 320 & 104 \\
\hline 3 & 384 & 96 & 616 & 120 \\
\hline
\end{tabular}

Table 3.5: Probability chart to determine volume level [40]

\begin{tabular}{|c|c|c|c|}
\hline & Level 1 & Level 2 & Level 3 \\
\hline Volume & $0-0.33$ & $0.34-0.66$ & $0.67-1$ \\
\hline
\end{tabular}

\subsubsection{The Number of the Room}

The number of rooms depends on the number of residents. In this simulation, room number relates to the designed case. For example, in case 1, there is one bedroom, one living room, one kitchen, and one restroom. Furthermore, the type of appliances is varied with the kind of room. At the 
beginning of this pattern generation simulation, the user has to select the case number and room number will be automatically fixed. Without choosing the case, the program will not execute in the next step. Table 3.6 shows detailed information about the number of rooms for each case.

Table 3.6: Details room number for each case

\begin{tabular}{|c|c|c|c|c|}
\hline Case & Bedroom & Living Room & Kitchen & Restroom \\
\hline Case 1 & 1 & 1 & 1 & 1 \\
\hline Case 2 & 1 & 1 & 1 & 1 \\
\hline Case 3 & 2 & 1 & 1 & 1 \\
\hline Case 4 & 2 & 1 & 1 & 1 \\
\hline Case 5 & 3 & 1 & 1 & 1 \\
\hline
\end{tabular}

\subsubsection{Weather}

Weather and climate conditions have a significant effect on overall energy consumption. Heating, cooling and hot water heater are the main significant electricity consumption sources, as these are related to the outside temperature and humidity. Therefore, in this study, the weather has been considered as one of the major input factors. Weather is divided into three levels - level 1 as mild, level 2 as moderate and level 3 as extreme weather conditions. The updated weather factor is considered at the beginning of every eight hours and is assumed to be the same for the next eight hours. To determine the weather factor, the year is split into five seasons and the rules are shown in table 3.7 .

Table 3.7: Rules to determine Whether Factor [40]

\begin{tabular}{|c|c|c|c|}
\hline Days & level 1 & level 2 & level 3 \\
\hline $1-59$ & $0-0.1$ & $0.11-0.4$ & $0.41-1$ \\
\hline $60-151$ & $0-0.4$ & $0.41-0.8$ & $0.81-1$ \\
\hline $152-243$ & $0-0.4$ & $0.41-0.75$ & $0.76-1$ \\
\hline $244-334$ & $0-0.4$ & $0.41-0.8$ & $0.81-1$ \\
\hline $335-365$ & $0-0.1$ & $0.11-0.4$ & $0.41-1$ \\
\hline
\end{tabular}

The climate conditions of the USA vary with the location. The United States is divided into nine regions based on their climate, as shown in figure 3.2. All these regions are considered to evaluate the energy consumption in this research work. There is a chart about the heating degree day 
$(\mathrm{HDD})^{1}$ and cooling degree days (CDD $)^{2}$ of 2016 for each climate zone in the reference sheet, as shown in table 3.8. Users can change this weather data according to their investigation year. Degree days measure the difference of outside temperature and baseline temperature for a given period and can be used to predict the energy use for heating or cooling.

Table 3.8: List of heating and cooling degree days for each climate zone

\begin{tabular}{|c|c|c|c|}
\hline S.No. & Location & HDD & CDD \\
\hline 1 & Pacific & 3032 & 930 \\
\hline 2 & Mountain & 4619 & 1496 \\
\hline 3 & West North Central & 5784 & 1073 \\
\hline 4 & West South Central & 1753 & 2882 \\
\hline 5 & East North Central & 5700 & 958 \\
\hline 6 & East South Central & 2420 & 1956 \\
\hline 7 & Middle Atlantic & 5354 & 888 \\
\hline 8 & South Atlantic & 2455 & 2412 \\
\hline 9 & New England & 5930 & 625 \\
\hline
\end{tabular}

Figure 3.2 depicts the nine-climate zone of the USA. At the input sheet, the user has to select the climate region for the specific case. The calculation of the weather level depends on the HDD and $\mathrm{CDD}$ of the selected region.

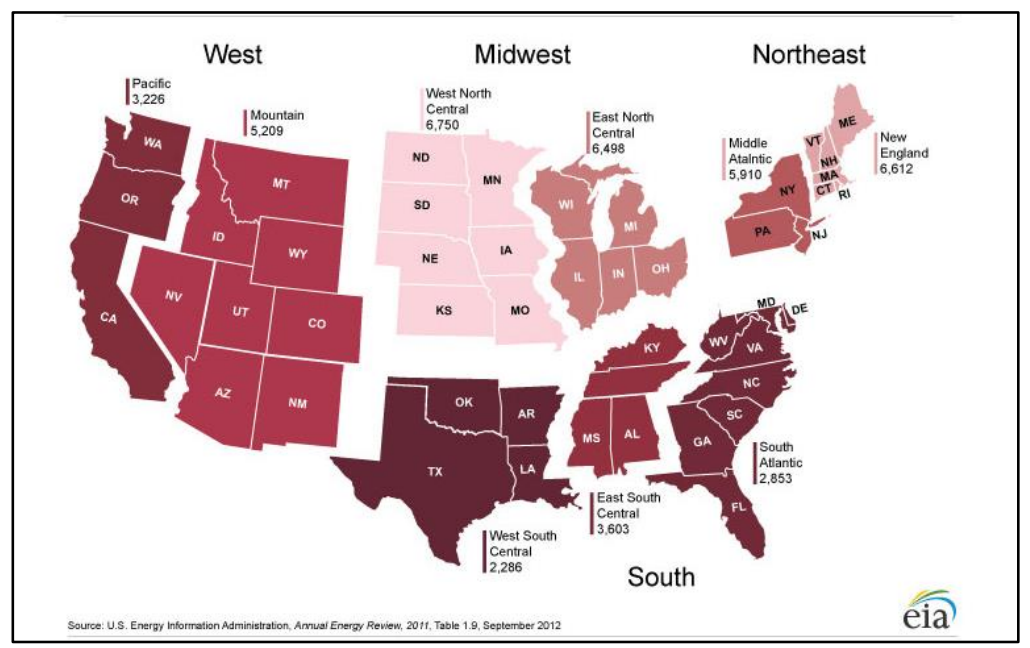

Figure 3-2: Census Regions [42]

\footnotetext{
${ }^{1}$ https://www.eia.gov/totalenergy/data/browser/index.php?tbl=T01.09\#/?f=M\&start=197301\&end=202007\&charted=10-32

${ }^{2}$ https://www.eia.gov/totalenergy/data/browser/index.php?tbl=T01.10\#/?f=A\&start=1949\&end=2019\&charted=32-10
} 
It is necessary to know the cooling ratio to determine the time when cooling or heating is occurring. The cooling ratio can be calculated by dividing CDD with the summation of CDD and HDD. The example of the South Atlantic region's cooling ratio data from the "Reference" worksheet is shown in Table 3.9. Cooling ratio information from the first row of table 3.9 says, that the chance of using electricity for cooling the space is $4 \%$ during the January month. An automatically generated random number will be compared with this cooling ratio for a specific day at 30 minutes interval to determine the energy usage for heating or cooling during the energy calculation part.

Table 3.9: Calculation of cooling ration for the South Atlantic region

\begin{tabular}{|c|c|c|c|c|c|c|}
\hline Month & Name & Days & Cumulative & HDD & CDD & Cooling Ratio \\
\hline 1 & January & 31 & 0 & 659 & 25 & $4 \%$ \\
\hline 2 & February & 28 & 31 & 483 & 24 & $5 \%$ \\
\hline 3 & March & 31 & 59 & 240 & 89 & $27 \%$ \\
\hline 4 & April & 30 & 90 & 152 & 87 & $36 \%$ \\
\hline 5 & May & 31 & 120 & 58 & 185 & $76 \%$ \\
\hline 6 & June & 30 & 151 & 1 & 379 & $100 \%$ \\
\hline 7 & July & 31 & 181 & 0 & 509 & $100 \%$ \\
\hline 8 & August & 31 & 212 & 0 & 484 & $100 \%$ \\
\hline 9 & September & 30 & 243 & 2 & 352 & $99 \%$ \\
\hline 10 & October & 31 & 273 & 91 & 157 & $63 \%$ \\
\hline 11 & November & 30 & 304 & 290 & 56 & $16 \%$ \\
\hline 12 & December & 31 & 334 & 479 & 65 & $12 \%$ \\
\hline
\end{tabular}

\subsubsection{Type of Appliances}

Nowadays, with the help of new technology, various appliances are available to make people's lives easy and comfortable. Essential and regularly used appliances have been considered for this research work. The detailed information of these appliances is shown in the following table 3.10 [43].

Table 3.10: List of appliances for energy consumption. The specification of the appliances are taken from online resources [43]

\begin{tabular}{|c|c|c|c|c|}
\hline \multirow{2}{*}{ Location } & Appliance & No. & Unit & Capacity \\
\hline \multirow{3}{*}{ General } & Washing Machine & 1 & $\mathrm{~W}$ & 500 \\
\cline { 2 - 5 } & Dryer & 1 & $\mathrm{~W}$ & 3000 \\
\cline { 2 - 5 } & Water heater & 1 & $\mathrm{~kW}$ & 10 \\
\hline
\end{tabular}




\begin{tabular}{|c|c|c|c|c|}
\hline Location & Appliance & No. & Unit & Capacity \\
\hline \multirow{15}{*}{ Kitchen } & Griller & 1 & $\mathrm{~W}$ & 1500 \\
\hline & Blender & 1 & $\mathrm{~W}$ & 625 \\
\hline & Dishwasher & 1 & $\mathrm{~W}$ & 1800 \\
\hline & Electric Water Heater & 1 & $\mathrm{~W}$ & 1200 \\
\hline & Exhaust Hood & 1 & $\mathrm{~W}$ & 350 \\
\hline & Refrigerator & 1 & $\mathrm{~W}$ & 180 \\
\hline & Incandescent(K) & 3 & $\mathrm{~W}$ & 50 \\
\hline & Microwave & 1 & $\mathrm{~W}$ & 1200 \\
\hline & Oven & 1 & $\mathrm{~W}$ & 2400 \\
\hline & Stove & 1 & $\mathrm{~kW}$ & 1.64 \\
\hline & Toaster & 1 & $\mathrm{~W}$ & 1200 \\
\hline & Rice Cooker & 1 & $\mathrm{~W}$ & 200 \\
\hline & Garbage Disposal & 1 & $\mathrm{~W}$ & 450 \\
\hline & Coffee Maker & 1 & $\mathrm{~W}$ & 800 \\
\hline & Freezer & 1 & $\mathrm{~W}$ & 200 \\
\hline \multirow{14}{*}{ Living Room } & Incandescent $(\mathrm{L})$ & 3 & $\mathrm{~W}$ & 50 \\
\hline & Television (CRT) & 1 & $\mathrm{~W}$ & 75 \\
\hline & TV & 1 & $\mathrm{~W}$ & 200 \\
\hline & Bluray Player & 1 & $\mathrm{~W}$ & 15 \\
\hline & Cable Box & 1 & $\mathrm{~W}$ & 35 \\
\hline & DVD & 1 & $\mathrm{~W}$ & 15 \\
\hline & Desktop & 1 & $\mathrm{~W}$ & 200 \\
\hline & LCD Monitor & 1 & $\mathrm{~W}$ & 100 \\
\hline & Laptop & 1 & $\mathrm{~W}$ & 60 \\
\hline & Printer & 1 & $\mathrm{~W}$ & 80 \\
\hline & Space Heater(L) & 1 & $\mathrm{~W}$ & 200 \\
\hline & Phone charger $(\mathrm{L})$ & 1 & $\mathrm{~W}$ & 5 \\
\hline & Ceiling Fan(L) & 1 & $\mathrm{~W}$ & 75 \\
\hline & Humidifier(L) & 1 & $\mathrm{~W}$ & 20 \\
\hline \multirow{5}{*}{ Bedroom } & Incandescent & 3 & $\mathrm{~W}$ & 50 \\
\hline & Phone Charger & 1 & $\mathrm{~W}$ & 10 \\
\hline & Humidifier & 1 & W & 20 \\
\hline & Space Heater & 1 & $\mathrm{~W}$ & 200 \\
\hline & Ceiling Fan & 1 & $\mathrm{~W}$ & 75 \\
\hline \multirow{6}{*}{$\begin{array}{c}\text { Bathroom / Rest } \\
\text { Room }\end{array}$} & Incandescent $(\mathrm{R})$ & 3 & $\mathrm{~W}$ & 50 \\
\hline & Aroma Lamp & 1 & $\mathrm{~W}$ & 15 \\
\hline & Electric Shaver & 1 & $\mathrm{~W}$ & 15 \\
\hline & Hair Dryer & 1 & $\mathrm{~W}$ & 1500 \\
\hline & Hair Iron & 1 & $\mathrm{~W}$ & 150 \\
\hline & Water heater(R) & 1 & $\mathrm{~kW}$ & 10 \\
\hline
\end{tabular}




\begin{tabular}{|c|c|c|c|c|}
\hline Location & Appliance & No. & Unit & Capacity \\
\hline & Exhaust Fan & 1 & W & 200 \\
\hline
\end{tabular}

The separate usages probability charts for each room appliances are listed on the reference sheet of the excel file. The usage probability is defined based on the time of the day, working days and weekends, residents' daily life schedule and workplace. For example, there will be a higher chance of using kitchen appliances in the mornings or weekends, compared to midnights or weekdays, respectively. In order to when appliances are using, first the occupancy of a room will be identified, as described in the "Calculate Occupancy" step. If the room is unoccupied, then the appliances usage possibility will be zero for that equipment at that specific time. If the room is occupied, the program will generate random numbers for each selected appliance and compare with the corresponding usage probability chart and make the usages decision based on the heuristic rule. As an example, lighting usage probability chat for bedroom is presented for the case 1 in table 3.11.

Table 3.11: The rules for using the light in the bedroom

\begin{tabular}{|c|c|c|c|c|c|c|c|c|c|c|c|c|c|c|c|c|c|c|c|}
\hline \multicolumn{20}{|c|}{ Lighting Probability } \\
\hline \multicolumn{20}{|c|}{ Bed Room } \\
\hline \multicolumn{4}{|c|}{$\begin{array}{c}\text { Case } 1 \text { (One Bedroom - } \\
\text { Single Couple without } \\
\text { kid, both works ) }\end{array}$} & \multicolumn{4}{|c|}{$\begin{array}{c}\text { Single Couple without } \\
\text { kid, one work from } \\
\text { home) }\end{array}$} & \multicolumn{4}{|c|}{$\begin{array}{c}\text { Case } 3 \text { (Two Bedroom - } \\
\text { Couple with kids, both } \\
\text { work outside) }\end{array}$} & \multicolumn{4}{|c|}{$\begin{array}{c}\text { Case } 4 \text { (Two Bedroom - } \\
\text { Couple with kids, one } \\
\text { work home) }\end{array}$} & \multicolumn{4}{|c|}{$\begin{array}{c}\text { Case } 5 \text { (Three bedrooms } \\
\text { - three students } \\
\text { apartment) }\end{array}$} \\
\hline \multicolumn{2}{|c|}{ Time zone } & \multirow{2}{*}{\begin{tabular}{|c|}
$\begin{array}{c}\text { Work } \\
\text { Days }\end{array}$ \\
0.15 \\
\end{tabular}} & \multirow{2}{*}{\begin{tabular}{|c|} 
Holiday \\
0.15
\end{tabular}} & \multicolumn{2}{|c|}{ Time zone } & \multirow{2}{*}{\begin{tabular}{|c|}
$\begin{array}{c}\text { Work } \\
\text { Days }\end{array}$ \\
0.15 \\
\end{tabular}} & \multirow{2}{*}{\begin{tabular}{|c|} 
Holiday \\
0.15 \\
\end{tabular}} & \multicolumn{2}{|c|}{ Time zone } & \multirow{2}{*}{\begin{tabular}{|c|}
$\begin{array}{c}\text { Work } \\
\text { Days }\end{array}$ \\
0.25 \\
\end{tabular}} & \multirow{2}{*}{\begin{tabular}{|c|} 
Holiday \\
0.25 \\
\end{tabular}} & \multicolumn{2}{|c|}{ Time zone } & \multirow{2}{*}{\begin{tabular}{|c|}
$\begin{array}{c}\text { Work } \\
\text { Days }\end{array}$ \\
0.25 \\
\end{tabular}} & \multirow{2}{*}{\begin{tabular}{|c|} 
Holida \\
0.25 \\
\end{tabular}} & \multicolumn{2}{|c|}{ Time zone } & \multirow{2}{*}{\begin{tabular}{|c|c|}
$\begin{array}{c}\text { Work } \\
\text { Days }\end{array}$ \\
0.3 \\
\end{tabular}} & \multirow{2}{*}{\begin{tabular}{|c|} 
Holiday \\
0.35 \\
\end{tabular}} \\
\hline $0: 00$ & $7: 00$ & & & 0:00 & $7: 00$ & & & $0: 00$ & $7: 00$ & & & $0: 00$ & $7: 00$ & & & $0: 00$ & $7: 00$ & & \\
\hline $7: 01$ & $8: 00$ & 0.3 & 0.15 & $7: 01$ & $8: 00$ & 0.3 & 0.15 & $7: 01$ & 8:00 & 0.4 & 0.3 & $7: 01$ & $8: 00$ & 0.3 & 0.3 & $7: 01$ & $8: 00$ & 0.25 & 0.1 \\
\hline $8: 01$ & 17:00 & 0.1 & & $8: 01$ & 17:00 & 0.3 & 0.2 & 8:01 & $17: 00$ & 0.15 & 0.25 & $8: 01$ & $17: 00$ & 0.3 & 0.3 & $8: 01$ & 17:00 & 0.1 & 0.15 \\
\hline 17:01 & 21:00 & 0.3 & 0.35 & 17:01 & 21:00 & 0.35 & 0.35 & 17:01 & $21: 00$ & 0. & 0.3 & 17:01 & $21: 00$ & 0.25 & 0.3 & 17:01 & $21: 00$ & 0 & 0.2 \\
\hline $21: 01$ & $23: 59$ & 0.15 & 0.2 & $21: 01$ & $23: 59$ & 0.15 & 0.2 & $21: 01$ & $23: 59$ & 0.3 & 0.3 & $21: 01$ & $23: 59$ & 0.3 & 0.3 & $21: 01$ & $23: 59$ & 0.35 & 0.3 \\
\hline
\end{tabular}

\subsection{Simulation Description}

The goal of this simulation is to generate electricity consumption patterns for the designed case. This pattern will show what type of appliance has been used at that specific time for a userspecified day. Visual Basic Applications (VBA) is used for running the simulation, which will be designed for 365 days for different five scenarios. The program that is developed here is very userinteractive, where the user has the option to choose from several different inputs to define the situation appropriately. Additionally, the user will be able to change the default input values such as appliance specifications and appliances usage and occupancy probabilities, weather data to simulate a customized scenario. 


\subsubsection{User Inputs and Outputs}

The pattern generating simulation tool has four sections: user manual, input, reference and day data analysis section. The simulation is developed with a graphical interface. At first, the user manual sheet of the MS excel describes the whole process step by step to guide the user through the simulation process. To begin the simulation, the user has to click the "STAR Simulation" button and it asks the user to select a case. After that, the user can choose the room's volume, thermostat set level, and building envelope. In addition, it will ask about the possibility of future construction work and time. Also, the user has to select the type of appliance for that particular simulation. The user's input will adjust the house envelope for the rest of the months. Finally, the user must enter the fuel cost and fuel type for the heating system, stove and hot water heater. The reference sheet contains all necessary information required for energy calculation, such as the weather, the probability chart for the apartment occupancy, the usage probability chart for all the appliances, the capacity of all appliances, the probability chart for the room volume, and the thermostat settings. Besides, the load factor chart for HVAC is included in the reference sheet in detail. Upon providing all the information on the input page, the program starts the calculation and shows the occupancy level and HVAC load factor for each room.

In the excel file, a sheet will be generated for each room with the associated appliances usages status, occupancy level, season, thermostat level and volume. A random number will be developed for each factor at 30 minutes time interval. With the Monte Carlo Simulation and Heuristic rules, the usage status was calculated for each appliance, heating and cooling, based on the occupancy level and random number. Finally, the simulation will calculate the electricity consumption at 30 minutes time interval for the apartment house for 365 days. There will be electricity and natural gas consumption for each appliance on the energy consumption sheet and a summary of total natural gas and electricity consumption and cost. On the summary sheet, 12-month energy consumption for all appliances will be presented with the graphs. Finally, all appliances' energy consumption patterns will be developed for a particular day according to the user input date at the day data analysis worksheet.

\subsubsection{Description of Energy Consumption Calculation}


To begin, we grouped all devices into two categories. The first group includes appliances that do not depend on occupancies such as refrigerator and freezer. The second group contains the rest of the appliances, which are related to the occupancy. Electricity consumption for the first type is continuous. For calculating the electricity consumption for the second type, several factors have been considered.

Appliances: The energy calculation for any kind of home appliance except HVAC systems can be calculated as:

$$
\text { Energy Consumption }=(\mathrm{C} \times \mathrm{UF} \times \mathrm{LF} \times \mathrm{OH}) /(\mathrm{Eff} \times \mathrm{K})
$$

Where,

$$
\begin{array}{ll}
\mathrm{C} & =\text { Capacity of the Appliance } \\
\mathrm{LF} & =\text { Load Factor }(\%) \\
\mathrm{UF} & =\text { Utilization Factor }(\%) \\
\mathrm{OH} & =\text { Operating Hours } \\
\mathrm{Eff} & =\text { Efficiency of the equipment }(100 \%) \\
\mathrm{K} & =\text { Constant, }(1000 \text { watts } / \mathrm{kW})
\end{array}
$$

Here, the efficiency, load factor and utilization factor for most of the appliance are considered $100 \%$ except some appliances which are described in the next chapter in detail.

The average capacity of the appliance is listed on the reference page. After providing all the building specifications on the input page, the system will ask the user to select the specific room's appliance type from the given list. Based on the user's selection, the simulation will account for the chosen appliances' energy consumption.

The energy consumption calculation for TV as an example is shown in below.

$$
\begin{array}{rll}
\text { TV Energy Consumption } & =(\mathrm{C} \times \mathrm{UF} \times \mathrm{LF} \times \mathrm{OH}) /(\mathrm{Eff} \times \mathrm{K}) \\
& =(200 \mathrm{~W} \times 1 \times 1 \times 0.5 \mathrm{~h}) /(1 \times 1000 \mathrm{~W} / \mathrm{kW}) \\
& =0.1 \mathrm{kWh}
\end{array}
$$

HVAC: HVAC energy consumption can be calculated as:

$\begin{array}{lll}\mathrm{HVAC}_{\text {Electric Cooling }} & = & \mathrm{LF} \times((\mathrm{C} \times 12) /(\mathrm{SEER})) \times \mathrm{OH} \\ & = & \mathrm{LF} \times \mathrm{OH} \times \mathrm{C} \\ \mathrm{HVAC}_{\text {NG Heating }} & \quad & \text { Or } \\ \mathrm{HVAC}_{\text {Electric Heating }} & = & \{\mathrm{LF} \times((\mathrm{C} \times 3412 \mathrm{Btu} / \mathrm{kWh}) / \mathrm{HSPF})\} / 1000 \mathrm{~W} / \mathrm{kW} \times \mathrm{OH}\end{array}$


Where,

$\begin{array}{lll}\mathrm{C} & = & \text { Capacity of the Appliance }(\text { ton/hr or MMBtu/hr or kW) } \\ \mathrm{LF} & = & \text { Load Factor }(\%) \\ \mathrm{OH} & = & \text { Operating Hours } \\ \mathrm{SEER} & = & \text { Seasonal Energy Efficiency Ratio }(\mathrm{Btu} / \mathrm{Wh}) \\ \mathrm{HSPF} & = & \text { Heating Seasonal Performance Factor }(\mathrm{Btu} / \mathrm{Wh})\end{array}$

Load factor: The load factor is the ratio of the actual current draws under certain operating conditions to that specific equipment's maximum capacity. For HVAC energy consumption calculation, load factor depends on five-factor - occupancy, building envelope, outside weather, thermostat set point, and volume of the room. All the functions are predefined (Occupancy - 2 level, weather -3 levels, the room's volume -3 levels, building envelope -2 levels and thermostat -2 levels) and 72 sets for the HVAC calculation. The worst conditions are considered to determine the load factor for the HVAC systems' 72 pre-determined sets. An example of the determination of the load factor for six sets is shown below in table 3.12.

Table 3.12: Load Factor Assignment [40]

\begin{tabular}{|l|c|c|c|c|c|c|}
\hline \multicolumn{1}{|c|}{ Category } & Set 1 & Set 2 & Set 3 & Set 4 & Set 5 & Set 6 \\
\hline Load Factor & $100 \%$ & $40 \%$ & $80 \%$ & $70 \%$ & $20 \%$ & $0 \%$ \\
\hline Occupancy & 1 & 0 & 1 & 1 & 1 & 0 \\
\hline Weather & 3 & 3 & 3 & 3 & 1 & 1 \\
\hline Volume of the Room & 3 & 3 & 2 & 2 & 1 & 1 \\
\hline Building Envelope & 2 & 2 & 2 & 1 & 1 & 1 \\
\hline Thermostat Set Point & 2 & 2 & 2 & 2 & 1 & 1 \\
\hline
\end{tabular}

In set 1 , it is considered that the room volume is large and occupied, the weather is severe, the building envelope is poor, and the user prefers a high comfort level of temperature. This situation is the worst possible combination for all the factors since the scenario's load factor is $100 \%$. A maximum better possible combination is shown in set 6 , where the load factor is $0 \%$. At 30 minutes, interval occupancy has been generated and this auto-generated set is compared to the predetermined set for assigning the load factor. Then this load factor is used in energy consumption calculation. In this study, other appliances load factor is assumed $100 \%$ except for washing machine, cloth dryer, water heater, refrigerator, freezer, stove and space heater. 
Seasonal Energy Efficiency Ratio (SEER): SEER is defined as the ratio of Btu heat removed by the $\mathrm{AC}$ to the electric input power drawn by the $\mathrm{AC}$ unit. The following equation can express it;

SEER = Btu of heat removal of the AC system $/$ Wh of electric input to the AC system $\mathrm{SEER}=\mathrm{COP} \times 3.412 \mathrm{Btu} / \mathrm{Wh}$

Most residential air conditioning unit is rated with SEER. According to the federal appliance efficiency standards and ASHRAE standards (2015), the minimum SEER should be 14 for air conditioning units. [44]

The user has to enter the HVAC unit capacity, fuel type and SEER at the end of the input page. Energy calculation for cooling with the $70 \% \mathrm{LF}$ and 1.5 ton $\mathrm{AC}$ unit can be calculated as:

$$
\text { HVAC Energy Consumption }=\quad(\mathrm{C} \times \mathrm{LF} \times \mathrm{OH}) / \mathrm{SEER}
$$

Where,

$\begin{array}{lll}\mathrm{C} & =(1.5 \text { ton } \times 12) \\ \mathrm{LF} & =70 \% \\ \mathrm{OH} & =0.5 \mathrm{~h} \\ \mathrm{COP} & =14\end{array}$

HVAC Energy Consumption $=(1.5$ ton $\times 12 \times 0.7 \times 0.5$ h $) /(14 \mathrm{Btu} / \mathrm{Wh})$

$$
=0.45 \mathrm{kWh}
$$

Lighting: CFL is considered for the lighting calculation. The energy consumption for the lighting can be calculated as:

$$
\text { Energy Consumption }_{(\mathrm{CFL})}=(\mathrm{C} \times(1+0.05) \times \mathrm{OC} \times \mathrm{OH}) / \mathrm{K}
$$

Where,

$$
\begin{array}{lll}
\mathrm{N} & = & \text { Number of the light } \\
\mathrm{C} & = & \text { Capacity of the light (watts) } \\
\mathrm{OC} & = & \text { Occupancy } \\
\mathrm{OH} & = & \text { Operating Hour } \\
\mathrm{K} & = & \text { Constant, }(1000 \text { watts } / \mathrm{kW})
\end{array}
$$

The capacity and number of lights depending on the user's input. Operating hour is 30 minutes because lighting operating hour is directly related to the occupancy. When the place is not occupied, lighting is not functioning, so there will be no energy consumption for the light. The 
auto-generated occupancy level by MCS indicates the usage amount of the light during that specific period. The electricity consumption for two CFL light with $23 \mathrm{~W}$ can be calculated as:

$$
\begin{array}{rll}
\text { Energy Consumption }_{(\mathrm{CFL})} & =\quad(2 \times 23 \times 1.05 \times 0.5) / 1000 \\
& =0.02 \mathrm{kWh}
\end{array}
$$

\subsection{Assumption and Limitation}

Several assumptions have been made during the development of this simulation program. Moreover, there are some limitations to this simulation, as well. All the assumptions and limitations are described below:

\section{Assumptions}

- The time interval for the simulation has been considered 30 minutes. So, it will not be able to detect any event in terms of occupancy between 0-30 minutes interval.

- The efficiency of every appliance is $100 \%$.

- The load factor for a 30 minutes interval is the average load factor for HVAC.

- When the room is occupied only at that time, most of the equipment is running.

- It is considered that a smart thermostat with zoning control is employed.

- It has been assumed that building envelopes improvement is implemented from the beginning of the month.

- The effect of ventilation and exhaust air are disregarded during the energy consumption calculation.

- The possibility of a natural disaster is ignored in this simulation.

- Weather factors are updated only after 8 hours.

- Washing machine, cloth dryer and dish washer are running for 30 minutes.

- The load factor for all the appliances except HVAC, Water Heater, Refrigerator, Freezer. Washing Machine and Dryer has been assumed to be $100 \%$.

\section{Limitations}

- Only 5 cases have been developed. In practical application, there are various other combinations of residents in terms of age, education, and occupation that can arise.

- The number of rooms directly relates to the designed case. The simulation cannot handle any random number for rooms. 
- The only apartment house is considered for energy consumption.

- Regular daily life usable appliance is considered, and any luxury equipment is ignored.

- Only electricity and natural gas are accounted as energy sources.

- Appliance capacity is given in the reference sheet. If actual capacity differs significantly, energy consumption will be different.

- This simulation is not able to calculate the size of the HVAC. So, energy consumption depends on the user's input.

- Nine weather regions are considered. The simulation cannot be specific about the location for weather data.

- Many input boxes have been used, none of them take any character(alphabets/words) or 0 or anything out of the range.

- The excel program may not respond when the simulation is running. However, the program responds once the simulation is complete.

- The season factor is generated in bedroom 1 and will remain constant for all the other rooms for that particular hours.

\subsection{Conclusions}

This chapter defines the methodology of this research work. All the factors and inputs are described here briefly. This study considered five different scenarios to simulate energy consumption for one year and develop energy consumption patterns. This chapter also explains the logic of selecting the value for some pre-determined factors and all other assumptions. As mentioned earlier, this is a user-interactive process, as the user can change the default values if desired. Additionally, the limitations of this work have been discussed. For practical application, the commercial enterprise and law enforcement personnel can run this simulation for the chosen scenario multiple times to develop an envelope of patterns to analyze the resident's behavior. It is to be noted that this work is intended to facilitate the analysis of building occupants' activities, subject to all legal provisions that apply. It is not intended for the general public to pursue these activities because legal ramifications might be involved. 


\section{Simulation Tool Development}

\subsection{Simulation Excel Input Tabs Details}

This excel-based pattern generating simulation contains six worksheets named as - User Manual, Reference, Inputs, Case 1 or 2 - Day Data Analysis, Case 3 or 4 - Day Data Analysis, and Case 5 - Day Data Analysis.

\subsection{1 "User Manual" Worksheet}

The "User Manual" worksheet briefly describes the simulation process; factors have been considered, assumptions, and limitations of this simulation tool. This manual aims to guide the user to run the simulation step by step and describe the necessary procedures user needs to follow to get the correct simulation results for the specific scenario. Figure 4.1 shows the screenshot of the user manual of the excel file.

In the first section, considered factors such as five cases, occupancy, thermostat settings, season, room size, building envelope, appliances usage condition, and type of appliances have been described. The manual also mentions which factors are responsible for varying the occupancy and appliances usage condition of that place. The appliances list with different load factors, except HVAC, is mentioned in the manual. Also, the different usage factors for appliances are presented in the manual. 


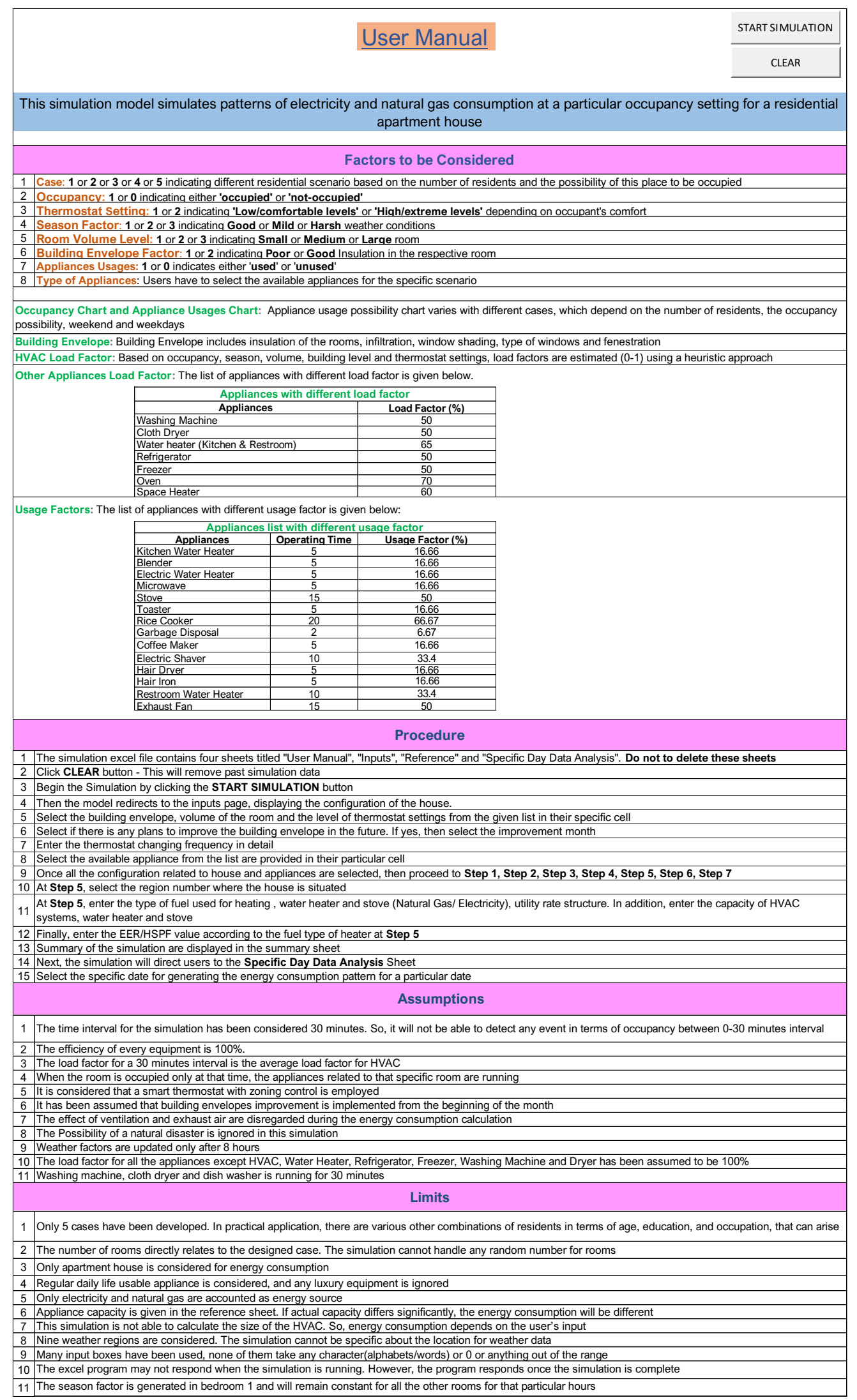

Figure 4-1: "User Manual” worksheet 
In the second section of the manual, the simulation running procedure is described in detail. As a first step to delete any previous simulation results, the user needs to click the "Clear" button. Multiple message boxes will ask the user to delete all auto-generated tabs. After that, the user needs to click the "Start Simulation" button to start the simulation. A message box, as shown in figure 4.2, will be displayed where the user needs to select the case number. Afterward, the excel file will open the "Inputs" worksheet, while user is required to provide necessary information to complete the entire simulation process. In the next input section, a detailed description has been provided.

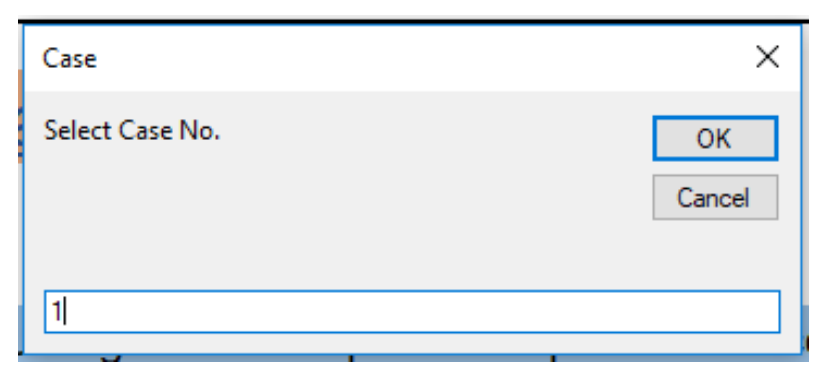

Figure 4-2: Screenshot of Start Simulation

The third section of the manual has stated all the assumptions mentioned in Chapter 3 of this thesis. After that, the fourth section describes the limitations of this work.

\subsection{2 "Reference" Worksheet}

The purpose of the "Reference" worksheet is to preserve all the information necessary to run the simulation. Occupancy probability percentages for each case are different at different time sections of the day and vary with weekdays and weekends. Figure 4.3 shows the occupancy probability in terms of the case, room-type, day of the week, and time of the day. The VBA code decides the occupancy by generating a random number, following a uniform distribution, and comparing the random number with the occupancy probability. Appliances usage decision and a load factor of HVAC depends on the occupancy. There are also probability charts of season, thermostat settings, and appliances at the reference tab. For simplification, the USA is divided into nine regions based on different climate conditions. The heating degree days and cooling degree days information of these nine regions has been provided in the reference section. Also, all the appliances' capacity has been added to this section. This user-driven simulation allows users to change all these numbers according to their requirements to simulate their embattled scenario. "Reference" sheet all information is provided in the appendix. 


\begin{tabular}{|c|c|c|c|c|c|c|c|c|c|c|c|c|c|c|c|c|c|c|c|}
\hline \multicolumn{20}{|c|}{ Occupancy Percentage } \\
\hline \multicolumn{20}{|c|}{ Bed Room } \\
\hline \multicolumn{4}{|c|}{ Case 1 (One Bedroom - Single Couple without kid, both works) } & \multicolumn{4}{|c|}{ Case 2 (One Bedroom - Single Couple without kid, one work from home) } & \multicolumn{4}{|c|}{ Case 3 (Two Bedroom - Couple with kids, both work outside) } & \multicolumn{4}{|c|}{ Case 4 (Two Bedroom - Couple with kids, one work home) } & \multicolumn{4}{|c|}{ Case 5 (Three bedrooms - three students apartment) } \\
\hline \multicolumn{2}{|c|}{ Time zone } & Working Days & Holiday & \multicolumn{2}{|c|}{ Time zone } & Working Days & Holiday & \multicolumn{2}{|c|}{ Time zone } & Working Days & Holiday & \multicolumn{2}{|c|}{ Time zone } & Working Days & Holiday & \multicolumn{2}{|c|}{ Time zone } & Working Days & Holiday \\
\hline $0: 00$ & $7: 00$ & 0.83 & 0.87 & $0: 00$ & 7:00 & 0.83 & 0.87 & $0: 00$ & 7:00 & 0.7 & 0.7 & 0:00 & 7:00 & 0.7 & 0.7 & $0: 00$ & 7:00 & 0.85 & 0.85 \\
\hline 7:01 & 8:00 & 0.10 & 0.85 & 7:01 & 8:00 & 0.2 & 0.85 & 7:01 & 8:00 & 0.2 & 0.4 & 7:01 & 9:00 & 0.3 & 0.45 & 7:01 & 9:00 & 0.12 & 0.8 \\
\hline 8:01 & 16:00 & 0.10 & 0.25 & 8:01 & 16:00 & 0.15 & 0.25 & $8: 01$ & 16:00 & 0.15 & 0.35 & 9:01 & 16:00 & 0.25 & 0.35 & 9:01 & 16:00 & 0.1 & 0.7 \\
\hline 16:01 & 22:00 & 0.15 & 0.15 & 16:01 & 22:00 & 0.15 & 0.15 & $16: 01$ & 21:00 & 0.3 & 0.35 & 16:01 & 21:00 & 0.2 & 0.1 & 16:01 & 22:00 & 0.4 & 0.3 \\
\hline 22:01 & $23: 59$ & 0.83 & 0.75 & 22:01 & $23: 59$ & 0.83 & 0.7 & 21:01 & $23: 59$ & 0.75 & 0.7 & 21:01 & $23: 59$ & 0.65 & 0.5 & 22:01 & $23: 59$ & 0.7 & 0.6 \\
\hline \multicolumn{20}{|c|}{ living Room } \\
\hline \multicolumn{4}{|c|}{ Case 1 (One Bedroom - Single Couple without kid, both works) } & \multicolumn{4}{|c|}{ Case 2 (One Bedroom - Single Couple without kid, one work from home) } & \multicolumn{4}{|c|}{ Case 3 (Two Bedroom - Couple with kids, both work outside) } & \multicolumn{4}{|c|}{ Case 4 (Two Bedroom - Couple with kids, one work home) } & \multicolumn{4}{|c|}{ Case 5 (Three bedrooms - three students apartment) } \\
\hline \multicolumn{2}{|c|}{ Time zone } & Working Days & Holiday & \multicolumn{2}{|c|}{ Time zone } & Working Days & Holiday & \multicolumn{2}{|c|}{ Time zone } & Working Days & Holiday & \multicolumn{2}{|c|}{ Time zone } & Working Days & Holiday & \multicolumn{2}{|c|}{ Time zone } & Working Days & Holiday \\
\hline $0: 00$ & $7: 00$ & 0.10 & 0.10 & $0: 00$ & $7: 00$ & 0.10 & 0.10 & $0: 00$ & $7: 00$ & 0.18 & 0.18 & $0: 00$ & 7:00 & \begin{tabular}{|l|l|}
0.20 \\
\end{tabular} & 0.20 & $0: 00$ & $7: 00$ & 0.20 & 0.25 \\
\hline 7:01 & $9: 00$ & 0.25 & 0.35 & 7:01 & $8: 00$ & 0.25 & 0.35 & 7:01 & $8: 00$ & 0.25 & 0.50 & 7:01 & 9:00 & 0.25 & 0.50 & 7:01 & $9: 00$ & 0.10 & 0.10 \\
\hline 9:01 & $16: 00$ & 0.10 & 0.70 & 8:01 & 16:00 & 0.55 & 0.70 & $8: 01$ & 18:00 & 0.10 & 0.50 & 9:01 & $16: 00$ & 0.45 & 0.50 & 9:01 & 16:00 & 0.10 & 0.60 \\
\hline 16:01 & 21:00 & 0.50 & 0.60 & $16: 01$ & 21:00 & 0.50 & 0.60 & 18:01 & 21:00 & 0.45 & 0.55 & 16:01 & 21:00 & 0.45 & 0.55 & $16: 01$ & 22:00 & 0.35 & 0.40 \\
\hline 21:01 & $23: 59$ & 0.12 & 0.40 & 21:01 & 23.59 & 0.12 & 0.45 & 21:01 & $23: 59$ & 0.85 & 0.70 & $21: 01$ & 23.59 & 0.85 & 0.85 & 22:01 & 23.59 & 0.15 & 0.40 \\
\hline & & & & & & & & & & & & & & & & & & & \\
\hline & Bedroom. & uple without kid, & & Case 210n & - Single Co & thout kid, one wo & om home) & Case 31 & droom $\cdot C$ & with kids, both & :outside) & & 10 Bedroo & - Couple with kids & work home) & & Three bed & ss - three students & tment) \\
\hline & & Working Days & Holiday & & & Working Days & Holiday & & & Working Days & Holiday & & & Working Days & Holiday & & & Working Days & Holiday \\
\hline 0:00 & $7: 00$ & 0.10 & 0.10 & $0: 00$ & $7: 00$ & 0.10 & 0.10 & $0: 00$ & 7:00 & 0.15 & 0.15 & 0:00 & $7: 00$ & 0.15 & 0.15 & $0: 00$ & 7:00 & 0.25 & 0.20 \\
\hline 7:01 & 9:00 & 0.45 & 0.30 & $7: 01$ & 9:00 & 0.40 & 0.30 & $7: 01$ & 9:00 & 0.55 & 0.70 & 7:01 & 9:00 & 0.45 & 0.60 & 7:01 & 10:00 & 0.65 & 0.15 \\
\hline 9:01 & 16:00 & 0.10 & 0.35 & 9:01 & 17:00 & 0.27 & 0.35 & 9:01 & 16:00 & 0.15 & 0.35 & 9:01 & 16:00 & 0.30 & 0.35 & 10:01 & $16: 00$ & 0.15 & 0.40 \\
\hline 16:01 & 21:00 & 0.40 & 0.50 & 17:01 & 22:00 & 0.40 & 0.45 & $16: 01$ & 21:00 & 0.45 & 0.50 & 16:01 & 21:00 & 0.45 & 0.50 & $16: 01$ & 20:00 & 0.10 & 0.45 \\
\hline 21:01 & 23:59 & 0.10 & 0.15 & 22:01 & $23: 59$ & 0.10 & 0.20 & 21:01 & 23:59 & 0.20 & 0.25 & 21:01 & 23:59 & 0.20 & 0.25 & 20:01 & 23:59 & 0.30 & 0.15 \\
\hline & & & & & & & & & & & & & & & & & & & \\
\hline & Bedroom- & uple without kid, & & $\operatorname{cose} 210 \mathrm{n}$ & - Single Co & thout kid, one wo & om home) & Case 31 & droom $-C$ & with kids, both & outside) & & ro Bedroo & -Couple with kids & work home) & & Three bed & ss - three students & tment) \\
\hline & & Working Days & Holiday & & & Working Days & Holiday & & & Working Days & Holiday & & & Working Days & Holiday & & & Working Days & Holiday \\
\hline $0: 00$ & $7: 00$ & 0.10 & 0.10 & $0: 00$ & 7:00 & 0.10 & 0.10 & $0: 00$ & 7:00 & 0.15 & 0.15 & 0:00 & 7:00 & \begin{tabular}{|l|}
0.15 \\
\end{tabular} & 0.15 & $0: 00$ & 7:00 & 0.10 & 0.10 \\
\hline 7:01 & $8: 00$ & 0.40 & 0.10 & 7:01 & $8: 00$ & 0.40 & 0.10 & 7:01 & $9: 00$ & 0.45 & 0.25 & 7:01 & $9: 00$ & 0.35 & 0.25 & 7:01 & $9: 00$ & 0.35 & 0.15 \\
\hline $8: 01$ & 17:00 & 0.10 & 0.30 & $8: 01$ & 16:00 & 0.20 & 0.30 & $9: 01$ & $16: 00$ & 0.10 & 0.30 & 9:01 & $16: 00$ & 0.30 & 0.35 & 9:01 & 16:00 & 0.10 & 0.20 \\
\hline 17:01 & 22:00 & 0.15 & 0.15 & 16:01 & 21:00 & 0.15 & 0.20 & $16: 01$ & 22:00 & 0.20 & 0.30 & 16:01 & 22:00 & 0.20 & 0.30 & $16: 01$ & 22:00 & 0.15 & 0.20 \\
\hline 22:01 & $23: 59$ & 0.10 & 0.15 & 21:01 & 23:59 & 0.10 & 0.15 & 22:01 & 23:59 & 0.15 & 0.15 & 22:01 & 23:59 & 0.15 & 0.15 & 22:01 & 23:59 & 0.15 & 0.15 \\
\hline
\end{tabular}

Figure 4-3: Occupancy Chart from "Reference" worksheet 


\subsection{3 "Inputs" Worksheet}

After selecting the case number on the user manual worksheet, the "Inputs" worksheet will be activated. The "Inputs" worksheet will be populated with the bedroom number affiliated with the case. In this input worksheet, the user has to select all the necessary information from dropdown list, pop-up boxes, and checkboxes. The essential information includes the building envelope, room size, thermostat settings levels, thermostat changing frequency, future building construction possibility and month of construction, and available appliances for the specific scenario, as shown in figure 4.4 . 


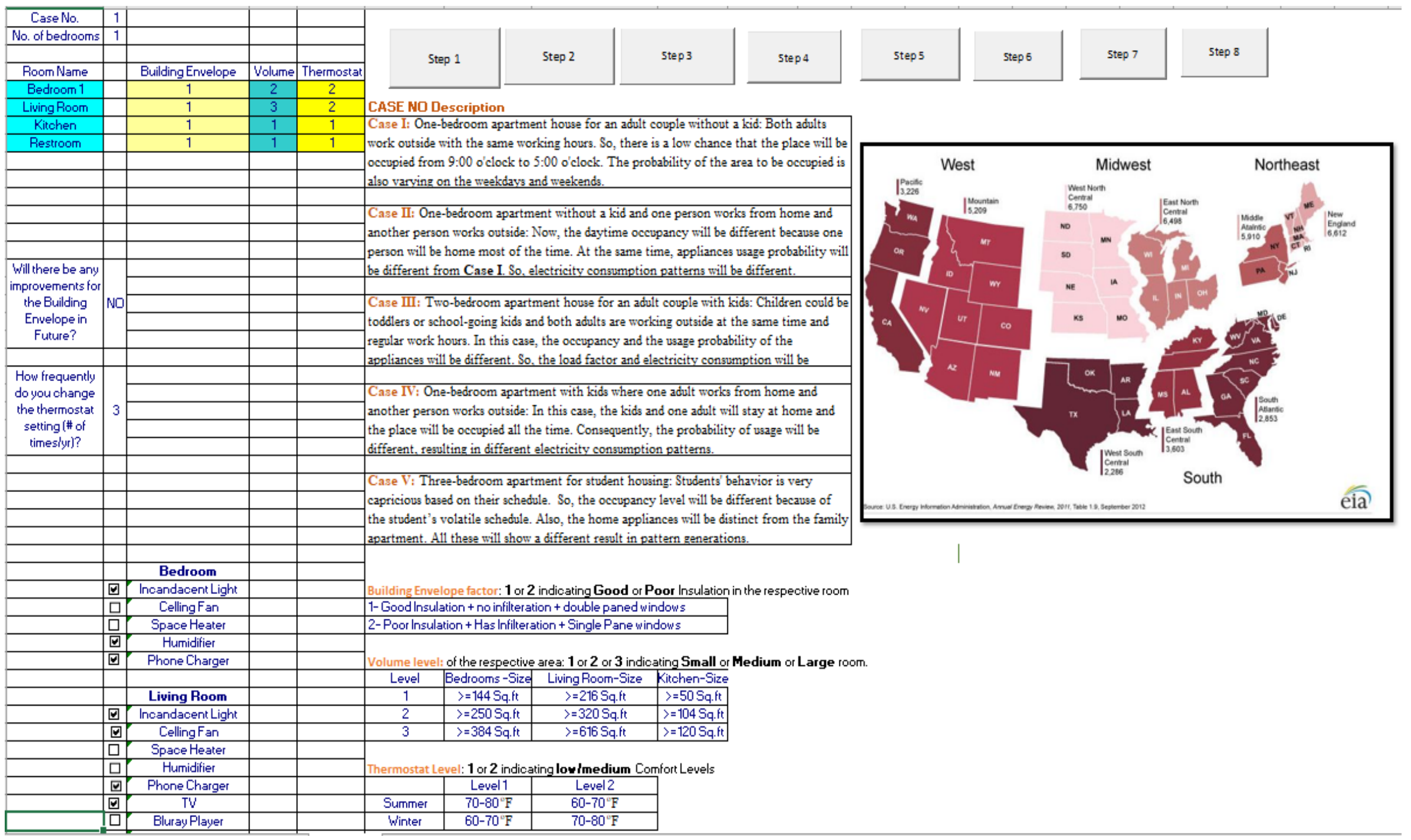

Figure 4-4: "Inputs" worksheet 


\subsection{4 "Day Data Analysis" Worksheet}

In this simulation, there are three other worksheets with the name: "Case 1 or 2- Day Data Analysis", "Case 3 or 4- Day Data Analysis", and "Case 5- Day Data Analysis". According to the case number selected in the "User Manual" worksheet, the corresponding day data analysis worksheet will be activated. For example, if the user simulates case 3, the "Case 3 or 4- Day Data Analysis" worksheet will be activated. In this worksheet, the user can change the date and observe the specific day's energy consumption pattern. The worksheet will develop an energy consumption graph for HVAC, low capacity appliances, medium-capacity appliances, second high capacity appliances, high capacity appliances, and stove-water heater (kitchen \& restroom).

\subsection{Developing Excel VBA Code}

The simulation was developed using Excel-based VBA code for five different cases with a graphical interface. "User Manual" and "Inputs" worksheets contain several pop-up message boxes and buttons to complete the simulation, which are generated with VBA code. To begin, the simulation "START SIMULATION" button is required to click while the VBA code will ask the user to select the case number. The apartment room number is related to the case, which will be automatically assigned by putting the case number in the pop-up box, and the following code will run to complete this process.

\begin{tabular}{|l|l|}
\hline Select Case Number & $\begin{array}{l}\text { 'Select Bedroom Number for Different Cases } \\
\text { ErrorHandler: }\end{array}$ \\
If $(\mathrm{CA}<3)$ Then \\
CA = InputBox("Select Case No.", "Case") & bedrooms $=1$ \\
If IsNumeric(CA) Then & ElseIf $(\mathrm{CA}>2$ And $\mathrm{CA}<5)$ Then \\
If $(\mathrm{CA}>5)$ Then & bedrooms $=2$ \\
MsgBox "Error- The simulation only has & ElseIf $(\mathrm{CA}=5)$ Then \\
the capacity to handle 5 different case" & bedrooms $=3$ \\
GoTo ErrorHandler & End If \\
ElseIf $(\mathrm{CA}>0$ And CA $<6)$ Then & ActiveSheet.Cells $(3,2)=$ bedrooms \\
CA = Round(CA, 0) & 'Count total room numbers and placement \\
ElseIf (CA =0) Then & rooms $=$ bedrooms $+1+1+1$ \\
MsgBox "Error- Enter a number greater & For $\mathrm{k}=2$ To rooms +1 \\
than 0" & If $\mathrm{k}<$ rooms -1 Then \\
GoTo ErrorHandler & ActiveSheet.Cells $(\mathrm{k}+4,1)=$ "Bedroom " \& \\
End If & $\mathrm{o}$ \\
Else & $\mathrm{o}=\mathrm{o}+1$ \\
MsgBox "Error- Enter a number" & ElseIf $\mathrm{k}=$ rooms -1 Then \\
GoTo ErrorHandler & \\
\hline
\end{tabular}




\begin{tabular}{|l|l|}
\hline End If & \multicolumn{1}{|c|}{ ActiveSheet.Cells $(\mathrm{k}+4,1)=$ "Living Room" } \\
ElseIf $\mathrm{k}=$ rooms Then \\
ActiveSheet.Cells $(\mathrm{k}+4,1)=$ "Kitchen" \\
ElseIf $\mathrm{k}=$ rooms +1 Then \\
ActiveSheet.Cells $(\mathrm{k}+4,1)=$ "Restroom" \\
End If \\
ActiveSheet.Cells $(\mathrm{k}$ \\
\\
1).Interior.ColorIndex $=28$
\end{tabular}

The user has to click eight buttons sequentially after providing all the necessary values at the "Inputs" worksheet through the pop-up boxes, drop-down lists, and checkboxes. The worksheet for each room will be automatically generated by clicking the "step 1" button. Besides, occupancy, season level, room volume, thermostat setting, and building envelope decision will be taken simultaneously. For example, the following code will run to generate a bedroom worksheet and decide about occupancy.

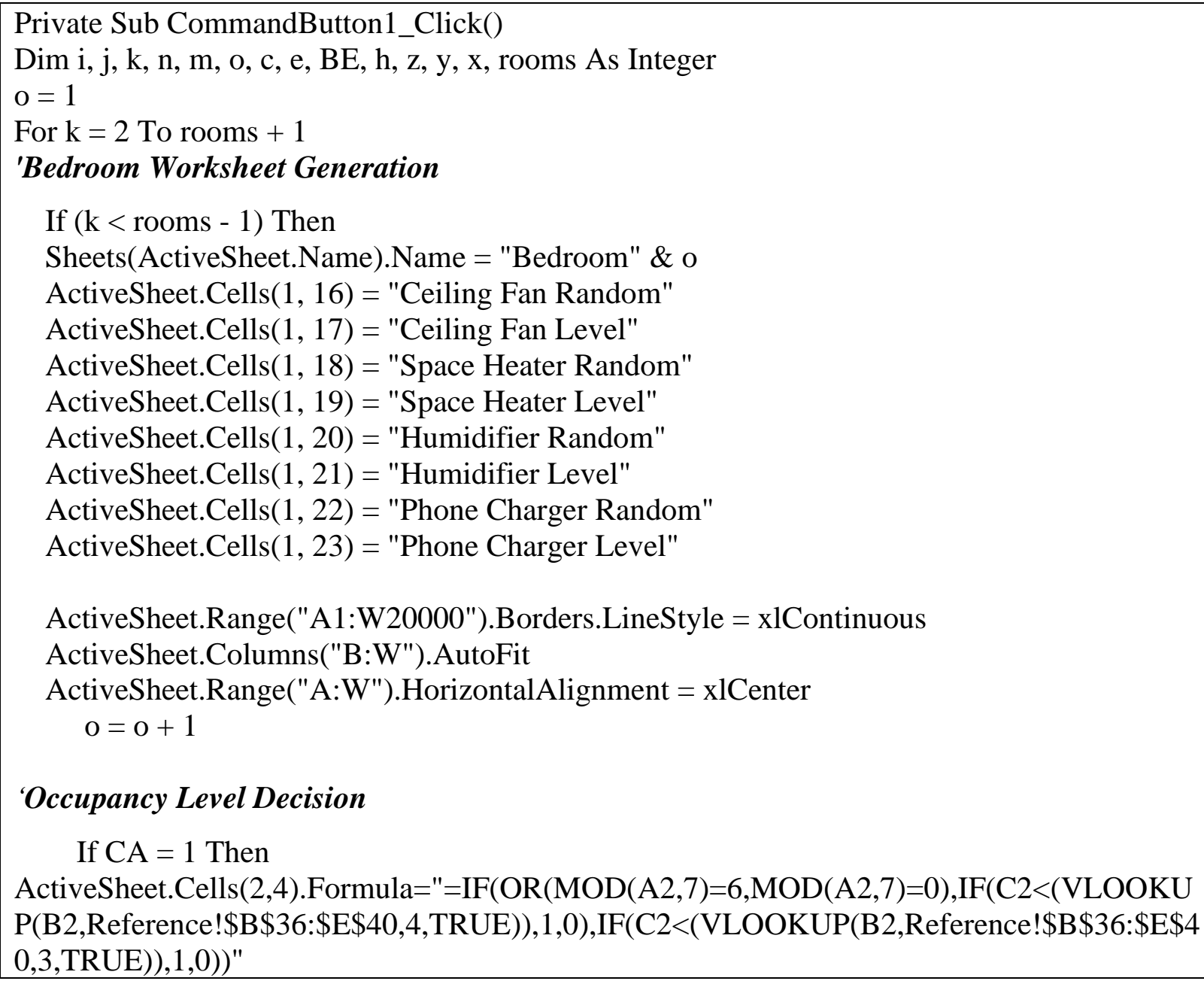

\section{'Occupancy Level Decision}

If $\mathrm{CA}=1$ Then

ActiveSheet.Cells(2,4).Formula $="=\mathrm{IF}(\mathrm{OR}(\mathrm{MOD}(\mathrm{A} 2,7)=6, \mathrm{MOD}(\mathrm{A} 2,7)=0), \mathrm{IF}(\mathrm{C} 2<(\mathrm{VLOOKU}$ P(B2,Reference!\$B \$36:\$E\$40,4,TRUE)),1,0),IF(C2<(VLOOKUP(B2,Reference!\$B \$36:\$E \$4 $0,3$, TRUE) $), 1,0))^{\prime \prime}$ 


\begin{tabular}{|c|}
\hline 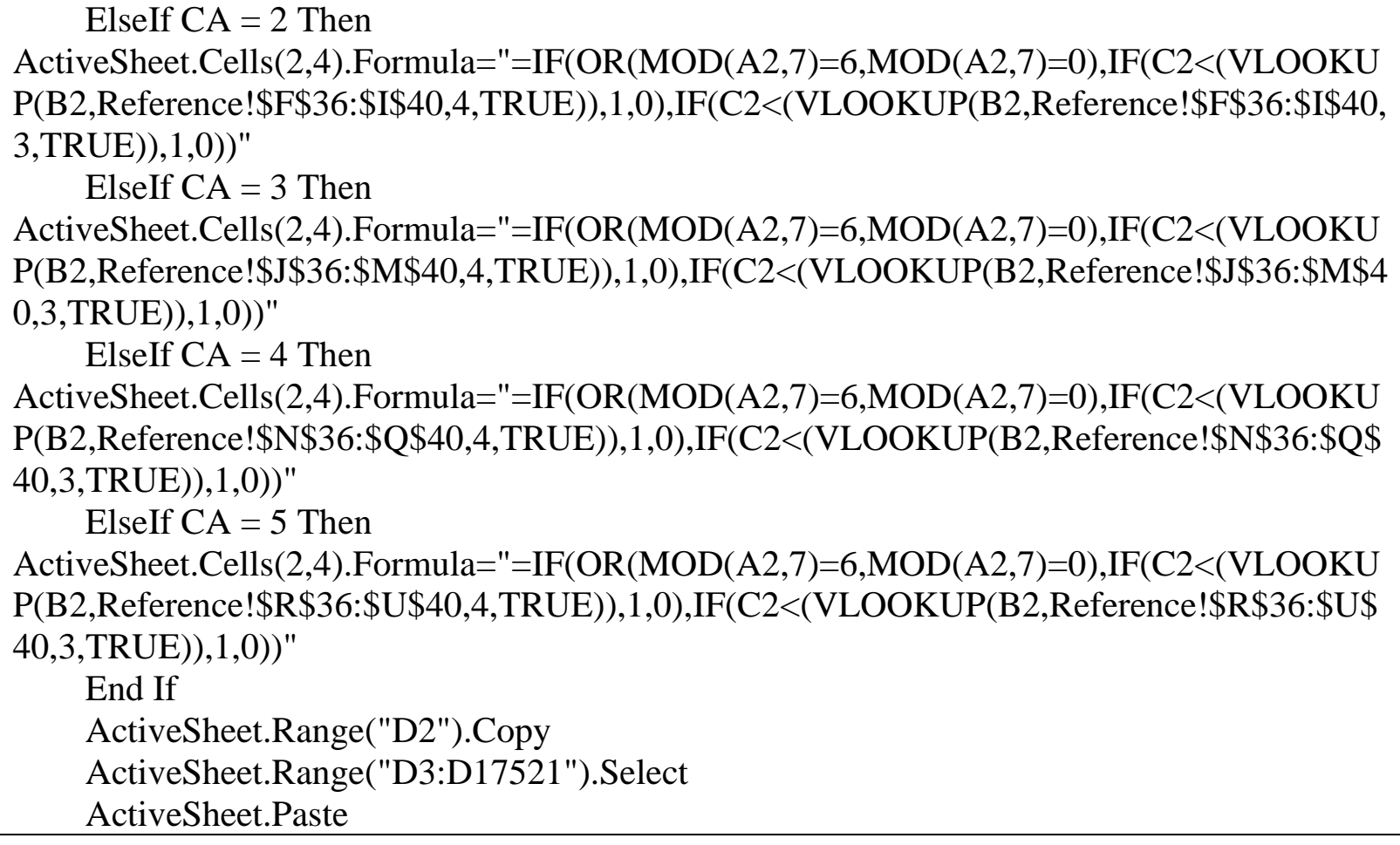 \\
\hline
\end{tabular}

"Step 2" and "Step 3" make the usage decision for the selected appliance for each time interval. For instance, the following code will run to decide the lighting usage level for a specific time.

\section{'Lighting Usage Decision}

If Worksheets("Inputs").Cells(34, 1) = "True" Then

ActiveSheet.Cells(2, 14).Formula = "=Round(Rand(), 2)"

ActiveSheet.Cells(2,15).Formula ="=IF(D2=1, IF(OR(MOD(A2,7)=6, MOD(A2,7)=0), IF(N2<( VLOOKUP(B2,Reference!\$N\$89:\$Q\$93,4,TRUE)), 1,0),IF(N2<(VLOOKUP(B2,Reference!\$ N\$89:\$Q\$93,3,TRUE)),1,0)),0)"

ActiveSheet.Cells $(2,15)$.Interior.ColorIndex $=28$

ElseIf Worksheets("Inputs").Cells(34, 1) = "False" Then

ActiveSheet.Cells $(2,14)=" "$

ActiveSheet.Cells $(2,15)=" "$

End If

"Step 4" button will generate the "Load Factor" worksheet and calculate HVAC's average load factor by running the VBA code. "Step 5" command button will show several pop-up message boxes for receiving the information about the region, heating and cooling fuel type, fuel cost, HVAC specification, hot water heater and stove fuel type and their capacity. All this information will be saved in the "Reference" worksheet to calculate all appliances' energy consumption. As a 
sample code, the following VBA code will run to take the information about the heater if this is run by natural gas.

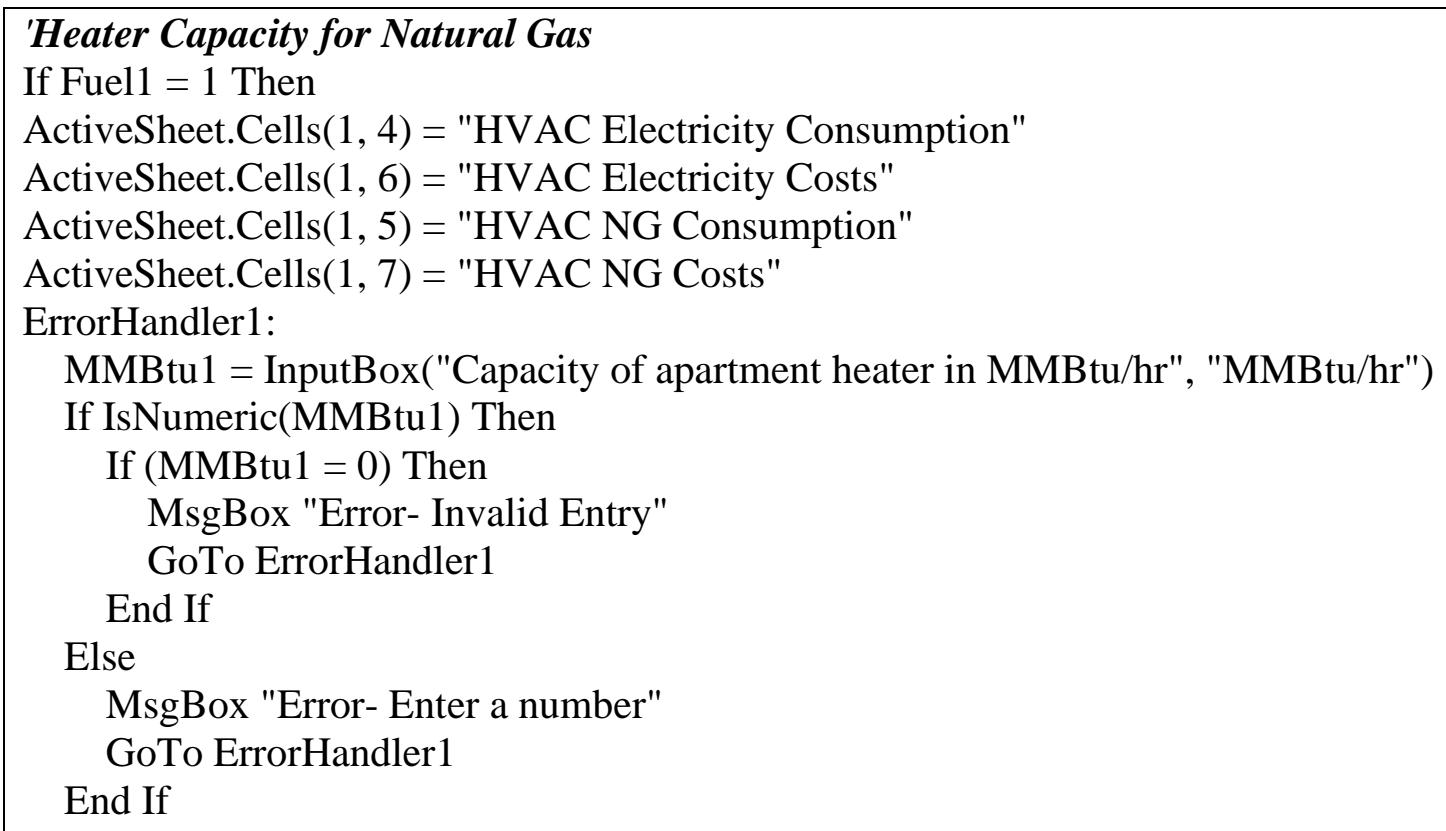

'Put heating heater and NG value in the reference sheet

Worksheets("Reference").Range("K54") = MMBtu1

Worksheets("Reference").Range("L54") = CMMBtu

Worksheets("Reference").Range("K56") = MMBtu1

Worksheets("Reference").Range("L56") = CMMBtu

\section{'Energy NG Cost Calculation}

ActiveSheet.Range("G2").Formula = "= IF(E2=""'"","'"',E2 * Reference!\$L\$54)"

ActiveSheet.Cells(2, 7).Copy

ActiveSheet.Range("G3:G17521").Select

ActiveSheet.Paste

The VBA code behind the "Step 6" button will generate a "Summary" worksheet containing each appliance one-month energy consumption summary up to twelve months. The code for the "Step 7" button is designed to develop two bar-chart of one-year cooling-heating energy consumption and twelve bar-charts for each appliance for each month's energy consumption. The first part of the code runs to calculate the cooling system's energy usage summary, and the second part of the code runs to develop a graph for all appliances for January month.

\section{'Twelve months of energy usage summary for Cooling System}

ActiveSheet.Cells(2, 2).Formula = "=ROUNDUP(SUM('Energy Consumption'!D2:D1489),0)" 


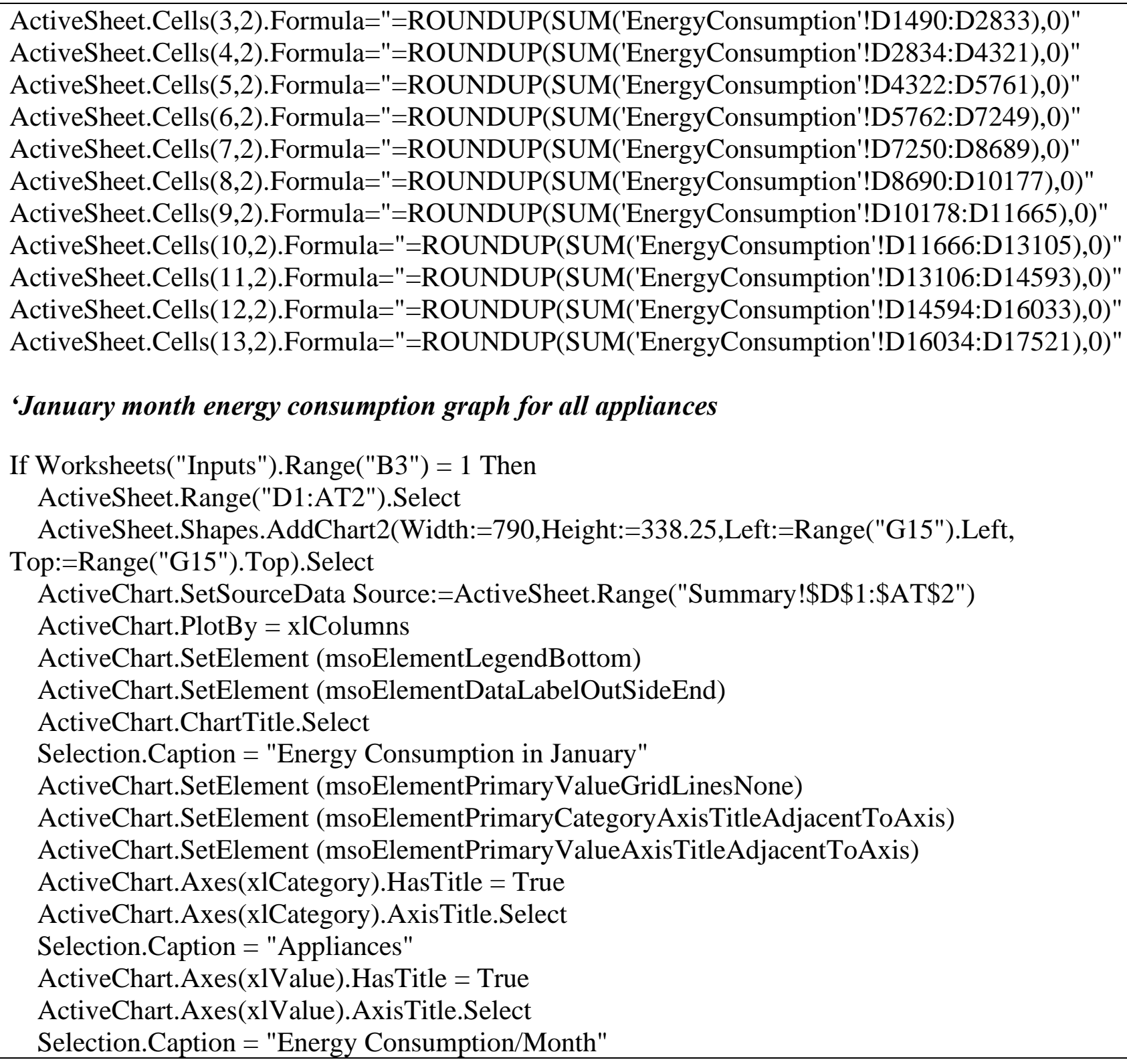

The code behind "Step 8" will run to calculate and demonstrate energy usage data for one specific date in the day data analysis worksheet.

\subsection{Simulation Demonstration with Case-1 Example}

As an example, the step-by-step simulation for Case-1 is described in this section. Case-1 is a onebedroom apartment with two adults and no kids. Both residents work outside of the house during the weekdays. So, there is a low chance that the place will be occupied from 8:00 am to 5:00 pm. First, the user has to provide the case number by clicking the "Start Simulation" button to begin 
the simulation. After that, the "Inputs" worksheet will be activated, and the number of rooms will be automatically generated. As shown in figure 4.5, the following message boxes will appear to notify the user which information needs to be entered.

\begin{tabular}{|l|l|l|}
\hline Microsoft Excel & Microsoft Excel \\
Select a Level Building Envelope, Volume, Thermostat & & OK \\
\hline
\end{tabular}

Figure 4-5: Direction for considered factors value in "Inputs" worksheet

After selecting the building envelope, room volume, thermostat setting level, and available appliances for each room from the checkboxes, the simulation will ask about the future building envelope changing possibility. If the building envelope changes in the future, then the user has to provide the construction month. At the next step, another message box will appear, asking about the thermostat changing frequency. Figure 4.6 shows the message boxes.

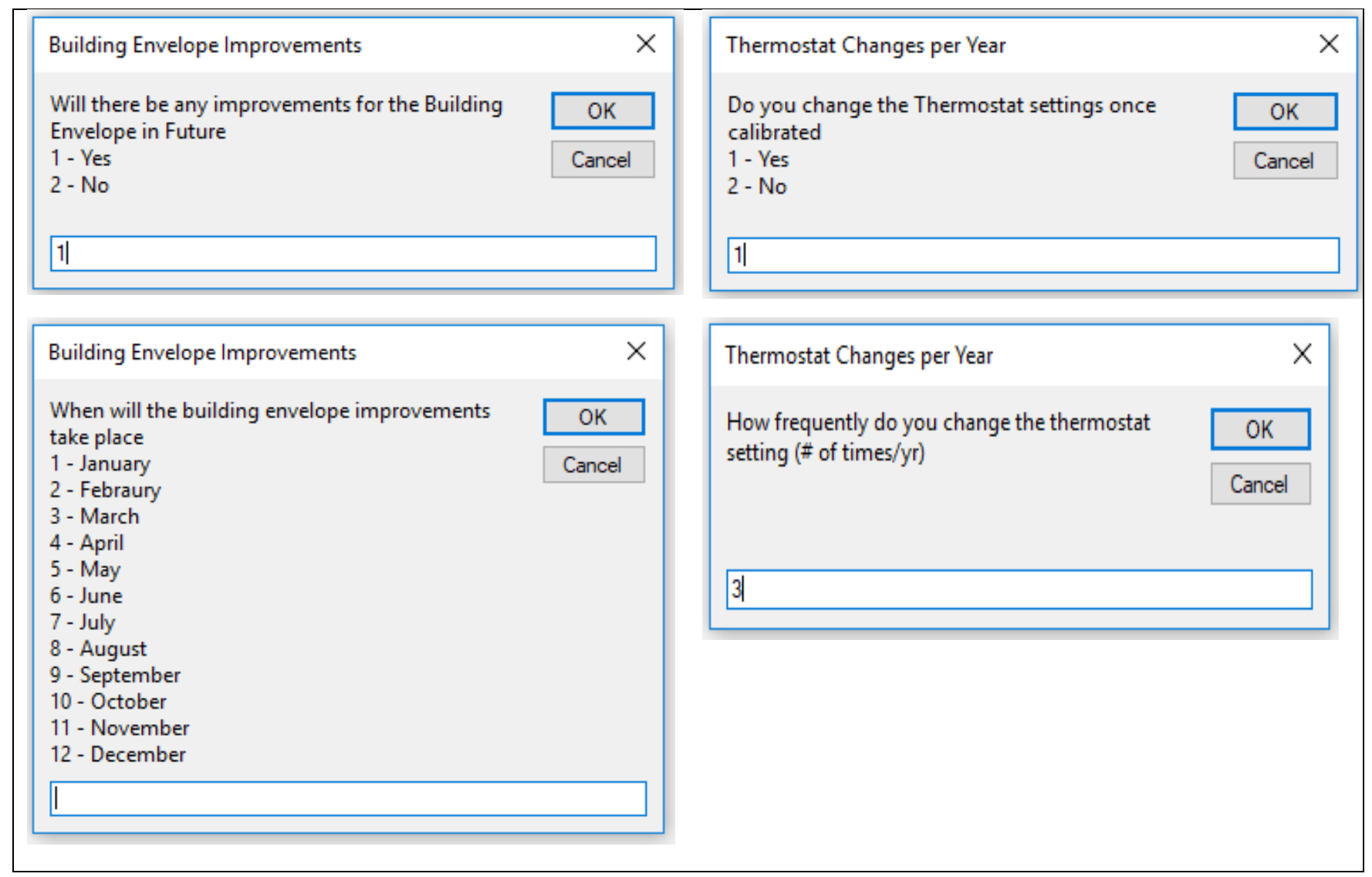


Figure 4-6: Pop-up input boxes for building construction and thermostat changing frequency

The appliances list from the "Inputs" worksheet is presented in table 4.1. The appliances will be selected by checking boxes in the given appliance list in the "Input" worksheet.

Table 4.1: Appliances list

\begin{tabular}{|l|l|l|l|}
\hline & Bedroom & & Living Room \\
\hline$\square$ & Incandescent Light & $\square$ & Incandescent Light \\
\hline$\square$ & Ceiling Fan & $\square$ & Ceiling Fan \\
\hline$\square$ & Space Heater & $\square$ & Space Heater \\
\hline$\square$ & Humidifier & $\square$ & Humidifier \\
\hline$\square$ & Phone Charger & $\square$ & Phone Charger \\
\hline & & $\square$ & TV \\
\hline & Kitchen & $\square$ & Blu-ray Player \\
\hline$\square$ & Incandescent Light & $\square$ & Cable Box \\
\hline$\square$ & Washing Machine & $\square$ & DVD \\
\hline$\square$ & Dryer & $\square$ & Desktop \\
\hline$\square$ & Electric Water & $\square$ & Laptop \\
\hline & Heater & & \\
\hline$\square$ & Coffee Maker & $\square$ & Printer \\
\hline$\square$ & Dishwasher & $\square$ & LCD Monitor \\
\hline$\square$ & Microwave Oven & & \\
\hline$\square$ & Stove & & Restroom \\
\hline$\square$ & Oven & $\square$ & Incandescent Light \\
\hline$\square$ & Blender & $\square$ & Aroma Lamp \\
\hline$\square$ & Toaster & $\square$ & Electric Shaver \\
\hline$\square$ & Griller & $\square$ & Hair Dryer \\
\hline$\square$ & Exhaust hood & $\square$ & Hair Iron \\
\hline$\square$ & Rice Cooker & $\square$ & Exhaust Fan \\
\hline$\square$ & Garbage Disposal & $\square$ & Water Heater \\
\hline$\square$ & Refrigerator & & \\
\hline$\square$ & Freezer & & \\
\hline$\square$ & Water Heater & & \\
\hline & & \\
\hline
\end{tabular}

There are eight buttons in the "Inputs" worksheet. The user needs to click these buttons sequentially. "Step 1" will generate worksheets for each room, i.e., Bedroom 1, Living Room, Kitchen, and Restroom. At this step, random numbers with uniform distribution will be generated for each room. These random numbers will be compared with the occupancy probability chart from the "Reference" worksheet to make the occupancy decision for 30 minutes time interval for one year. For example, the probability chart of case -1 from time 12:00 to 7:00 says that the place will be occupied for any number from 0 to 0.83 . If the automated generated random number at 
12:00 am for the bedroom is 0.71 , that means the place is occupied, and the occupancy level will be 1. Figure 4.7 presents the screenshot of the "Bedroom1" after step 1.

There is also a probability chart for selecting the season level on the "Reference" worksheet, and it will follow the same rules as occupancy. If the user has not already chosen the thermostat setting, building envelopes, and room volume from the dropdown list, random numbers are automatically generated for these factors at "Step 1". The random number will be compared with the probability chart to decide on these factors.

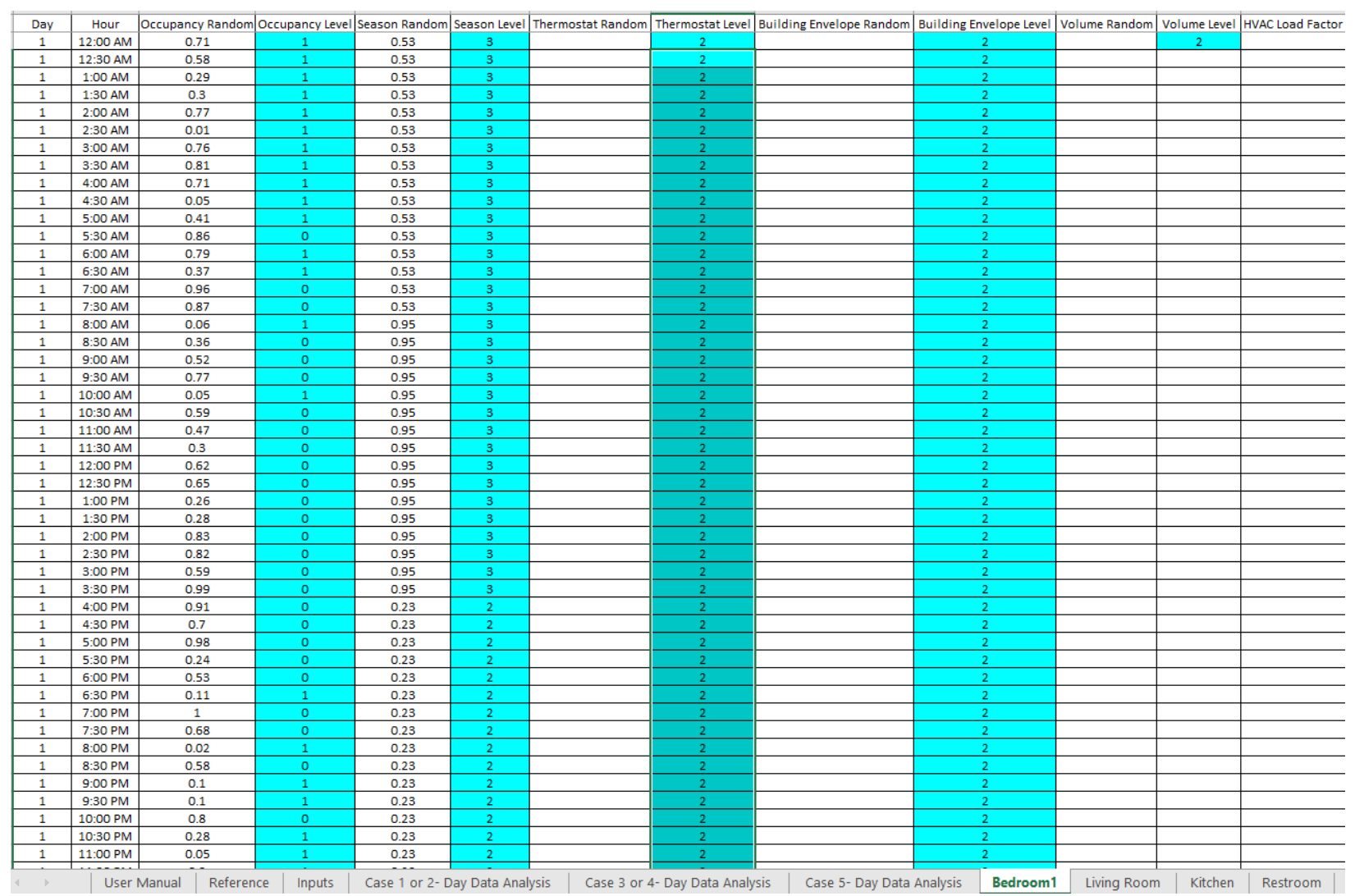

Figure 4-7: "Bedroom1" sheet after Step 1

Clicking "Step 2" button will generate random numbers for bedroom, living room, and restroom's appliances. It will follow the same heuristics rules to decide if the appliances are being used or are unused. "Step 3" will generate random numbers for the kitchen's appliances and determine which appliances are being used on that specific 30 minutes time interval. 


\begin{tabular}{|c|c|c|c|c|c|c|}
\hline & & Bedroom1 & Living room & Kitchen & Restroom & HVAC Average Load Factor \\
\hline Floor Area & & 250 & 616 & 50 & 54 & \\
\hline & & & & & & \\
\hline Day & Time & HVAC Load Factor & HVAC Load Factor & HVAC Load Factor & \begin{tabular}{|l|} 
HVAC Load Factor \\
\end{tabular} & Average Load Factor \\
\hline 1 & 12:00 AM & 0.6 & 0.3 & 0.2 & 0.5 & 0.38 \\
\hline 1 & 12:30 AM & 0.6 & 0.3 & 0.2 & 0.2 & 0.37 \\
\hline 1 & 1:00 AM & 0.6 & 0.7 & 0.2 & 0.2 & 0.62 \\
\hline 1 & $1: 30 \mathrm{AM}$ & 0.6 & 0.3 & 0.2 & 0.2 & 0.37 \\
\hline 1 & $2: 00 \mathrm{AM}$ & 0.6 & 0.3 & 0.2 & 0.2 & 0.37 \\
\hline 1 & $2: 30 \mathrm{AM}$ & 0.6 & 0.3 & 0.2 & 0.2 & 0.37 \\
\hline 1 & 3:00 AM & 0.6 & 0.3 & 0.2 & 0.2 & 0.37 \\
\hline 1 & $3: 30 \mathrm{AM}$ & 0.6 & 0.3 & 0.2 & 0.2 & 0.37 \\
\hline 1 & 4:00 AM & 0.6 & 0.3 & 0.2 & 0.2 & 0.37 \\
\hline 1 & $4: 30 \mathrm{AM}$ & 0.6 & 0.3 & 0.2 & 0.2 & 0.37 \\
\hline 1 & $5: 00 \mathrm{AM}$ & 0.6 & 0.3 & 0.2 & 0.2 & 0.37 \\
\hline 1 & $5: 30 \mathrm{AM}$ & 0.25 & 0.3 & 0.2 & 0.2 & 0.28 \\
\hline 1 & 6:00 AM & 0.6 & 0.3 & 0.2 & 0.2 & 0.37 \\
\hline 1 & $6: 30 \mathrm{AM}$ & 0.6 & 0.3 & 0.2 & 0.2 & 0.37 \\
\hline 1 & 7:00 AM & 0.25 & 0.3 & 0.2 & 0.2 & 0.28 \\
\hline 1 & $7: 30 \mathrm{AM}$ & 0.25 & 0.7 & 0.2 & 0.5 & 0.55 \\
\hline 1 & $8: 00 \mathrm{AM}$ & 0.6 & 0.7 & 0.2 & 0.2 & 0.62 \\
\hline 1 & $8: 30 \mathrm{AM}$ & 0.25 & 0.3 & 0.2 & 0.2 & 0.28 \\
\hline 1 & 9:00 AM & 0.25 & 0.7 & 0.2 & 0.5 & 0.55 \\
\hline 1 & $9: 30 \mathrm{AM}$ & 0.25 & 0.3 & 0.2 & 0.5 & 0.29 \\
\hline 1 & $10: 00 \mathrm{AM}$ & 0.6 & 0.3 & 0.2 & 0.2 & 0.37 \\
\hline 1 & $10: 30 \mathrm{AM}$ & 0.25 & 0.3 & 0.2 & 0.5 & 0.29 \\
\hline 1 & 11:00 AM & 0.25 & 0.3 & 0.2 & 0.5 & 0.29 \\
\hline 1 & $11: 30 \mathrm{AM}$ & 0.25 & 0.3 & 0.2 & 0.2 & 0.28 \\
\hline 1 & 12:00 PM & 0.25 & 0.7 & 0.2 & 0.5 & 0.55 \\
\hline 1 & 12:30 PM & 0.25 & 0.7 & 0.2 & 0.2 & 0.53 \\
\hline 1 & 1:00 PM & 0.25 & 0.3 & 0.2 & 0.2 & 0.28 \\
\hline 1 & 1:30 PM & 0.25 & 0.3 & 0.2 & 0.2 & 0.28 \\
\hline
\end{tabular}

Figure 4-8: Average HVAC load factor in "Load factor" Worksheet

"Step 4" will calculate the average load factor for the HVAC system, as shown in figure 4.8. The average load factor calculation for first row are shown as below,

Avg. Load Factor $=((\mathrm{bda} \times \mathrm{bdlf})+($ lra $\times$ lrlf $)+(\mathrm{ka} \times \mathrm{klf})+(\mathrm{ra} \times \mathrm{rlf})) /(\mathrm{bda}+\mathrm{lra}+\mathrm{ka}+\mathrm{ra})$

Where,

$\begin{array}{lll}\text { bda } & = & \text { bedroom area } \\ \text { bdlf } & = & \text { bedroom load factor } \\ \text { lra } & = & \text { living room area } \\ \text { lrlf } & = & \text { living room load factor } \\ \mathrm{ka} & = & \text { kitchen area } \\ \mathrm{klf} & = & \text { kitchen load factor } \\ \mathrm{ra} & = & \text { restroom area } \\ \mathrm{rlf} & = & \text { restroom load factor }\end{array}$

Avg. Load Factor $\quad=((.6 \times 250)+(0.3 \times 616)+(0.2 \times 50)+(0.5 \times 54)) /(250+616+50+54)$ $=0.38$ 
To simplify the calculation, most load factors are assumed 100\% at the "Load factor" worksheet. However, making the calculation more realistic, it is assumed that the following critical appliances have different load factors, as listed in the "Reference" worksheet (shown in table $4.2)$.

Table 4.2: Load Factor Assignment

\begin{tabular}{|c|c|}
\hline Appliances & Load Factor (\%) \\
\hline Washing Machine & 50 \\
\hline Cloth Dryer & 50 \\
\hline Refrigerator & 50 \\
\hline Freezer & 50 \\
\hline Water Heater (kitchen \& restroom) & 65 \\
\hline Oven & 70 \\
\hline Space Heater & 60 \\
\hline
\end{tabular}

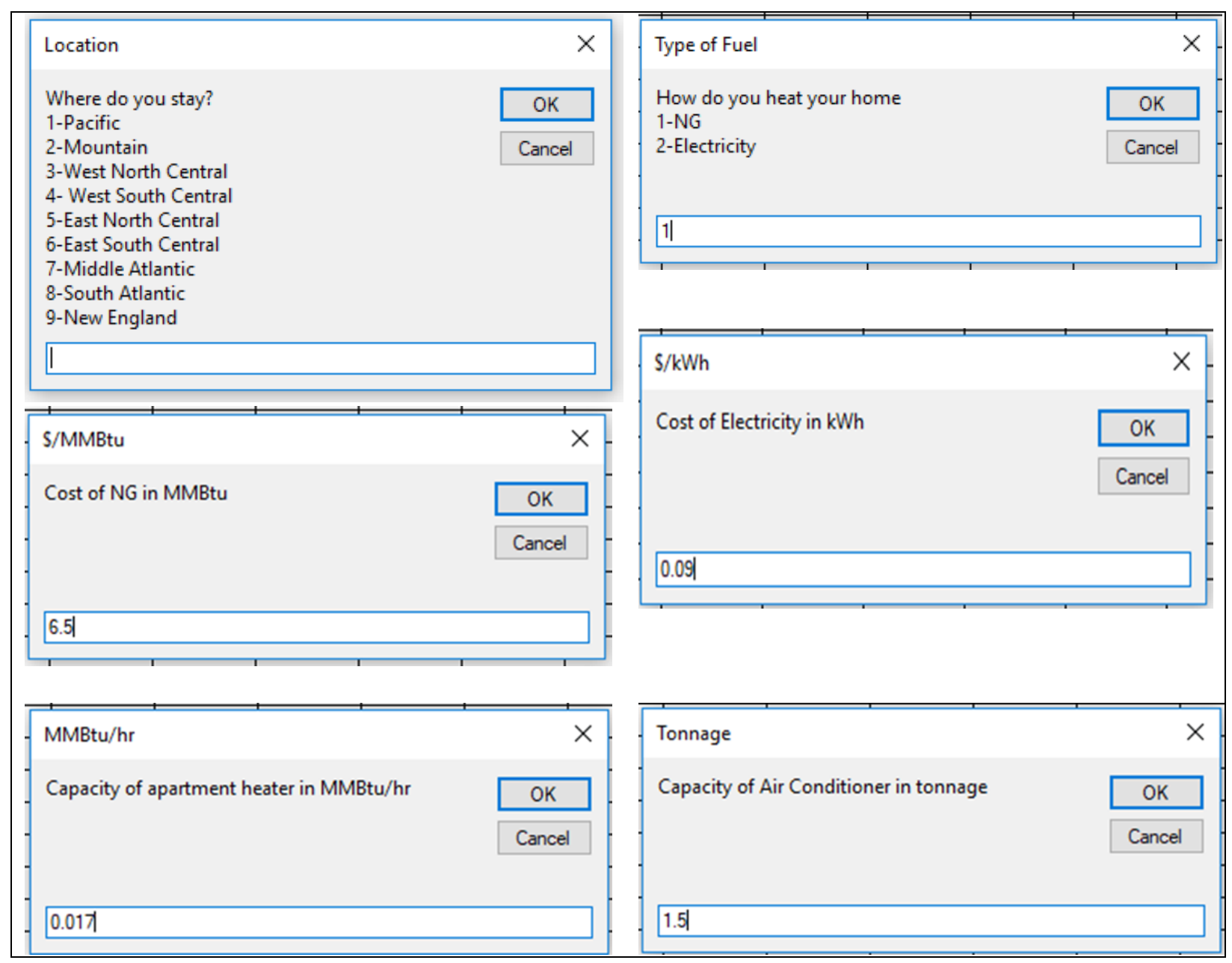




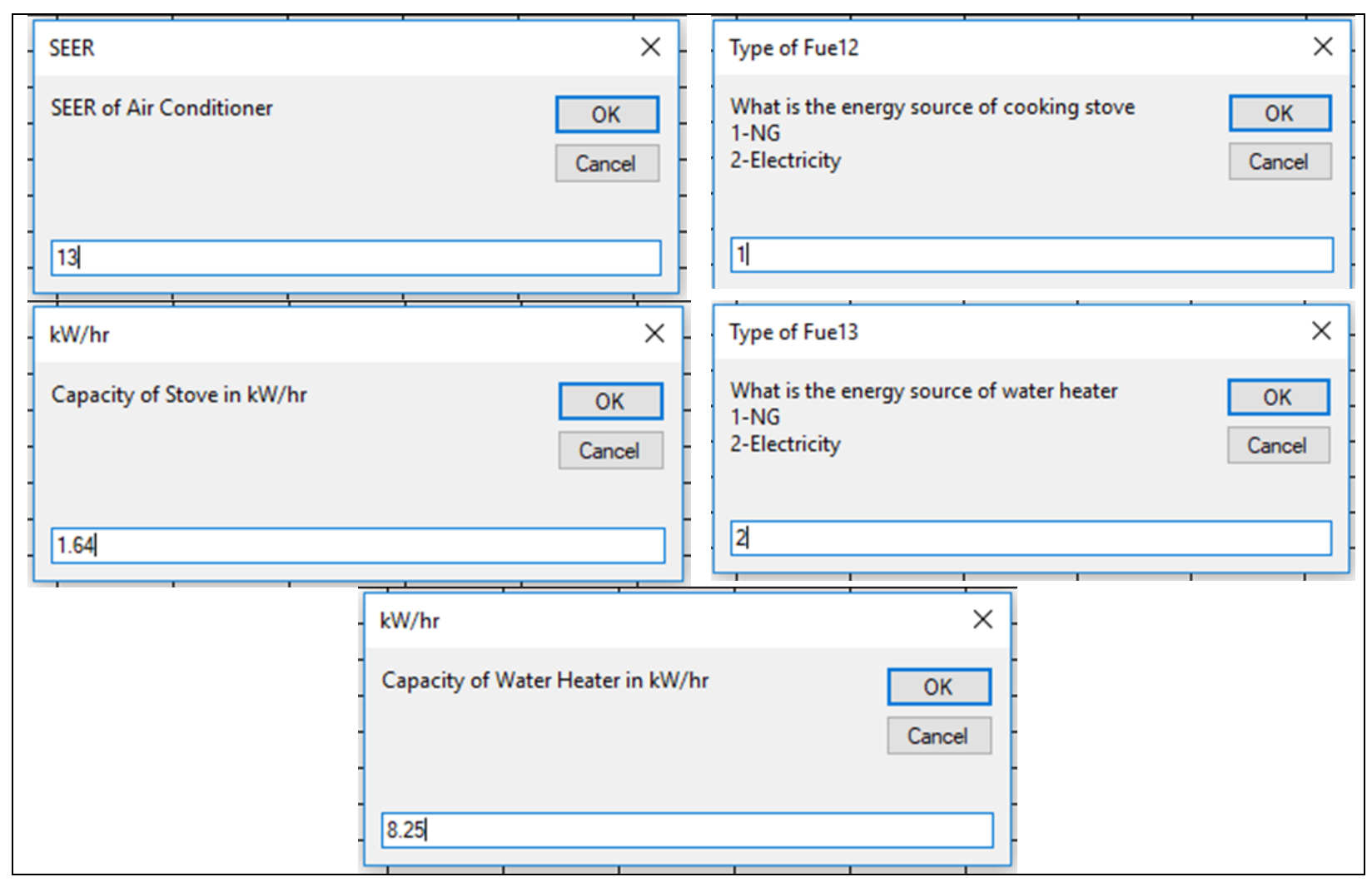

Figure 4-9: Message boxes from "Step 5"

After clicking the "Step 5" button, several message boxes will appear, which are shown in figure 4.9. The first message box will ask the user to select the location. Region- 8 was chosen in this example. According to the selected region, heating degree days (HDD) and cooling degree days (CDD) have been updated on the "Reference" worksheet, as shown in figure 4.10.

\begin{tabular}{|c|c|c|c|c|c|c|}
\hline \multicolumn{7}{|c|}{ Selected Region Data } \\
\hline Month & Name & Days & Cumulative & HDD & CDD & Cooling \\
\hline 1 & January & 31 & 0 & 659 & 25 & 0.04 \\
\hline 2 & February & 28 & 31 & 483 & 24 & 0.05 \\
\hline 3 & March & 31 & 59 & 240 & 89 & 0.28 \\
\hline 4 & April & 30 & 90 & 152 & 87 & 0.37 \\
\hline 5 & May & 31 & 120 & 58 & 185 & 0.77 \\
\hline 6 & June & 30 & 151 & 1 & 379 & 1.00 \\
\hline 7 & July & 31 & 181 & 0 & 509 & 1.00 \\
\hline 8 & August & 31 & 212 & 0 & 484 & 1.00 \\
\hline 9 & September & 30 & 243 & 2 & 352 & 1.00 \\
\hline 10 & October & 31 & 273 & 91 & 157 & 0.64 \\
\hline 11 & November & 30 & 304 & 290 & 56 & 0.17 \\
\hline 12 & December & 31 & 334 & 479 & 65 & 0.12 \\
\hline
\end{tabular}

Figure 4-10: Selected Region Heating Degree Days (HDD) and Cooling Degree Days (CDD) at the "Reference" worksheet 
These HDD and CDD information are used to identify when the heater will run and when the air conditioner will run. To make this decision, an automatic generated random number will be compared with the cooling ratio. In this example, the chosen region is South Atlantic and figure 4.10 shows a $4 \%$ chance of using electricity for cooling purposes during the January month. If the random number is lower than 0.04 for the January month, electricity will be used to cool the space. Similarly, if the random number is equal or greater than 0.04 , the heater will run. The second message box will ask the user about the heater fuel source of the place. For this example, it is chosen that the area is heated by natural gas. At the next message box, the user needs to provide natural gas cost $(\$ 6.5 / \mathrm{MMBtu})$ and electricity $\operatorname{cost}(\$ 0.09 / \mathrm{kWh})$. In the next three following message boxes, the user will put the heater and air conditioner capacity and SEER rate of the air conditioner. For this example, heater capacity is $0.017 \mathrm{MMBtu} / \mathrm{hr}$, and the air conditioner capacity is 1.5 ton with 13 SEER value.

$\begin{array}{lll}\text { Heater }_{(\mathrm{NG})} \text { Consumption } & = & \text { Avg Load Factor } \times \mathrm{MMBtu} / \mathrm{hr} \times \text { Operating time } \\ & = & 0.38 \times 0.017 \mathrm{MMBtu} / \mathrm{hr} \times 0.5 \mathrm{hr} \\ & = & 0.00323 \mathrm{MMBtu}\end{array}$

Cooling Electricity Consumption $=$ Avg Load Factor $\times(($ ton $\times 12) /($ SEER $)) \times$ Operating time

$$
\begin{aligned}
& =0.38 \times((1.5 \text { ton } \times 12) / 13) \times 0.5 \mathrm{hr} \\
& =0.26 \mathrm{kWh}
\end{aligned}
$$

If the heating fuel source is electricity, then user also needs to put the heating seasonal performance factor (HSPF) value for the heating $\mathrm{kWh}$ calculation. For example, the heater capacity is $5 \mathrm{~kW}$ with $10 \mathrm{Btu} / \mathrm{Wh} \mathrm{HSPF}$, the energy consumption is calculated as below-

$$
\begin{aligned}
\text { Heater kWh consumptions } & =\text { Load Factor } \times(((\text { Heater } \mathrm{kW} \times 3412 \mathrm{Btu} / \mathrm{kWh}) / \mathrm{HSPF})) / 1000 \\
& \mathrm{~W} / \mathrm{kW} \times 0.5 \mathrm{hr} \\
& =0.38 \times((5 \mathrm{~kW} \times 3412 \mathrm{Btu} / \mathrm{kWh}) / 10 \mathrm{Btu} / \mathrm{Wh}) \times 0.5 \mathrm{hr} \\
& =0.32 \mathrm{kWh}
\end{aligned}
$$

It is assumed in this study that the efficiency is $100 \%$ for all appliances. However, the usage factors are assumed to be $100 \%$ for most appliances, except for the appliances listed in table 4.3.

Table 4.3: Appliances list with usage factor different than the default value of $100 \%$

\begin{tabular}{|c|c|c|}
\hline Appliances & $\begin{array}{c}\text { Operating Time } \\
(\mathbf{m i n}) / \mathbf{0 . 5} \mathbf{~ h r}\end{array}$ & $\begin{array}{c}\text { Usage Factor } \\
(\mathbf{\%})\end{array}$ \\
\hline Kitchen Water Heater & 5 & 16.66 \\
\hline
\end{tabular}




\begin{tabular}{|l|c|c|}
\hline \multicolumn{1}{|c|}{ Appliances } & $\begin{array}{c}\text { Operating Time } \\
(\mathbf{m i n}) / \mathbf{0 . 5} \mathbf{~ h r}\end{array}$ & $\begin{array}{c}\text { Usage Factor } \\
(\mathbf{\%})\end{array}$ \\
\hline Blender & 5 & 16.66 \\
\hline Electric Water Heater & 5 & 16.66 \\
\hline Microwave & 5 & 16.66 \\
\hline Stove & 15 & 50 \\
\hline Toaster & 5 & 16.66 \\
\hline Rice Cooker & 20 & 66.67 \\
\hline Garbage Disposal & 2 & 6.67 \\
\hline Coffee Maker & 5 & 16.66 \\
\hline Electric Shaver & 10 & 33.4 \\
\hline Hair Dryer & 5 & 16.66 \\
\hline Hair Iron & 5 & 16.66 \\
\hline Restroom Water Heater & 10 & 33.4 \\
\hline Exhaust Fan & 15 & 50 \\
\hline
\end{tabular}

The energy consumption for appliances are calculated as below:

$$
\text { Energy Consumption }=\quad(\mathrm{C} \times \mathrm{UF} \times \mathrm{LF} \times \mathrm{OH}) /(\mathrm{Eff} \times \mathrm{K})
$$

Where,
$\mathrm{C}=$ Capacity of the Appliance, $\mathrm{W}$
$\mathrm{LF}=$ Load Factor $(\%)$
$\mathrm{UF}=$ Utilization Factor $(\%)$
$\mathrm{OH}=$ Operating Hours
Eff $=$ Efficiency of the equipment (\%)
$\mathrm{K}=$ Constant, $(1000 \mathrm{watts} / \mathrm{kW})$

For example, the energy consumption (EC) of "Kitchen water heater" for this specific scenario can be calculated as;

Kitchen Water heater EC $=(11 \mathrm{~kW} \times 16.66 \% \times 65 \% \times 0.5 \mathrm{hr}) / 100 \%$

$$
=\quad 0.59 \mathrm{kWh}
$$

This step will complete the energy consumption calculation for HVAC appliances for one year at 30 minutes time interval. The energy consumption calculation screenshot from excel is shown in figure 4.11 . 


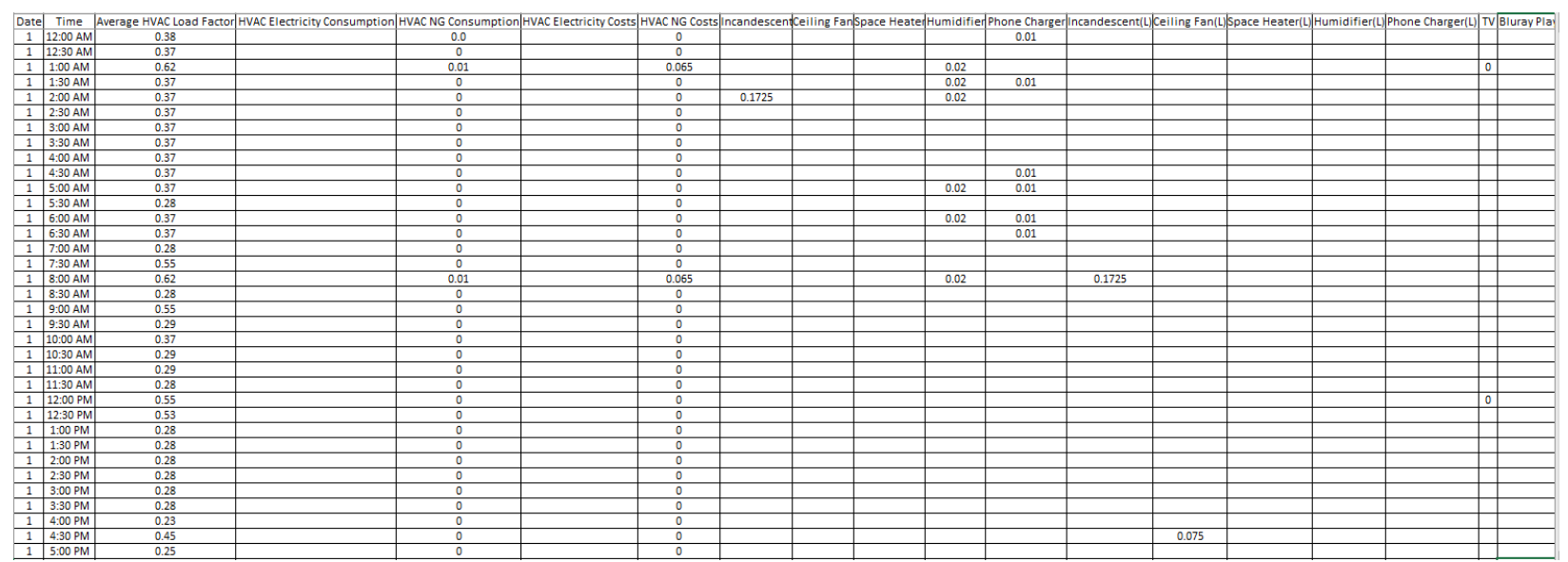

Figure 4-11: Total $\mathrm{kWh}$ and MMBtu consumption at 30 minutes interval for one year

Moreover, the total electricity cost and the cost of natural gas will also be calculated at this step, and the summary results are presented in the following figure 4.12.

\begin{tabular}{|c|c|}
\hline Total kWh Energy Consumption & Total MMBtu Energy Consumption \\
\hline 7868 & 21 \\
\hline Total kWh Costs (\$) & Total MMBtu Costs (\$) \\
\hline 709 & 137 \\
\hline
\end{tabular}

Figure 4-12: Total electricity cost and the cost of natural gas.

The next step is to click the "Step 6" button to generate the "Summary" worksheet. It will summarize each appliance's energy consumption value for all twelve months, as shown in figure 4.13.

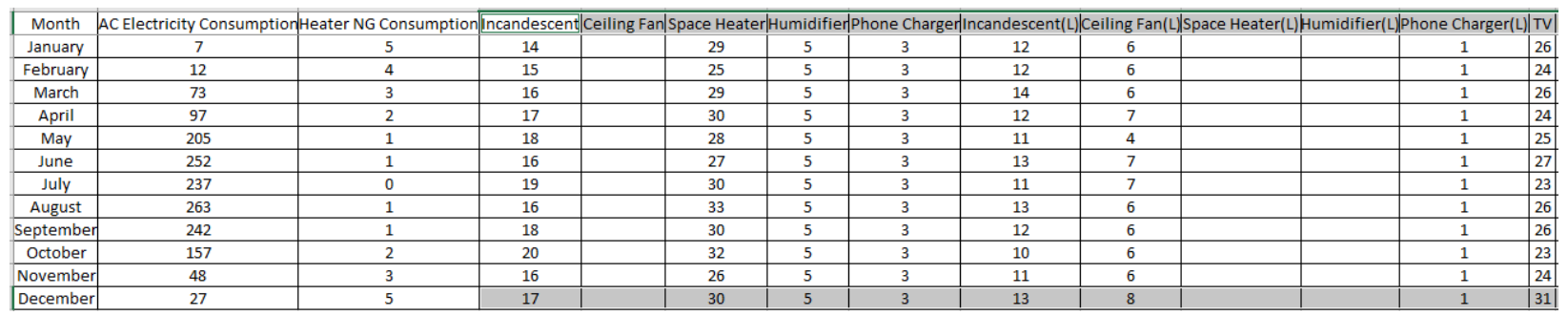

Figure 4-13: "Summary” worksheet screenshot

One of this research's essential purposes is to generate energy consumption patterns for each selected appliance in a specific scenario. Proceeding through "Step 7", the energy consumption graphs for the HVAC system and appliances will be generated. At first, heating and cooling energy consumption graph will be plotted against the months of the year, as shown in Figure 4.14. Next, energy consumptions of all different appliances will be plotted for specific months for all 12 
months. For example, all appliances' energy consumption is shown for the January month in Figure 4.15 .
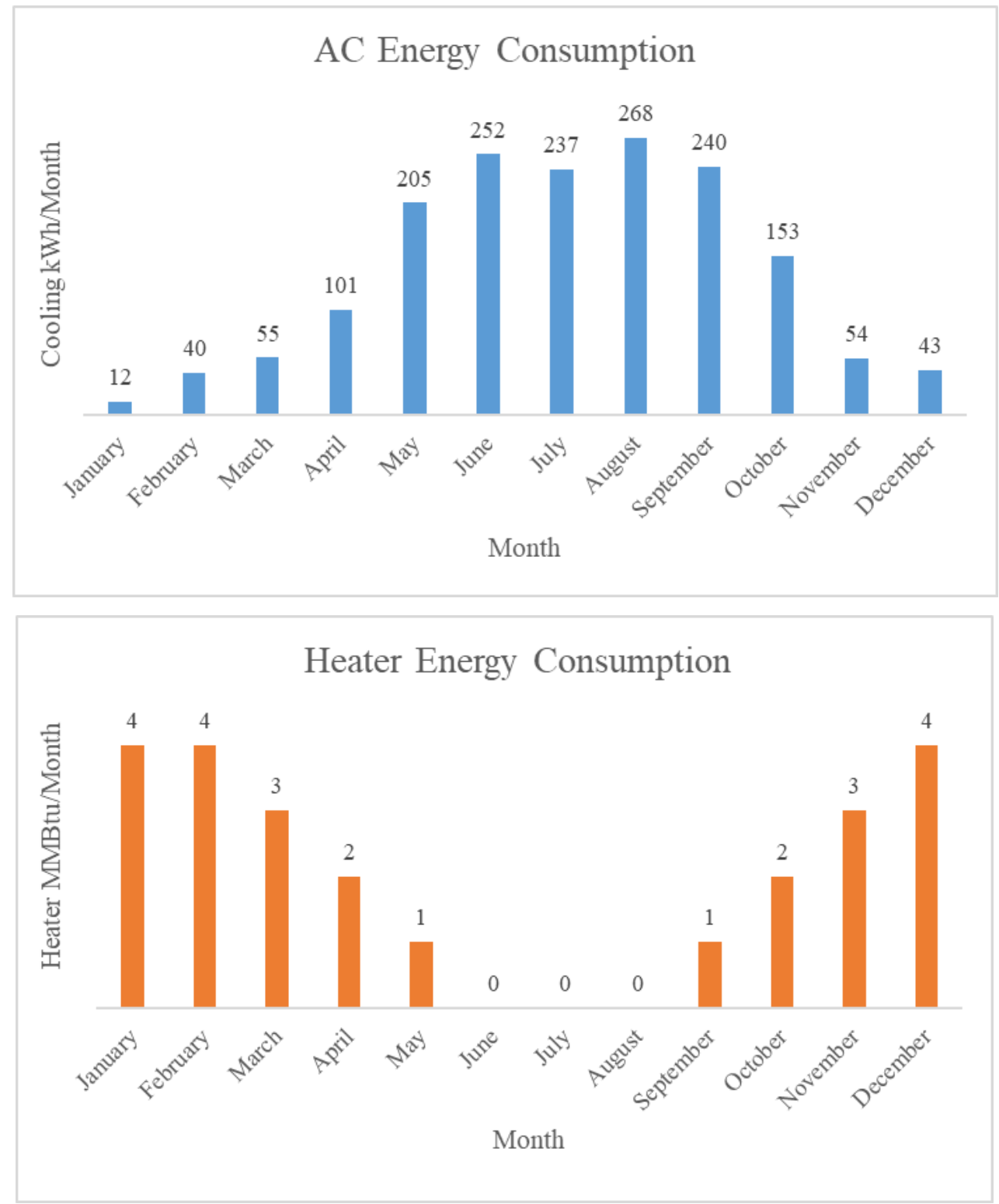

Figure 4-14: HVAC energy consumption summary of 12 months 


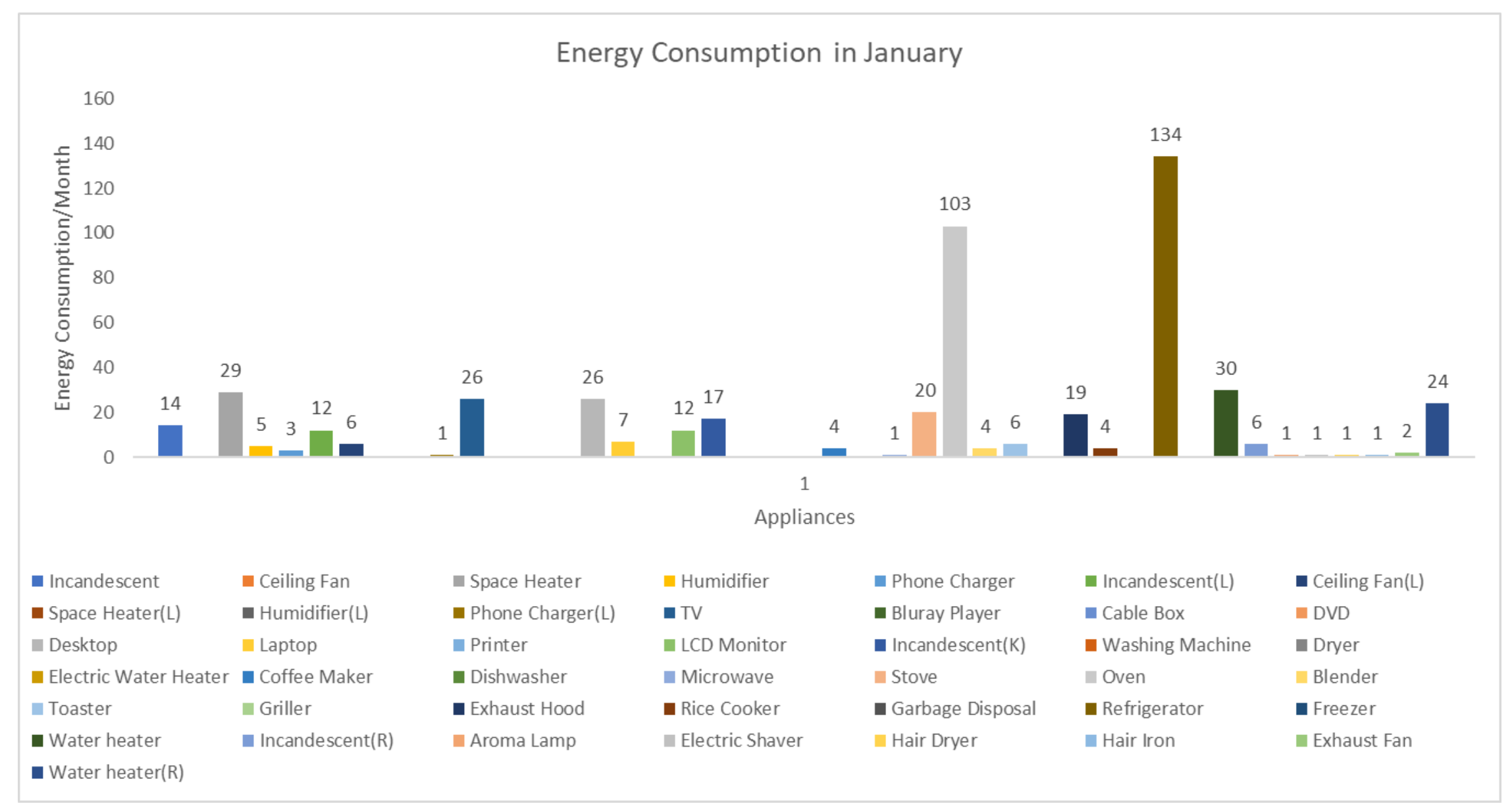

Figure 4-15: Appliances energy consumption summary for January 
As the final step, the user needs to click the "Step 8" button to generate the energy consumption pattern for a specific day. In the Day Data Analysis worksheet, the user has to put a desired date at the designated area to observe the particular date's energy consumption. It will generate an HVAC energy consumption graph for that specific date at 30 minutes time interval. For this example, 10 July has been selected and the total electricity and natural gas consumption for 24 hours at 30 minutes interval are shown in figure 4.16.

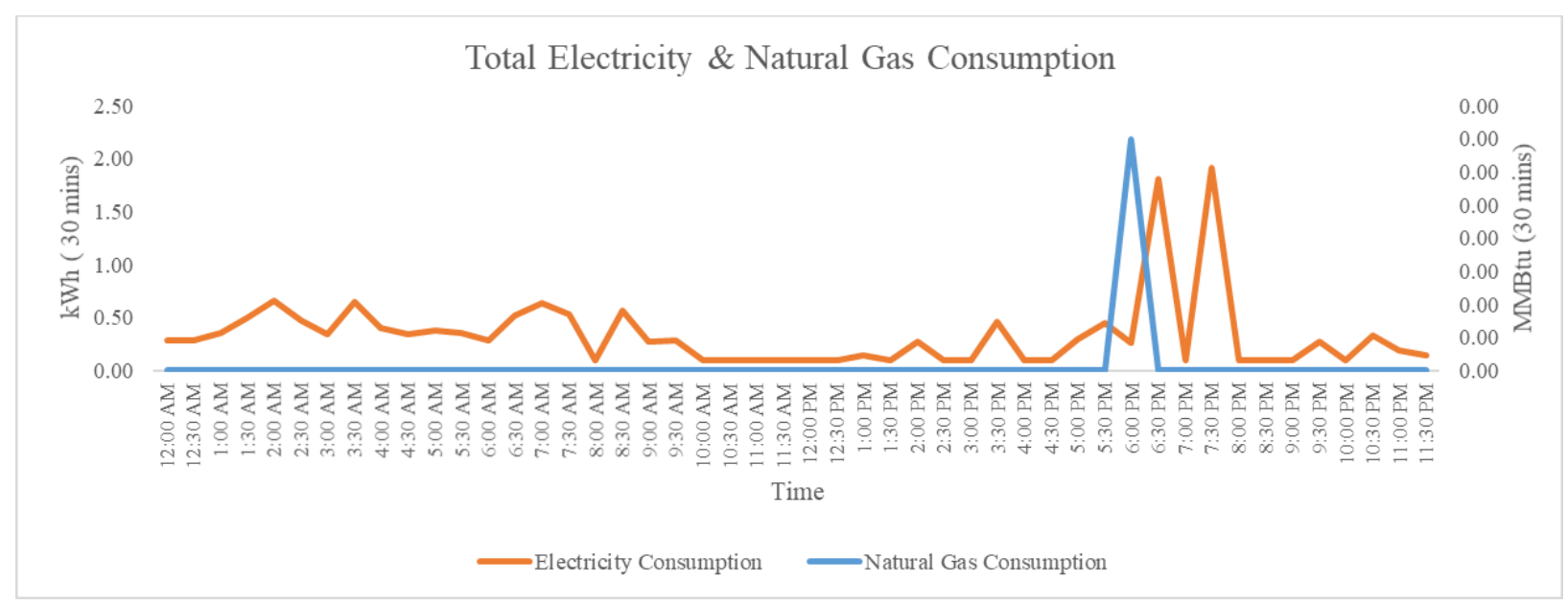

Figure 4-16: Total energy consumption pattern for $10^{\text {th }} \mathrm{July}$

It is a summer day, so AC was only running and HVAC energy consumption graph is shown in figure 4.17 .

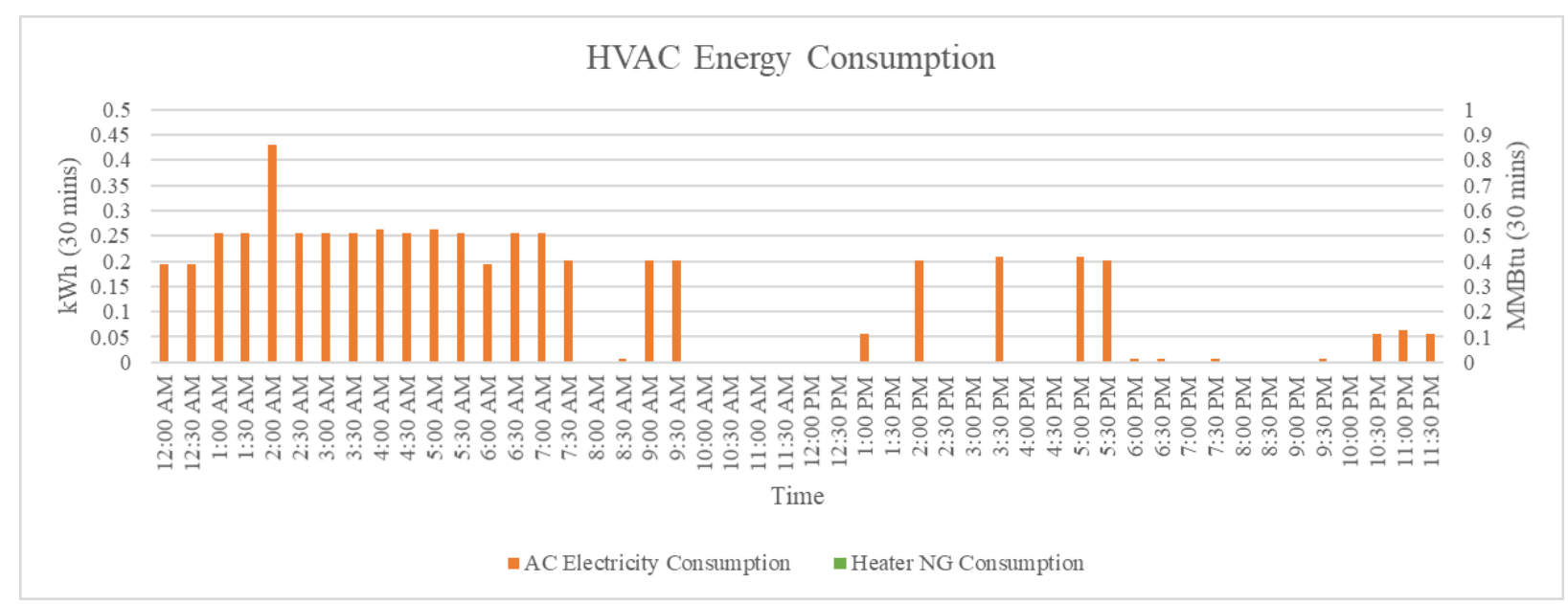

Figure 4-17: HVAC energy consumption pattern for $10^{\text {th }}$ July

In order to improve the graph visualization, appliances are divided into four groups: low capacity (0-100W), medium-capacity (101-500), moderately high capacity (500-1000W), and high capacity 
(>1000W). Additionally, the energy consumptions of the stove, kitchen water heater, and restroom water heater are plotted separately in another graph, as the energy source for these appliances can vary between electricity and natural gas. The appliance energy consumption graphs for Case- 1 on $10^{\text {th }}$ July are shown in figure 4.18, figure 4.19, figure 4.20, figure 4.21, figure 4.22.

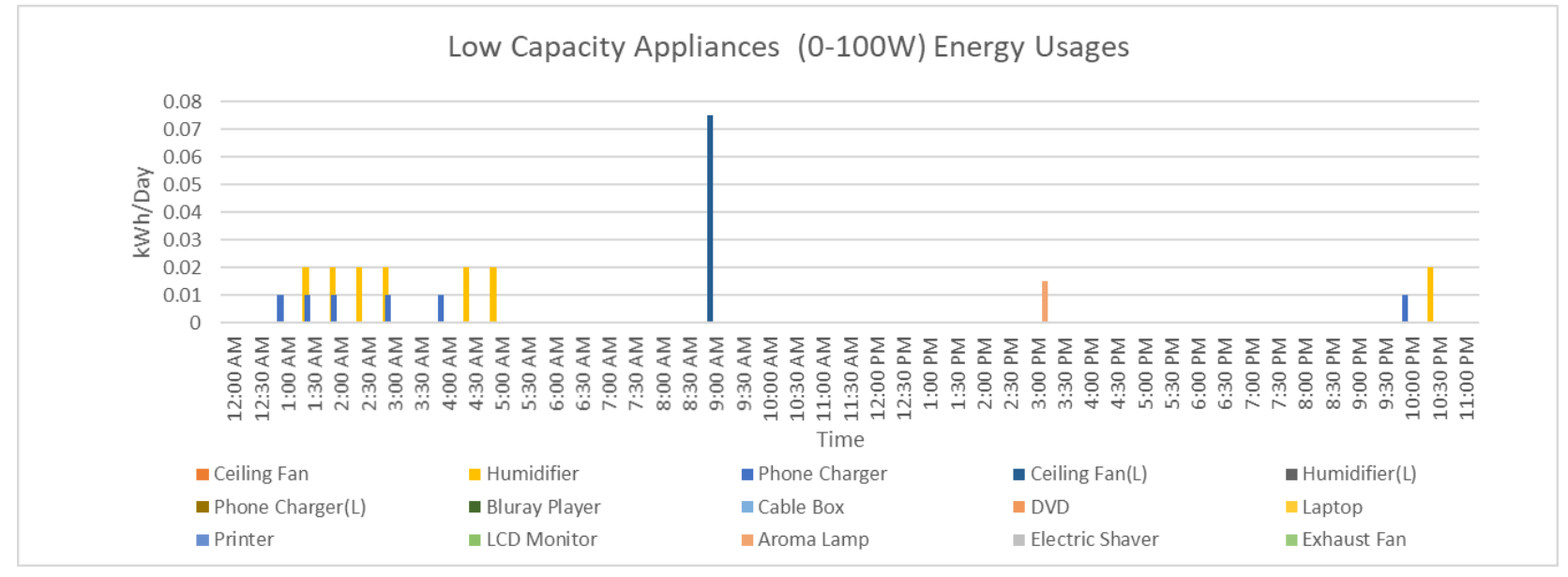

Figure 4-18: Low-capacity appliances energy consumption pattern of $10^{\text {th }} \mathrm{July}$

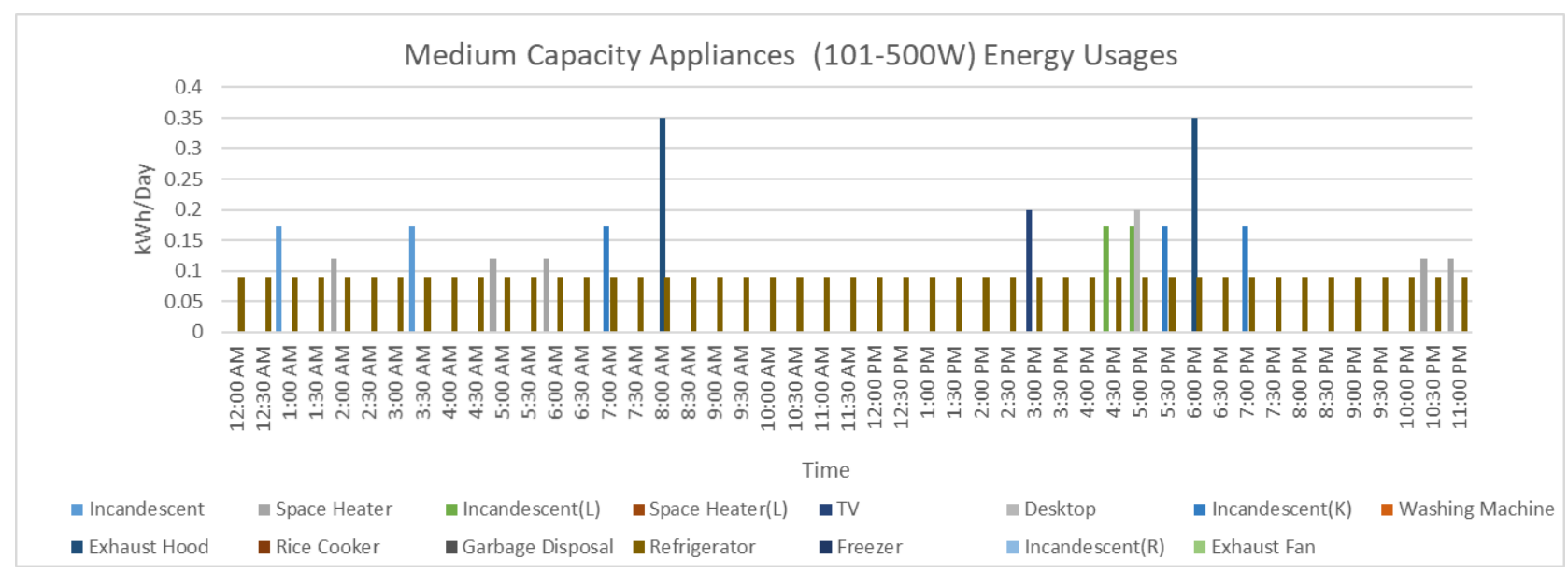

Figure 4-19: Medium-capacity appliances energy consumption pattern of $10^{\text {th }} \mathrm{July}$ 


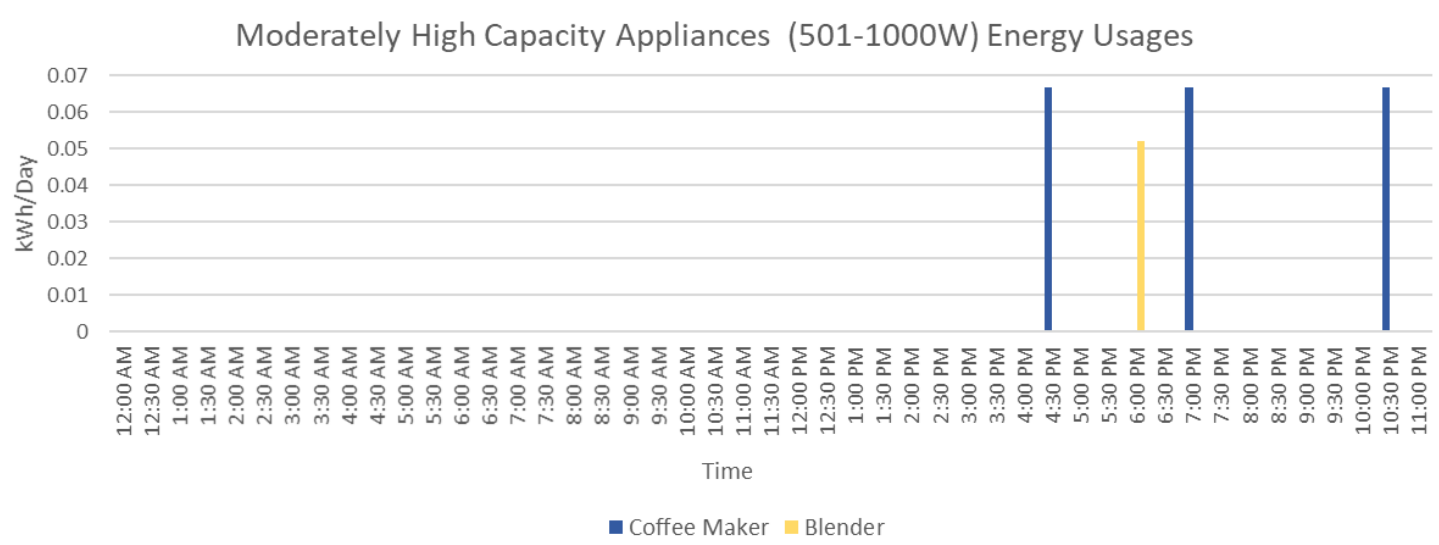

Figure 4-20: Moderately high-capacity appliances energy consumption pattern of $10^{\text {th }}$ July

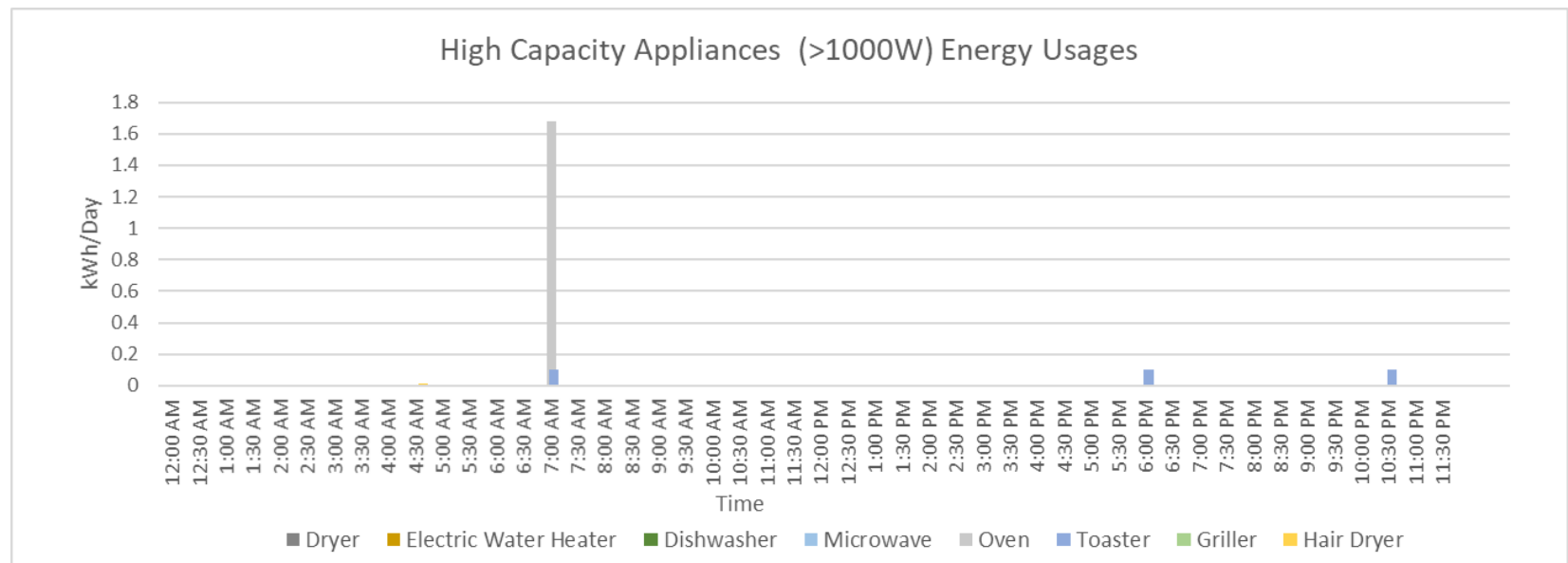

Figure 4-21: High-capacity appliances energy consumption pattern of $10^{\text {th }}$ July

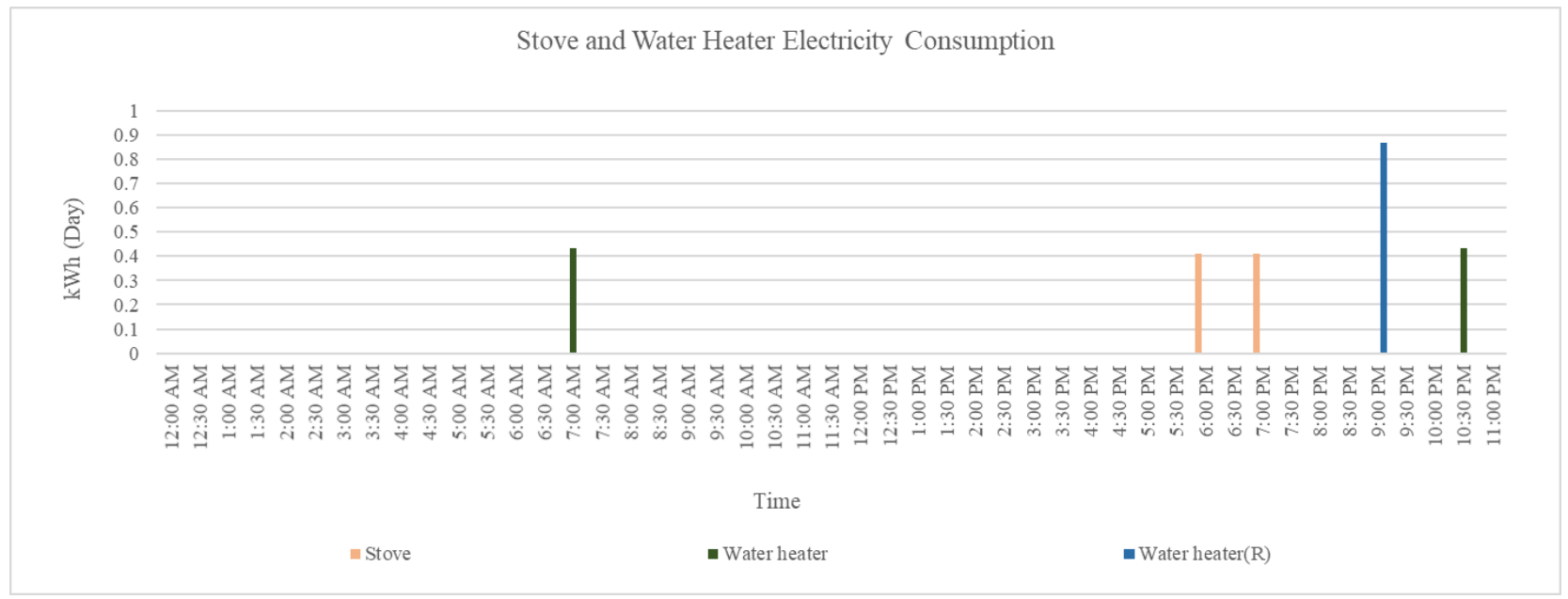

Figure 4-22: Stove and water heater energy consumption pattern of $10^{\text {th }}$ July 


\subsection{Conclusion}

This simulation is based on the discrete-event Monte Carlo Simulation (MCS) and designed to develop a specific scenario's energy consumption pattern. The automated generated randomness for occupancy and all appliances variables creates new results after running this simulation each time. This simulation provides the liberty to its user to fulfill the most appropriate and reasonable values for all parameters to obtain simulation results according to their requirements. This simulation can handle five different scenarios. Electricity and natural gas consumption and cost for the specific scenario are calculated for one year. This simulation result can be used to analyze resident behavior for different commercial reasons and compare with known utility data for similarities to identify unlawful activities. It is to be noted that this work is intended to facilitate the analysis of building occupants' activities, subject to all legal provisions that apply. It is not intended for the general public to pursue these activities because legal ramifications might be involved. 


\section{Simulation System Execution and Results}

\subsection{Realistic Data-Based Simulation Tool}

This research work developed a user-driven simulation tool with realistic data options for the user. User has the flexibility to change the probability of resident occupancy, thermostat settings level, season level and appliances usage in the "Reference" worksheet according to their requirements. The user can also choose the room volume, number of appliances and their capacities, usage factors and load factors for all appliances, and HVAC load factors to achieve realistic results for each specific scenario. Furthermore, the user can decide on future building construction, thermostat setting frequency, HVAC specifications, fuel type for the heater, water heater and stove, and the unit cost of natural gas and electricity. All this information leads to the results where one-year energy consumption at 30 minutes time interval will be calculated for a chosen scenario. From the final energy consumption pattern, the user can identify when the place was occupied and which appliances were used at that precise time.

\subsection{Verification of Simulation Results}

To verify that five cases lead to different energy consumptions, the simulation was run for all five scenarios. It was assumed that there were the same appliances for all cases, as listed in Table 5.1. Furthermore, building specifications were kept unchanged for the cases with the same number of bedrooms (Figure 5.1). Appropriate HVAC specifications for five cases were chosen, as shown in table 5.2.

Table 5.1: List of Used Appliance for Five Cases

\begin{tabular}{|c|c|c|c|}
\hline Room & Usage Appliances & Room & Usage Appliance \\
\hline \multirow{4}{*}{ Bedroom } & Incandescent & \multirow{7}{*}{ Living Room } & Incandescent \\
\hline & Space Heater & & Ceiling Fan \\
\hline & Humidifier & & Phone Charger \\
\hline & Phone Charger & & TV \\
\hline \multirow{8}{*}{ Kitchen } & Incandescent & & Desktop \\
\hline & Coffee Maker & & Laptop \\
\hline & Microwave Oven & & LCD Monitor \\
\hline & Stove & \multirow{5}{*}{ Restroom } & Incandescent Light \\
\hline & Oven & & Aroma Lamp \\
\hline & Blender & & Electric Shaver \\
\hline & Toaster & & Hair Dryer \\
\hline & Exhaust hood & & Hair Iron \\
\hline
\end{tabular}




\begin{tabular}{|l|l|l|l|}
\hline & Rice Cooker & \multirow{4}{*}{} & Exhaust Fan \\
\cline { 2 - 2 } & Refrigerator & Water Heater \\
\cline { 2 - 2 } & Water Heater & \\
\hline
\end{tabular}

Table 5.2: HVAC Specifications for five cases

\begin{tabular}{|c|c|c|c|c|}
\hline Case No. & Heating Source & $\begin{array}{c}\text { Heating Capacity } \\
\text { (MMBtu/hr) }\end{array}$ & $\begin{array}{c}\text { Cooling } \\
\text { Capacity (ton) }\end{array}$ & SEER \\
\hline Case -1 & Natural Gas & 0.017 & 1.5 & 13 \\
\hline Case -2 & Natural Gas & 0.017 & 1.5 & 13 \\
\hline Case -3 & Natural Gas & 0.024 & 2 & 13 \\
\hline Case -4 & Natural Gas & 0.024 & 2 & 13 \\
\hline Case -5 & Natural Gas & 0.03 & 2.5 & 13 \\
\hline
\end{tabular}

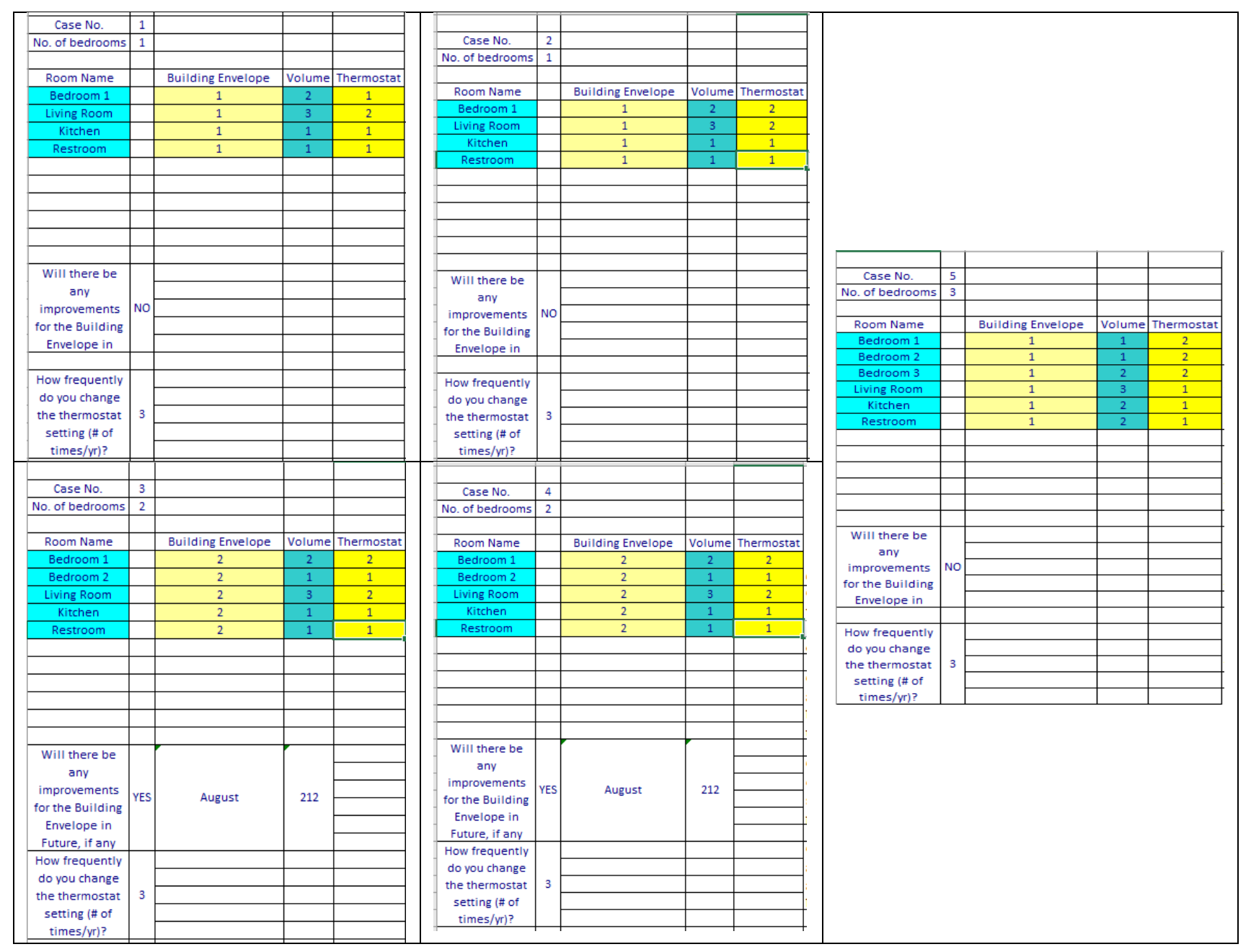

Figure 5-1: Building Specification in "Inputs" Sheet for Five Different Cases 
The simulated total one-year electricity and natural gas consumption and cost were accurately found to be different for five cases, as summarized in figure 5.2. Also, the HVAC energy consumption patterns for one year for all five cases are shown in Figure 5.3. Energy consumption patterns for the appliances for one example case (Case 1) are added in the Appendix section.

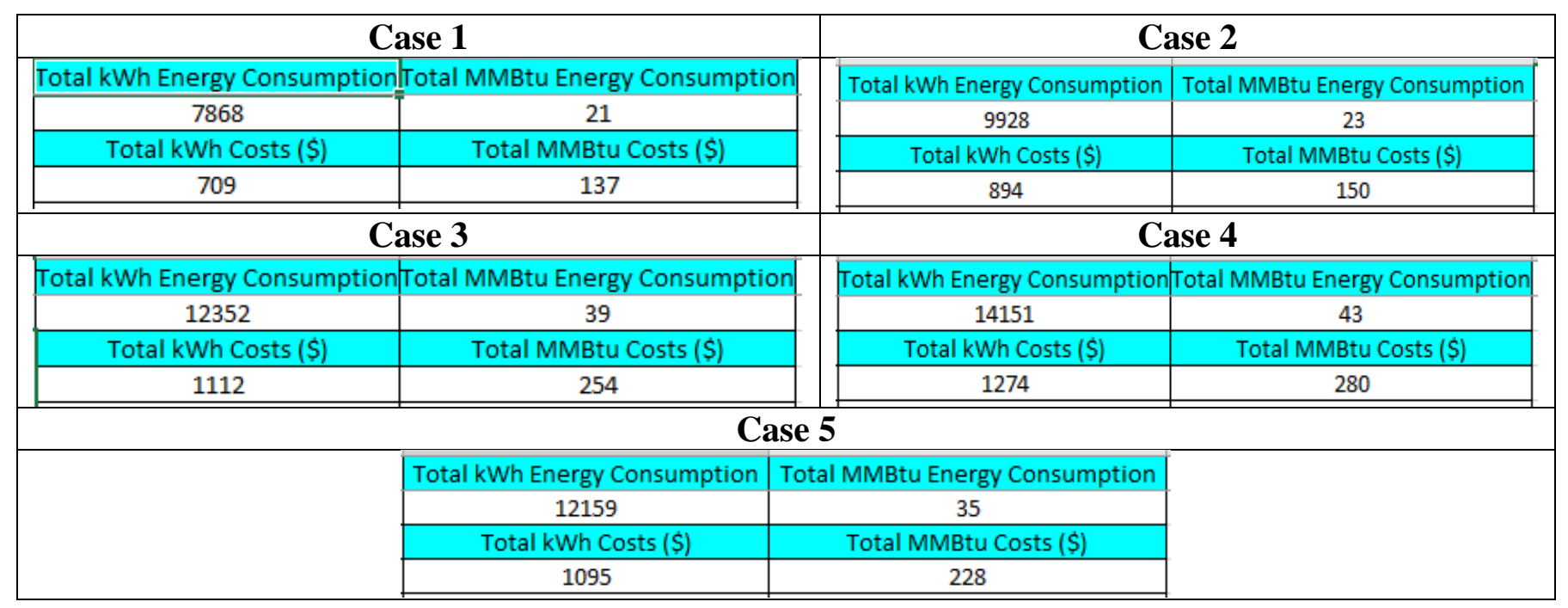

Figure 5-2: Total energy consumption and cost for five different cases. The $k$ Wh indicates electricity consumption, and the MMBtu indicates natural gas consumption.

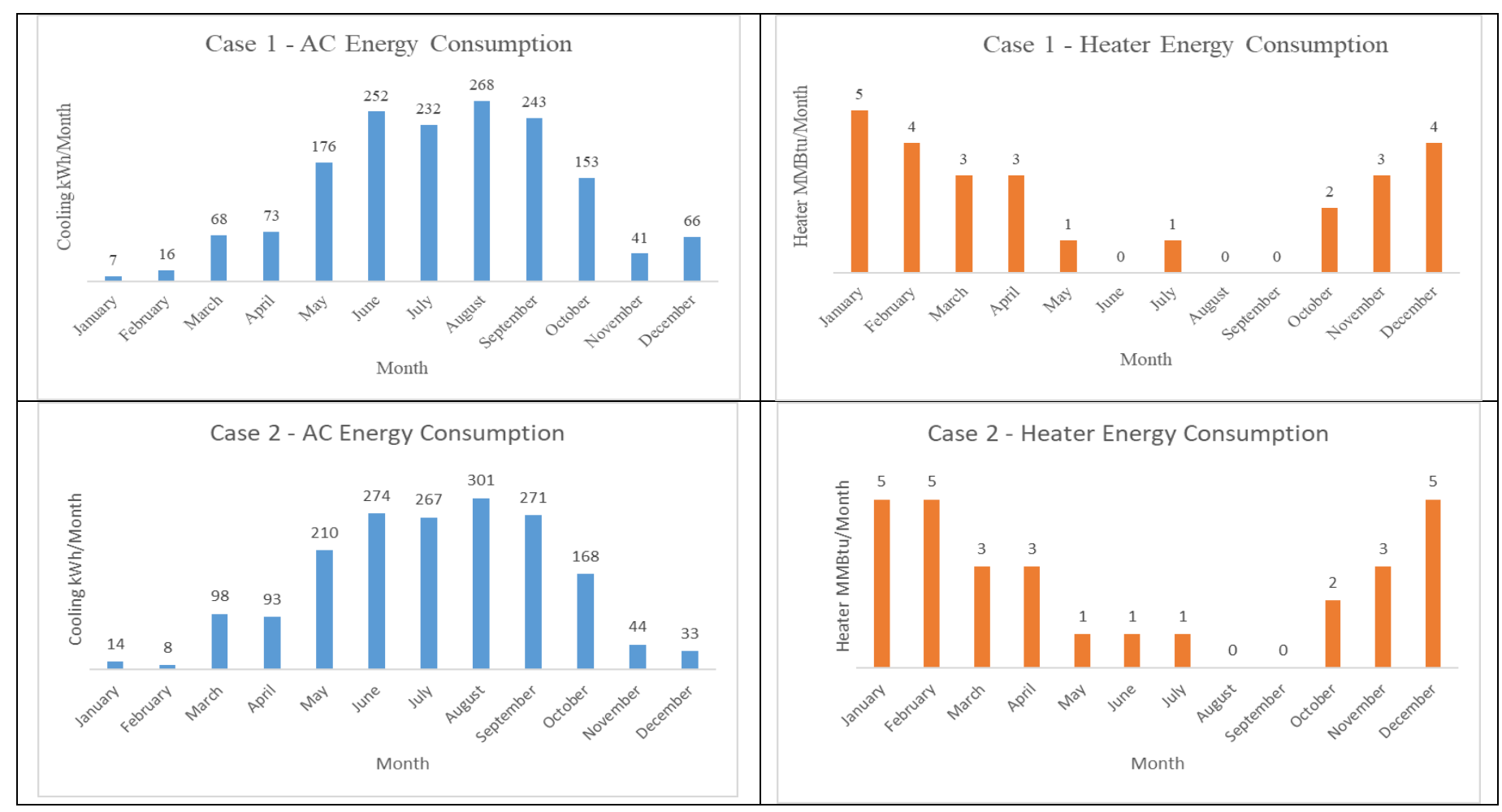




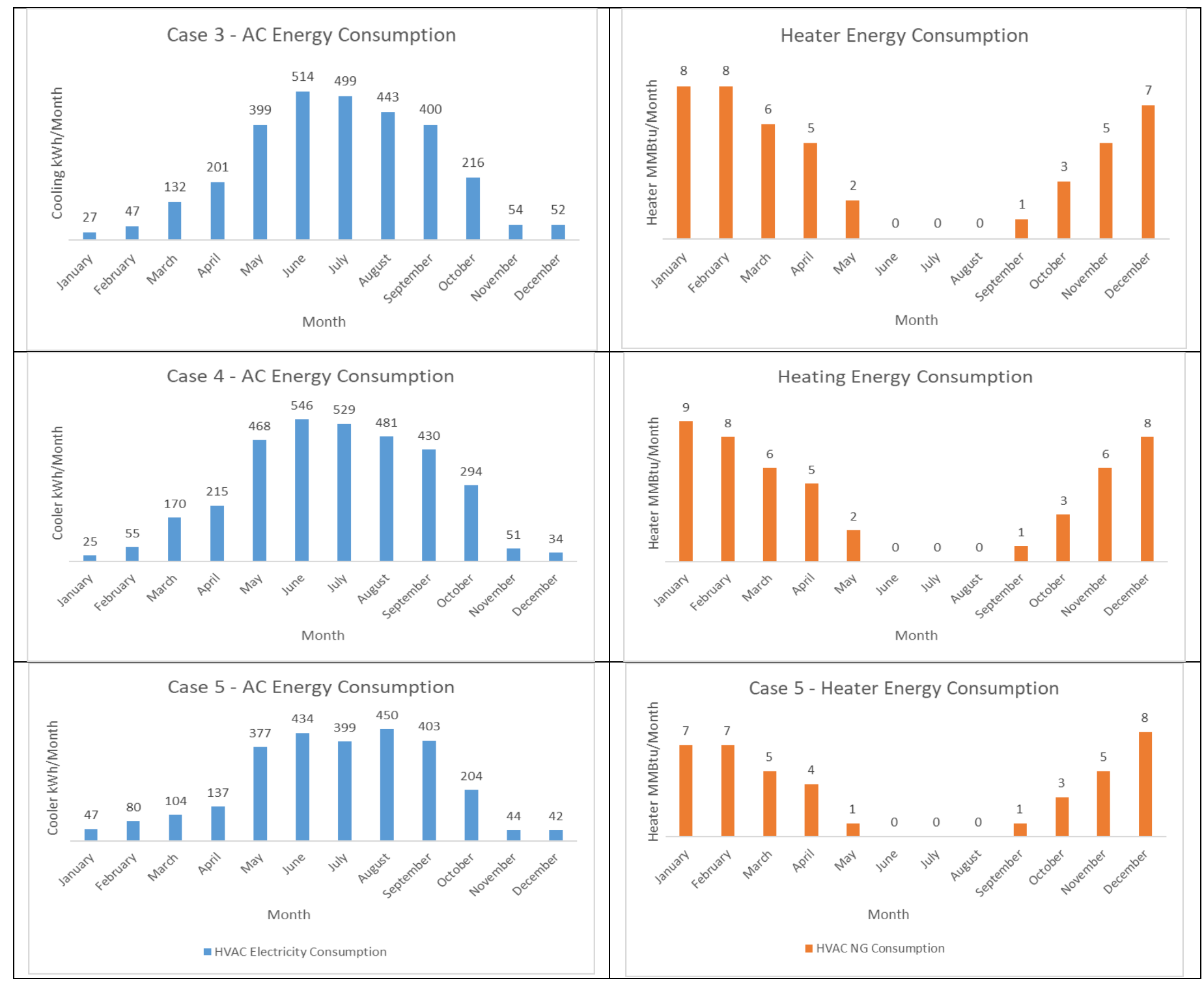

Figure 5-3: One Year Energy consumption of HVAC for Five Different Cases

\subsubsection{Compare Simulated Results with Real Data}

To check the simulated results validity, total electricity consumption from case 1 and case 2 were compared with collected real energy consumption data. Two identical one-bedroom apartment houses located in Morgantown, WV were selected. First house occupancy is similar to case 1 and second house occupancy is similar to case 2. The insulation of the house is excellent and there was no upgraded building construction. The apartment is equipped with a natural gas heater, which is centrally paid by the landlord. In this case, only the electricity cost was verified. Airconditioning unit capacity is 1.5 ton and all other major appliances are the same for both apartments. Cooking 
Stove and water heater are electric with the same capacity. Twelve-month energy consumption for two cases are shown in figure 5.4

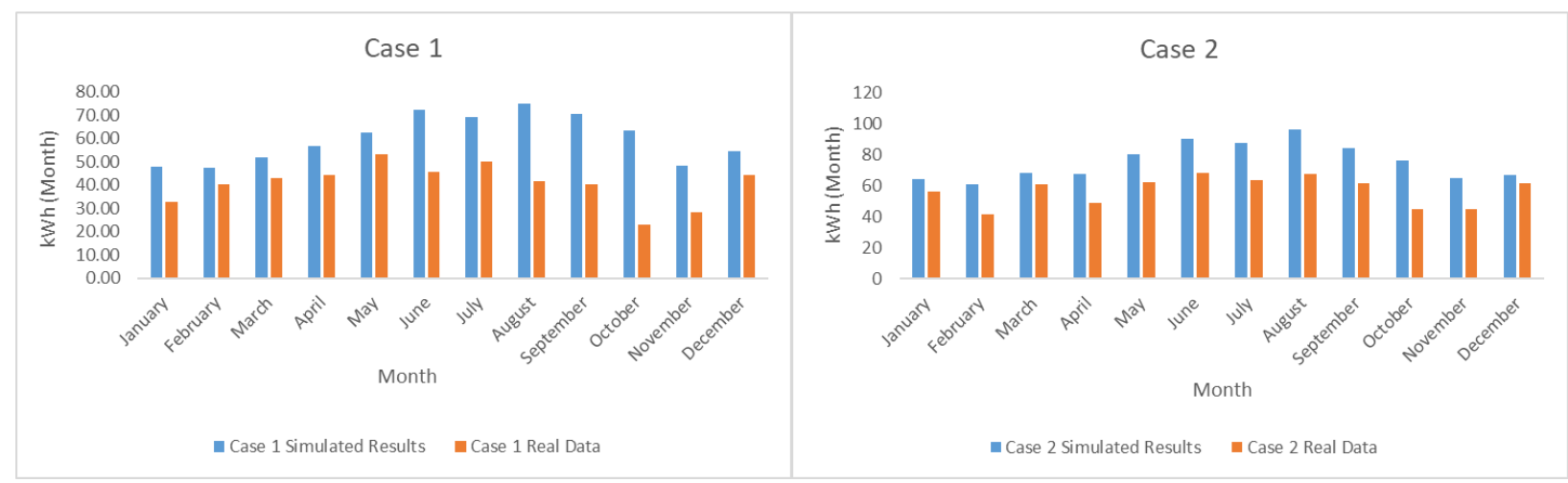

Figure 5-4: Simulated results vs. real data one-year electricity consumption comparison

The simulated energy consumption is shows similar trend as the collected electricity consumption data. The discrepancy was probably occurred from the difference in appliance type and usage probability.

\subsection{Research Work Relation with Forensics}

It is to be noted that this work is intended to simulate the energy consumption pattern to pave the way to analyze human behavior. In this simulation tool, energy consumption was calculated based on predetermined probability of residents' behavior. This work can be used in forensics purposes as the simulation tool provides example scenarios to the law enforcement agencies or commercial companies that how human behavior is related to energy consumption. The law enforcement groups have lots of data about human behavior. For example, from the available previous characteristics data of a criminal, they have developed several psychological models. By providing information about a suspected person characteristic in this model, it is possible to identify the probability of being a criminal.

Similarly, they have large amount of data about the residents' behavior and occupancy regarding different factors, such as their number, job, and occupation. They can train this simulation tool with the known previous cases and compare the simulated results to check how close it is with the real data. From the deviation between the simulated and real data, it might be possible to identify probable criminal activity. 
However, it would be beneficial to enrich this simulation tool with different probability charts for different scenarios. More realistic probability charts can be developed by observing how electricity consumption patterns vary with specific human behavior over a longer period of time. With the more fitting and realistic input, the law enforcing entities can improve this simulation tool to be more effective.

\subsection{Sensitivity Analysis}

A scrutinized analysis is carried out in this section to check the simulation performance. For the random number-based Monte Carlo Simulation, the results differ slightly each time with the same parameter for the same case. However, parameters such as the resident's number, occupancy duration, and appliance number and usage significantly affect energy consumption. All this information reveals necessary evidence of resident's number and their activity in a building space. Therefore, the effect of each of these parameters on energy consumption was studied here. Other parameters, such as building specifications and weather, were assumed similar for each case.

\subsubsection{Different Occupancy Probability}

The occupancy probability is different for different cases. For example, occupancy probability is lower for case-1 than case-2, despite both scenarios describing a one-bedroom apartment. In case1 , the residents are two adults who work outside the building in the daytime, while in case-2, one adult work from home and one work outside. Similarly, case -3 and case -4 are two-bedroom apartments where residents are two adults with kids, but the residents' different workplace locations lead to different occupancy probabilities. The case-5 is designed as a three-bedroom apartment with three student residents, and the residents' schedule is quite different from each other. Therefore, in all these cases, the occupancy and, subsequently, the energy consumption will be different. The probability chart of five cases for the bedroom, living room, and kitchen is shown in table 5.3 for different time intervals on weekdays (WD) and holidays (H).

Table 5.3: Occupancy probability chart for five different cases

\begin{tabular}{|c|c|c|c|c|c|c|c|c|c|c|c|}
\hline \multirow{3}{*}{\multicolumn{2}{|c|}{ Time zone }} & \multicolumn{2}{|c|}{ Case 1} & \multicolumn{2}{|c|}{ Case 2} & \multicolumn{2}{|c|}{ Case 3} & \multicolumn{2}{|c|}{ Case 4} & \multicolumn{2}{|c|}{ Case 5} \\
\hline & & WD & H & WD & H & WD & H & WD & H & WD & H \\
\hline & & \multicolumn{10}{|c|}{ Bedroom } \\
\hline 0:00 & $7: 00$ & 0.83 & 0.87 & 0.83 & 0.87 & 0.7 & 0.7 & 0.7 & 0.7 & 0.85 & 0.85 \\
\hline
\end{tabular}




\begin{tabular}{|c|c|c|c|c|c|c|c|c|c|c|c|}
\hline 7:01 & 8:00 & 0.10 & 0.85 & 0.2 & 0.85 & 0.2 & 0.4 & 0.3 & 0.45 & 0.12 & 0.8 \\
\hline $8: 01$ & $16: 00$ & 0.10 & 0.25 & 0.15 & 0.25 & 0.15 & 0.35 & 0.25 & 0.35 & 0.1 & 0.7 \\
\hline 16:01 & 22:00 & 0.15 & 0.15 & 0.15 & 0.15 & 0.3 & 0.35 & 0.2 & 0.1 & 0.4 & 0.3 \\
\hline 22:01 & $23: 59$ & 0.83 & 0.75 & 0.83 & 0.7 & 0.75 & 0.7 & 0.65 & 0.5 & 0.7 & 0.6 \\
\hline \multicolumn{2}{|c|}{ Time zone } & \multicolumn{10}{|c|}{ Living Room } \\
\hline 0:00 & $7: 00$ & 0.10 & 0.10 & 0.10 & 0.10 & 0.18 & 0.18 & 0.20 & 0.20 & 0.20 & 0.25 \\
\hline 7:01 & 8:00 & 0.25 & 0.35 & 0.25 & 0.35 & 0.25 & 0.50 & 0.25 & 0.50 & 0.10 & 0.10 \\
\hline 8:01 & $16: 00$ & 0.10 & 0.70 & 0.55 & 0.70 & 0.10 & 0.50 & 0.45 & 0.50 & 0.10 & 0.60 \\
\hline 16:01 & 21:00 & 0.50 & 0.60 & 0.50 & 0.60 & 0.45 & 0.55 & 0.45 & 0.55 & 0.35 & 0.40 \\
\hline 21:01 & 23:59 & 0.12 & 0.40 & 0.12 & 0.45 & 0.85 & 0.70 & 0.85 & 0.85 & 0.15 & 0.40 \\
\hline \multicolumn{2}{|c|}{ Time zone } & \multicolumn{10}{|c|}{ Kitchen } \\
\hline 0:00 & $7: 00$ & 0.10 & 0.10 & 0.10 & 0.10 & 0.15 & 0.15 & 0.15 & 0.15 & 0.25 & 0.20 \\
\hline 7:01 & 9:00 & 0.45 & 0.30 & 0.40 & 0.30 & 0.55 & 0.70 & 0.45 & 0.60 & 0.65 & 0.15 \\
\hline 9:01 & 16:00 & 0.10 & 0.35 & 0.27 & 0.35 & 0.15 & 0.35 & 0.30 & 0.35 & 0.15 & 0.40 \\
\hline 16:01 & 21:00 & 0.40 & 0.50 & 0.40 & 0.45 & 0.45 & 0.50 & 0.45 & 0.50 & 0.10 & 0.45 \\
\hline 21:01 & $23: 59$ & 0.10 & 0.15 & 0.10 & 0.20 & 0.20 & 0.25 & 0.20 & 0.25 & 0.30 & 0.15 \\
\hline
\end{tabular}

Summary of the energy consumption results and graphs are presented in figure 5.5. The summary results accurately indicate that occupancy has a significant influence on the energy consumption rate and cost.
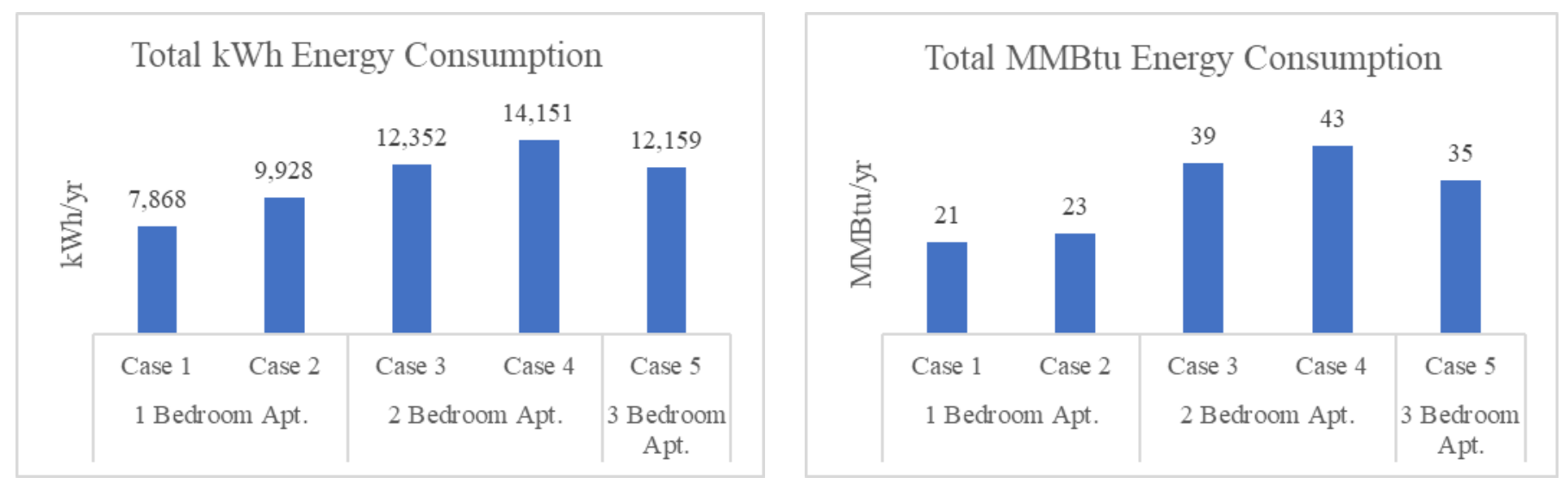

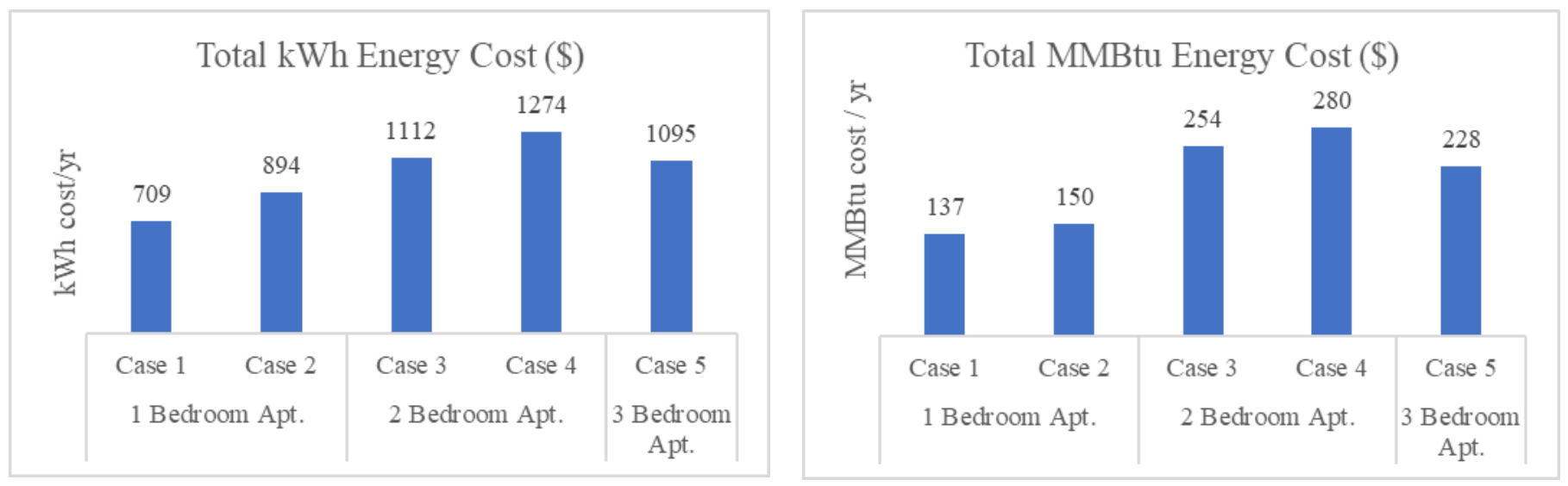

Figure 5-5: One-year energy consumption and costs for five different cases

\subsubsection{Probability of Appliances Usage}

The type of appliances and quantity of appliances are other lead parameters for this work, dictated by the resident activities. To examine the appliance's effect on energy consumptions, case- 1 and case-5 were considered as example scenarios. In case- 1 at first, the simulation was run with all the appliances selected. Next, a subset of appliances was deliberately considered. The energy consumption with all appliances vs. selected appliances for case-1 is shown in figure 5.6. In case 5, student apartments can use some extra laptops, entertainment systems and appliances than a usual household. Therefore, a total of three laptops, one blu-ray player, a cable box, a printer, and a dishwasher were considered, in addition to the appliances listed in case-1. The energy consumption comparison between all appliances and selected appliances for case-5 is shown in figure 5.7.

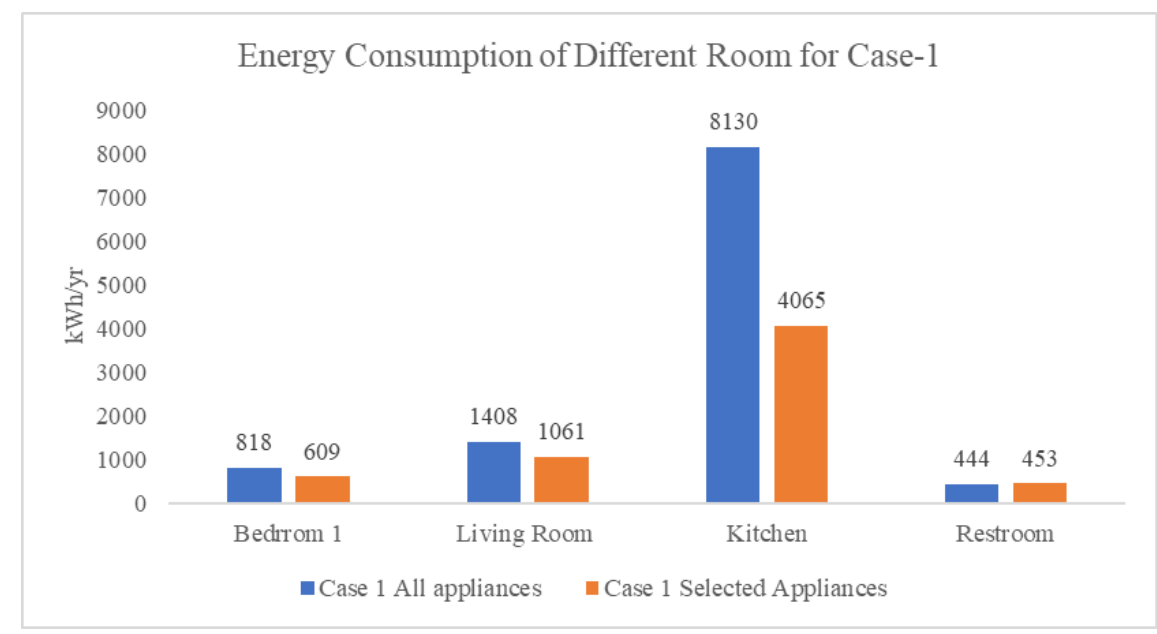

Figure 5-6: Energy consumption for case-1 with different appliances combination 


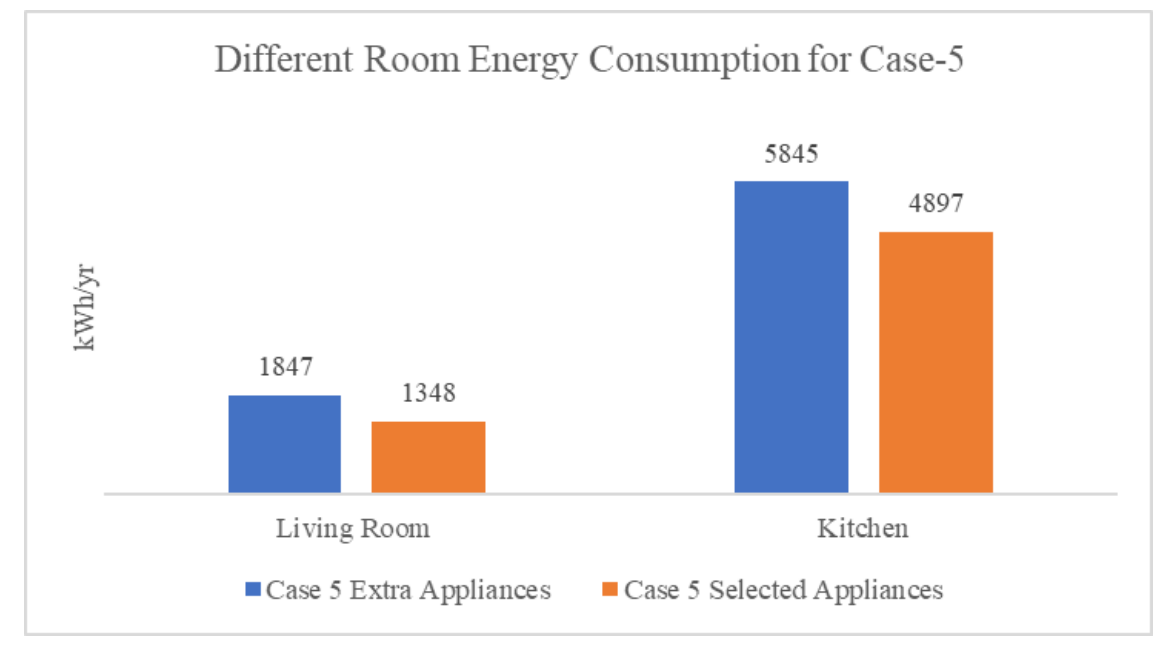

Figure 5-7: Energy consumption for case-5 with different appliances combinations in the living room and kitchen

\subsubsection{Weekdays and Weekends}

The resident's presence at the house also changes the energy consumption rate. During the weekend, the apartment will be more occupied compare to two weekdays. Besides, there will be more activity in the daytime at the weekends, which indicates more appliances were being used. As a result, energy consumption during the weekend energy consumption will be high. To identify if a day of the year is weekdays or weekends, the day of the year is first divided by 6 . If the remainder is 0 or 1, it would be the weekend for this simulation. Energy consumption was found to be higher during weekends compared to the weekdays (Figure 5.8).

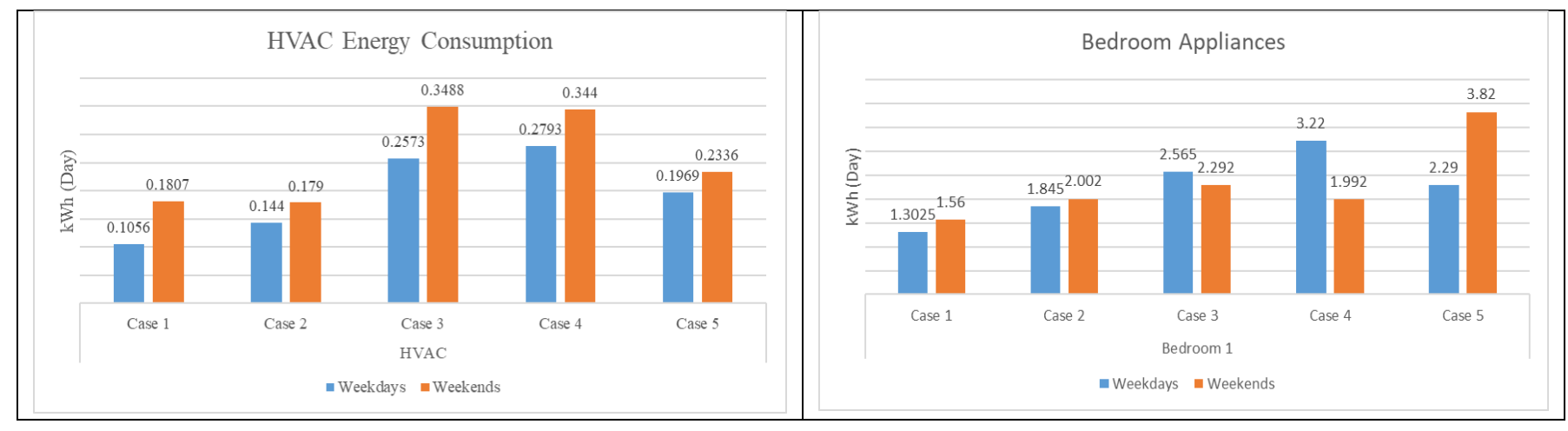




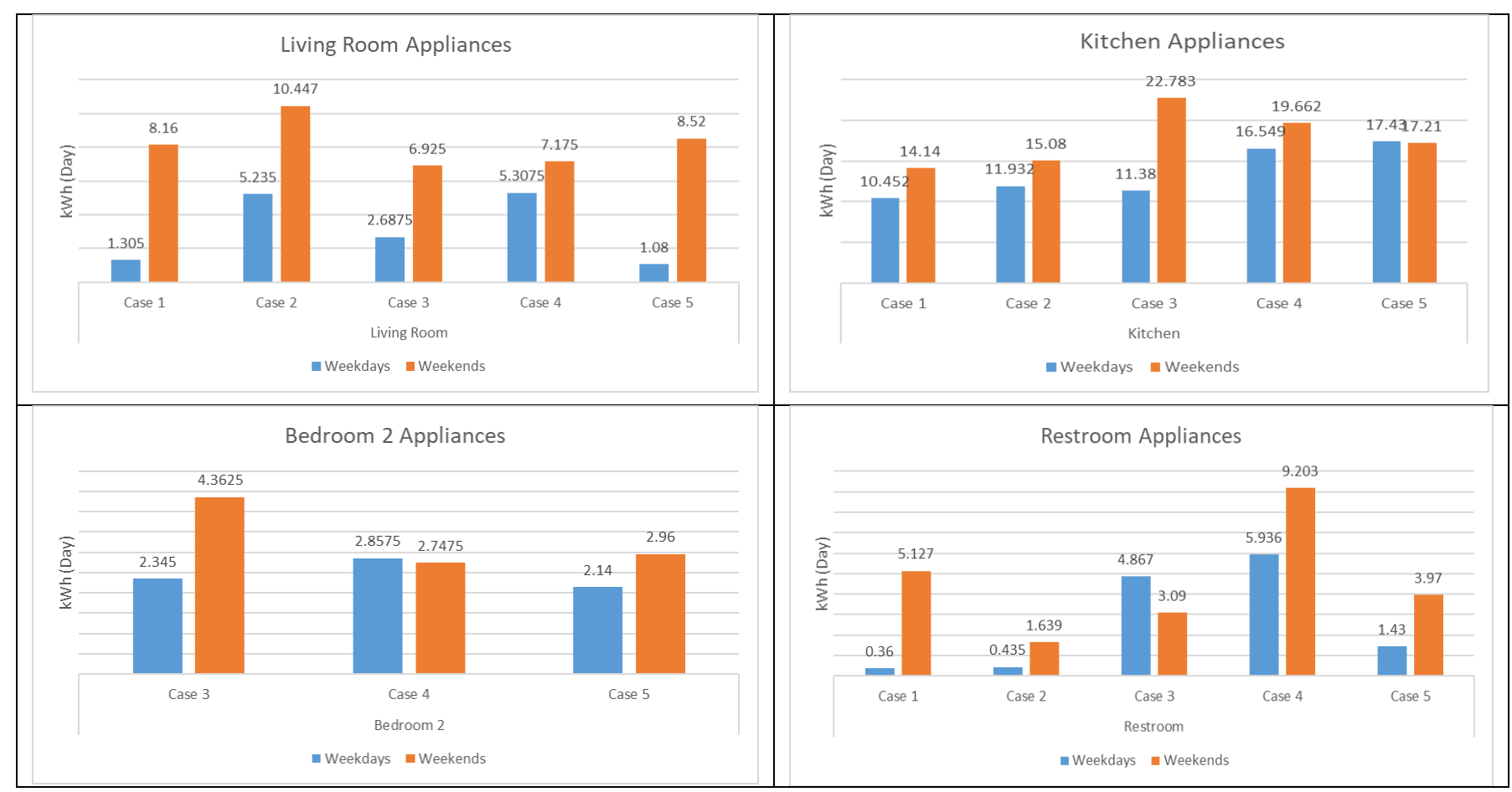

Figure 5-8: Energy consumption weekends Vs. weekdays

The graph shows that the weekend energy consumption for case 3 is higher than case 4 , despite both of them being 2 bedroom apartment and having the same number of residents. The low energy consumption reason for case 4 (occupied on weekdays) is the household workload was distributed throughout the week.

\subsubsection{Time of the Day}

Occupancy and the appliance usage depend on the time of the day, dictated by the residents' age and work location. If the residents work from home, or if there are children as residents, then the place will be more occupied and appliances usage probability will be high. Therefore, different cases can have the same number of rooms, but their energy consumption will differ due to the occupancy difference. Figure 5.9 compares the energy consumption between cases with the same room numbers- case- 1 vs. case-2 ( 1 bedroom apartment), case- 3 vs. case-4 ( 2 bedroom apartment), and case-5 ( 3 bedroom apartment). The energy consumption was different at the same time of the day, despite having the same room numbers. 


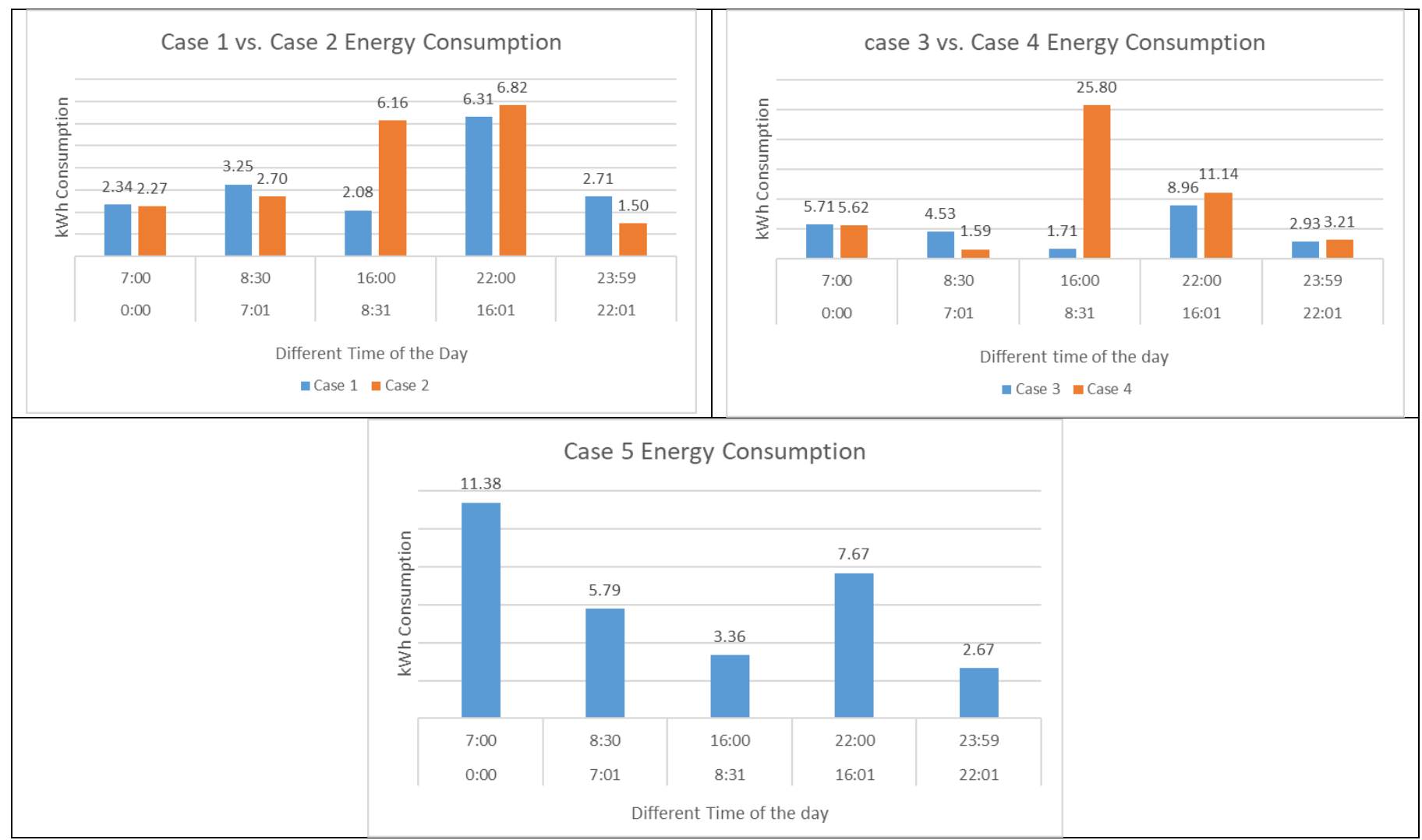

Figure 5-9: Energy consumption comparison for the same time of day for different case 


\section{Conclusion and Future Work}

This pattern generating simulation tool is developed to identify the occupancy number and resident activity. In developing an energy consumption simulation tool, several factors that directly impact energy consumption have been considered. These factors include residents' number, residents' age, residents' workplace location, appliances type, day of the week, and time of the day help depict the occupancy and inside activities of that specific building space. In this study, the effects of these abovementioned factors on energy consumption have been verified. This simulation is a user-driven simulation with realistic data options for the user, developed in Microsoft Excel® built Visual Basic Application (VBA)®. Here, Monte Carlo Simulation method and heuristic rules are applied to make the occupancy decision for short segmented times. The simulation allows the user to choose appliances and their capacity, building conditions, and weather. The study computes the results of the detailed energy consumption patterns. These patterns represent the occupancy, people activity, and lifestyle in a building space. The generated patterns can be compared with real-world data with similar scenarios. A discrepancy between the simulated and real-data may indicate unusual activity or occupancy. In other cases, energy consumption in a case with unusual occupancy or activities can be simulated, and any real-data similar to the simulated data may also indicate unusual activities. This research can pave the way for commercial entities to study various appliance usage patterns to develop better products. Additionally, law enforcement personnel can evaluate potential unlawful human activities within apartment spaces using data analytics simulation approaches. However, it is to be noted that this work is intended to facilitate the analysis of building occupants' activities, subject to all legal provisions that apply. It is not intended for the general public to pursue these activities because legal ramifications might be involved.

Also, the simulation has been justified by comparing different scenarios with different parameter combinations. The summary of the analysis are listed below:

- The energy consumption is high with the same building specifications, room number, appliances, and regional location if the place is more occupied.

- The energy consumption pattern shows that most of the energy usage should happen in the morning and evening time within a standard everyday lifestyle. 
- Appliance number and type also make a difference in energy consumption, while occupancy, weather, and building parameters remain the same.

- The Resident's activities are different during the weekdays and weekends. The energy consumption pattern shows that the place will be more occupied at the weekends, and most of the appliance will be used compared with weekdays.

Several assumptions have been made to keep this simulation simple. This simulation can be updated with more realistic values and more cases depicting other scenarios as future work. The possible future works for this study are listed below:

- This study only considers five scenarios to show how energy consumption patterns will reveal the residents ' inside activity. More scenarios should be included to make the simulation more versatile.

- Detail weather data will make the results more accurate. Besides, in this work, only the USA weather has been considered, and it is possible to extend its applicability to other countries.

- To better visualize inside activity, a smaller time interval frequency than 30 minutes should be considered.

- The occupancy probability chart and appliances usage probability chart can be updated with values for every hour to make a more realistic and robust simulation.

- Including additional appliances will make this simulation more usable for diverse scenarios.

- Detail insulation type, building construction material, and the ventilation system should be considered for further study.

- This work considered an apartment house, but the future work should include townhouses and bigger houses. 


\section{Appendix}

\begin{tabular}{|c|c|c|c|c|c|c|c|c|c|}
\hline \multicolumn{10}{|c|}{ Heating Degree Days } \\
\hline & 1 & 2 & 3 & 4 & 5 & 6 & 7 & 8 & 9 \\
\hline Month & Pacific & Mountain & West North Central & West South Central & East North Central & East South Central & Middle Atlantic & South Atlantic & New England \\
\hline January & 569 & 918 & 1303 & 565 & 1241 & 857 & 1119 & 659 & 1127 \\
\hline February & 342 & 618 & 937 & 310 & 957 & 573 & 901 & 483 & 957 \\
\hline March & 396 & 542 & 653 & 179 & 670 & 324 & 644 & 240 & 754 \\
\hline April & 242 & 381 & 424 & 61 & 506 & 162 & 515 & 152 & 605 \\
\hline May & 181 & 254 & 207 & 17 & 221 & 71 & 213 & 58 & 251 \\
\hline June & 44 & 42 & 27 & 0 & 25 & 0 & 22 & 1 & 45 \\
\hline July & 20 & 15 & 11 & 0 & 2 & 0 & 1 & 0 & 4 \\
\hline August & 12 & 31 & 17 & 0 & 5 & 0 & 1 & 0 & 5 \\
\hline September & 66 & 115 & 75 & 1 & 40 & 5 & 38 & 2 & 67 \\
\hline October & 201 & 265 & 304 & 22 & 285 & 89 & 316 & 91 & 389 \\
\hline November & 332 & 512 & 569 & 154 & 582 & 339 & 609 & 290 & 672 \\
\hline December & 627 & 926 & 1257 & 444 & 1166 & 672 & 975 & 479 & 1054 \\
\hline \multicolumn{10}{|c|}{ Cooling Degree Days } \\
\hline & 1 & 2 & 3 & 4 & 5 & 6 & 7 & 8 & 9 \\
\hline Month & Pacific & Mountain & West North Central & West South Central & East North Central & East South Central & Middle Atlantic & South Atlantic & New England \\
\hline January & 8 & 0 & 0 & 9 & $\begin{array}{l}0 \\
\end{array}$ & 2 & 0 & 25 & 0 \\
\hline February & 15 & 10 & 0 & 25 & 0 & 3 & 0 & 24 & 0 \\
\hline March & 13 & 24 & 10 & 86 & 3 & 36 & 0 & 89 & 0 \\
\hline April & 27 & 42 & 8 & 123 & 1 & 37 & 0 & 87 & 0 \\
\hline May & 37 & 90 & 49 & 238 & 42 & 124 & 17 & 185 & 7 \\
\hline June & 166 & 331 & 263 & 475 & 188 & 371 & 129 & 379 & 75 \\
\hline July & 236 & 408 & 306 & 620 & 277 & 473 & 310 & 509 & 241 \\
\hline August & 234 & 305 & 269 & 547 & 297 & 460 & 312 & 484 & 241 \\
\hline September & 122 & 173 & 138 & 429 & 131 & 321 & 114 & 352 & 61 \\
\hline October & 47 & 99 & 28 & 233 & 19 & 113 & 6 & 157 & 0 \\
\hline November & 17 & 14 & 2 & 80 & 0 & 12 & 0 & 56 & 0 \\
\hline December & 8 & 0 & 0 & 17 & 0 & 4 & 0 & 65 & 0 \\
\hline
\end{tabular}

Figure 1: Detail heating degree days and cooling degree days information for nine regions 


\begin{tabular}{|c|c|c|c|c|c|c|}
\hline \multicolumn{7}{|c|}{ HVAC Load Factor } \\
\hline Occupancy & Weather & Thermostat & Insulation & Volume & Combination NO. & Load Factor \\
\hline 1 & 1 & 1 & 1 & 1 & 11111 & 0.2 \\
\hline 1 & 1 & 2 & 1 & 1 & 11211 & 0.3 \\
\hline 1 & 1 & 1 & 1 & 2 & 11112 & 0.3 \\
\hline 1 & 1 & 2 & 1 & 2 & 11212 & 0.4 \\
\hline 1 & 1 & 1 & 1 & 3 & 11113 & 0.45 \\
\hline 1 & 1 & 2 & 1 & 3 & 11213 & 0.5 \\
\hline 1 & 1 & 1 & 2 & 1 & 11121 & 0.4 \\
\hline 1 & 1 & 2 & 2 & 1 & 11221 & 0.4 \\
\hline 1 & 1 & 1 & 2 & 2 & 11122 & 0.4 \\
\hline 1 & 1 & 2 & 2 & 2 & 11222 & 0.45 \\
\hline 1 & 1 & 1 & 2 & 3 & 11123 & 0.45 \\
\hline 1 & 1 & 2 & 2 & 3 & 11223 & 0.5 \\
\hline 1 & 2 & 1 & 1 & 1 & 12111 & 0.4 \\
\hline 1 & 2 & 2 & 1 & 1 & 12211 & 0.5 \\
\hline 1 & 2 & 1 & 1 & 2 & 12112 & 0.5 \\
\hline 1 & 2 & 2 & 1 & 2 & 12212 & 0.6 \\
\hline 1 & 2 & 1 & 1 & 3 & 12113 & 0.6 \\
\hline 1 & 2 & 2 & 1 & 3 & 12213 & 0.7 \\
\hline 1 & 2 & 1 & 2 & 1 & 12121 & 0.6 \\
\hline 1 & 2 & 2 & 2 & 1 & 12221 & 0.6 \\
\hline 1 & 2 & 1 & 2 & 2 & 12122 & 0.6 \\
\hline 1 & 2 & 2 & 2 & 2 & 12222 & 0.5 \\
\hline 1 & 2 & 1 & 2 & 3 & 12123 & 0.7 \\
\hline 1 & 2 & 2 & 2 & 3 & 12223 & 0.7 \\
\hline 1 & 3 & 1 & 1 & 1 & 13111 & 0.5 \\
\hline 1 & 3 & 2 & 1 & 1 & 13211 & 0.6 \\
\hline 1 & 3 & 1 & 1 & 2 & 13112 & 0.6 \\
\hline 1 & 3 & 2 & 1 & 2 & 13212 & 0.7 \\
\hline 1 & 3 & 1 & 1 & 3 & 13113 & 0.7 \\
\hline 1 & 3 & 2 & 1 & 3 & 13213 & 0.8 \\
\hline 1 & 3 & 1 & 2 & 1 & 13121 & 0.7 \\
\hline 1 & 3 & 2 & 2 & 1 & 13221 & 0.8 \\
\hline 1 & 3 & 1 & 2 & 2 & 13122 & 0.7 \\
\hline 1 & 3 & 2 & 2 & 2 & 13222 & 0.8 \\
\hline 1 & 3 & 1 & 2 & 3 & 13123 & 0.9 \\
\hline 1 & 3 & 2 & 2 & 3 & 13223 & 1 \\
\hline 0 & 1 & 1 & 1 & 1 & 1111 & 0 \\
\hline 0 & 1 & 2 & 1 & 1 & 1211 & 0 \\
\hline 0 & 1 & 1 & 1 & 2 & 1112 & 0 \\
\hline 0 & 1 & 2 & 1 & 2 & 1212 & 0 \\
\hline 0 & 1 & 1 & 1 & 3 & 1113 & 0 \\
\hline 0 & 1 & 2 & 1 & 3 & 1213 & 0 \\
\hline 0 & 1 & 1 & 2 & 1 & 1121 & 0 \\
\hline 0 & 1 & 2 & 2 & 1 & 1221 & 0.05 \\
\hline 0 & 1 & 1 & 2 & 2 & 1122 & 0 \\
\hline 0 & 1 & 2 & 2 & 2 & 1222 & 0.1 \\
\hline 0 & 1 & 1 & 2 & 3 & 1123 & 0 \\
\hline 0 & 1 & 2 & 2 & 3 & 1223 & 0.2 \\
\hline 0 & 2 & 1 & 1 & 1 & 2111 & 0 \\
\hline 0 & 2 & 2 & 1 & 1 & 2211 & 0.2 \\
\hline 0 & 2 & 1 & 1 & 2 & 2112 & 0.2 \\
\hline 0 & 2 & 2 & 1 & 2 & 2212 & 0.25 \\
\hline 0 & 2 & 1 & 1 & 3 & 2113 & 0.25 \\
\hline 0 & 2 & 2 & 1 & 3 & 2213 & 0.3 \\
\hline 0 & 2 & 1 & 2 & 1 & 2121 & 0.2 \\
\hline 0 & 2 & 2 & 2 & 1 & 2221 & 0.25 \\
\hline 0 & 2 & 1 & 2 & 2 & 2122 & 0.25 \\
\hline 0 & 2 & 2 & 2 & 2 & 2222 & 0.3 \\
\hline 0 & 2 & 1 & 2 & 3 & 2123 & 0.3 \\
\hline 0 & 2 & 2 & 2 & 3 & 2223 & 0.35 \\
\hline 0 & 3 & 1 & 1 & 1 & 3111 & 0.2 \\
\hline 0 & 3 & 2 & 1 & 1 & 3211 & 0.25 \\
\hline 0 & 3 & 1 & 1 & 2 & 3112 & 0.25 \\
\hline 0 & 3 & 2 & 1 & 2 & 3212 & 0.3 \\
\hline 0 & 3 & 1 & 1 & 3 & 3113 & 0.3 \\
\hline 0 & 3 & 2 & 1 & 3 & 3213 & 0.35 \\
\hline 0 & 3 & 1 & 2 & 1 & 3121 & 0.2 \\
\hline 0 & 3 & 2 & 2 & 1 & 3221 & 0.25 \\
\hline 0 & 3 & 1 & 2 & 2 & 3122 & 0.3 \\
\hline 0 & 3 & 2 & 2 & 2 & 3222 & 0.35 \\
\hline 0 & 3 & 1 & 2 & 3 & 3123 & 0.35 \\
\hline 0 & 3 & 2 & 2 & 3 & 3223 & 0.4 \\
\hline
\end{tabular}

Figure 2: Average load factor of HVAC 


\begin{tabular}{|c|c|c|c|c|c|c|c|c|c|c|c|c|c|c|c|c|c|c|c|}
\hline \multicolumn{20}{|c|}{ Lighting Probability } \\
\hline \multicolumn{20}{|c|}{ Bed Room } \\
\hline \multicolumn{4}{|c|}{ Case 1 (One Bedroom - Single Couple without kid, both works) } & \multicolumn{4}{|c|}{ Case 2 (One Bedroom - Single Couple without kid, one work from home) } & \multicolumn{4}{|c|}{ Case 3 (Two Bedroom - Couple with kids, both work outside) } & \multicolumn{4}{|c|}{ Case 4 (Two Bedroom - Couple with kids, one work home) } & \multicolumn{4}{|c|}{ Case 5 (Three bedrooms - three students apartment) } \\
\hline \multicolumn{2}{|c|}{ Time zone } & Working Days & Holiday & \multicolumn{2}{|c|}{ Time zone } & Working Days & Holiday & \multicolumn{2}{|c|}{ Time zone } & Working Days & Holiday & \multicolumn{2}{|c|}{ Time zone } & Working Days & Holiday & \multicolumn{2}{|c|}{ Time zone } & Working Days & Holiday \\
\hline $0: 00$ & 7:00 & 0.15 & 0.15 & $0: 00$ & 7:00 & 0.15 & 0.15 & $0: 00$ & 7:00 & 0.25 & 0.25 & 0:00 & 7:00 & 0.25 & 0.25 & $0: 00$ & 7:00 & 0.3 & 0.35 \\
\hline 7:01 & $8: 00$ & 0.3 & 0.15 & 7:01 & $8: 00$ & 0.3 & 0.15 & 7:01 & $8: 00$ & 0.4 & 0.3 & 7:01 & 8:00 & 0.3 & 0.3 & 7:01 & 8:00 & 0.25 & 0.1 \\
\hline $8: 01$ & 17:00 & 0.1 & 0.2 & 8:01 & 17:00 & 0.3 & 0.2 & $8: 01$ & 17:00 & 0.15 & 0.25 & 8:01 & 17:00 & 0.3 & 0.3 & 8:01 & 17:00 & 0.1 & 0.15 \\
\hline 17:01 & 21:00 & 0.3 & 0.35 & 17:01 & 21:00 & 0.35 & 0.35 & 17:01 & 21:00 & 0.25 & 0.3 & 17:01 & 21:00 & 0.25 & 0.3 & 17:01 & 21:00 & 0.2 & 0.2 \\
\hline 21:01 & $23: 59$ & 0.15 & 0.2 & $21: 01$ & 23:59 & 0.15 & 0.2 & 21:01 & $23: 59$ & 0.3 & 0.3 & 21:01 & $23: 59$ & 0.3 & 0.3 & 21:01 & $23: 59$ & 0.35 & 0.3 \\
\hline & & & & & & & & & & & & & & & & & & & \\
\hline \multirow{2}{*}{\multicolumn{20}{|c|}{ Living Room }} \\
\hline & & & & & & & & & & & & & & & & & & & \\
\hline \multicolumn{4}{|c|}{ Case 1 (One Bedroom - Single Couple without kid, both works) } & \multicolumn{4}{|c|}{ Case 2 (One Bedroom - Single Couple without kid, one work from home) } & \multicolumn{4}{|c|}{ Case 3 (Two Bedroom - Couple with kids, both work outside) } & \multicolumn{4}{|c|}{ Case 4 (Two Bedroom - Couple with kids, one work home) } & \multicolumn{4}{|c|}{ Case 5 (Three bedrooms - three students apartment) } \\
\hline \multicolumn{2}{|c|}{ Time zone } & Working Days & Holiday & \multicolumn{2}{|c|}{ Time zone } & Working Days & Holiday & \multicolumn{2}{|c|}{ Time zone } & Working Days & Holiday & & & Working Days & Holiday & & & Working Days & Holiday \\
\hline $0: 00$ & 7:00 & 0.1 & 0.1 & $0: 00$ & 7:00 & 0.1 & 0.1 & $0: 00$ & $7: 00$ & 0.2 & 0.2 & $0: 00$ & $7: 00$ & \begin{tabular}{|l|}
0.2 \\
\end{tabular} & 0.2 & $0: 00$ & $7: 00$ & \begin{tabular}{|l|}
0.25 \\
\end{tabular} & 0.25 \\
\hline 7:01 & 9:00 & 0.1 & 0.1 & 7:01 & $9: 00$ & 0.1 & 0.1 & 7:01 & $9: 00$ & 0.25 & 0.3 & 7:01 & 9:00 & 0.25 & 0.3 & 7:01 & 9:00 & 0.25 & 0.1 \\
\hline 9:01 & 19:00 & 0.1 & 0.3 & 9:01 & 17:00 & 0.3 & 0.3 & 9:01 & 17:00 & 0.15 & 0.3 & 9:01 & 17:00 & 0.3 & 0.3 & 9:01 & $18: 00$ & 0.1 & 0.3 \\
\hline 19:01 & 21:00 & 0.2 & 0.25 & 17:01 & 21:00 & 0.2 & 0.25 & 17:01 & 21:00 & 0.3 & 0.35 & 17:01 & 21:00 & 0.3 & 0.35 & 18:01 & 22:00 & 0.3 & 0.3 \\
\hline 21:01 & $23: 59$ & 0.15 & 0.2 & 21:01 & 23:59 & 0.15 & 0.2 & 21:01 & 23:59 & 0.3 & 0.35 & $21: 01$ & $23: 59$ & 0.3 & 0.35 & 22:01 & 23:59 & 0.2 & 0.2 \\
\hline & & & & & & & & & & & & & & & & & & & \\
\hline & & & & & & & & & Kitch & & & & & & & & & & \\
\hline Case 11 & Bedroom & ingle Couple with & id, both works ) & Case 2 (One & $m \cdot$ Singl & uple without kid, & ork from home) & Case 3 & droom-c & with kids, both & k outside) & Case 4 (Tw & om-Cour & with kids, one w & rk home) & Case 517 & rooms - t & ree students apa & tment) \\
\hline & & Working Days & $\begin{array}{l}\text { Holiday } \\
\end{array}$ & & & Working Days & Holiday & & & Working Days & Holiday & & & \begin{tabular}{|l|} 
Working Days \\
\end{tabular} & Holiday & & & Working Days & Holiday \\
\hline $0: 00$ & 7:00 & \begin{tabular}{|l|}
0.1 \\
\end{tabular} & 0.1 & $0: 00$ & 7:00 & 0.1 & 0.1 & $0: 00$ & 7:00 & 0.2 & 0.2 & $0: 00$ & 7:00 & 0.2 & 0.2 & $0: 00$ & 7:00 & \begin{tabular}{|l|}
0.25 \\
\end{tabular} & 0.3 \\
\hline 7:01 & $8: 00$ & 0.6 & 0.35 & 7:01 & $8: 00$ & 0.5 & 0.3 & 7:01 & $8: 00$ & 0.75 & 0.4 & 7:01 & $8: 00$ & 0.6 & 0.4 & 7:01 & 9:00 & 0.5 & 0.1 \\
\hline $8: 01$ & 17:00 & 0.15 & 0.5 & $8: 01$ & 17:00 & 0.25 & 0.55 & $8: 01$ & 17:00 & 0.2 & 0.6 & $8: 01$ & 17:00 & 0.3 & 0.65 & 9:01 & $18: 00$ & 0.1 & 0.45 \\
\hline 17:01 & 21:00 & 0.5 & 0.4 & 17:01 & 21:00 & 0.5 & 0.4 & 17:01 & 21:00 & 0.55 & 0.5 & 17:01 & 21:00 & 0.55 & 0.5 & $18: 01$ & $20: 00$ & 0.4 & 0.4 \\
\hline 21:01 & 23:59 & 0.15 & 0.2 & 21:01 & $23: 59$ & 0.15 & 0.2 & 21:01 & 23:59 & 0.2 & 0.2 & 21:01 & 23:59 & 0.2 & 0.2 & 20:01 & 23:59 & 0.2 & 0.25 \\
\hline & & & & & & & & & & & & & & & & & & & \\
\hline & & & & & & & & & Restrc & & & & & & & & & & \\
\hline Case 11 & Bedroom & ingle Couple with & id, both works ) & Case 2 (One & $m-$ Singl| & uple without kid, & ork from home) & Case 3 & edroom-C & with kids, both & k outside) & Case 4 (Tw & om-Cour & with kids, one w & rk home) & Case 51T & rooms - t & ree students apa & tment) \\
\hline & & Working Days & Holiday & & & Working Days & Holiday & & & Working Days & Holiday & & & \begin{tabular}{|l|} 
Working Days \\
\end{tabular} & Holiday & & & Working Days & Holiday \\
\hline $0: 00$ & 7:00 & 0.1 & 0.1 & $0: 00$ & 7:00 & 0.1 & 0.1 & $0: 00$ & $7: 00$ & 0.2 & 0.2 & $0: 00$ & 7:00 & \begin{tabular}{|l|}
0.2 \\
\end{tabular} & 0.2 & $0: 00$ & 7:00 & \begin{tabular}{|l|}
0.15 \\
\end{tabular} & 0.15 \\
\hline 7:01 & $8: 00$ & 0.3 & 0.15 & 7:01 & $8: 00$ & 0.25 & 0.15 & 7:01 & $8: 00$ & 0.35 & 0.2 & 7:01 & $8: 00$ & 0.25 & 0.2 & 7:01 & $8: 00$ & 0.25 & 0.1 \\
\hline $8: 01$ & 18:00 & 0.1 & 0.25 & $8: 01$ & $18: 00$ & 0.2 & 0.25 & $8: 01$ & 18:00 & 0.15 & 0.25 & $8: 01$ & 18:00 & 0.25 & 0.25 & 8:01 & $18: 00$ & 0.1 & 0.2 \\
\hline 18:01 & 22:00 & 0.25 & 0.25 & 18:01 & 22:00 & 0.2 & 0.2 & 18:01 & 22:00 & 0.2 & 0.2 & 18:01 & 22:00 & 0.2 & 0.2 & 18:01 & 22:00 & 0.25 & 0.2 \\
\hline 22:01 & 23:59 & 0.15 & 0.2 & 22:01 & $23: 59$ & 0.15 & 0.2 & 22:01 & $23: 59$ & 0.2 & 0.2 & 22:01 & $23: 59$ & 0.2 & 0.2 & 22:01 & $23: 59$ & 0.25 & 0.25 \\
\hline
\end{tabular}

Figure 3: Different room lighting usage probability chart for five scenarios 


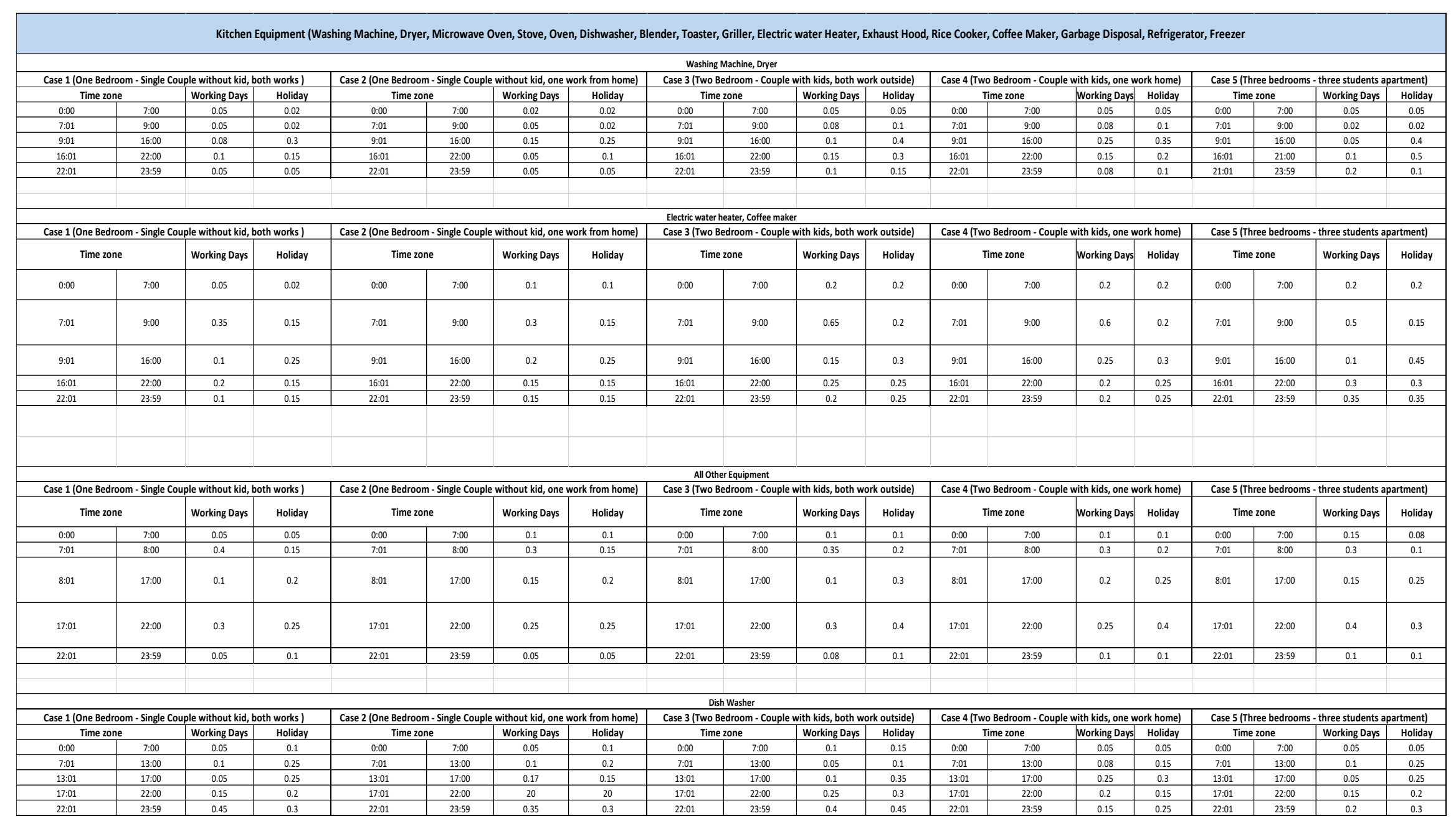

Figure 4: Kitchen appliances usage probability chart for five cases 
Livingroom Equipment (Television, Bluray Player, Cabel Box, DVD, Desktop(CPU), Monitor, Laptop, Printer)

\begin{tabular}{|c|c|c|c|c|c|c|c|c|c|c|c|c|c|c|c|c|c|c|c|}
\hline \multicolumn{20}{|c|}{ Livingroom Equipment (Television, Bluray Player, Cabel Box, DVD, Desktop(CPU), Monitor, Laptop, Printer) } \\
\hline \multicolumn{20}{|c|}{$\begin{array}{l}\text { Livingroom Equipment (Television, Bluray Player, Cabel Box, DVD, Desktop(CPU), Monitor, Laptop, Printer) } \\
\text { Living Room }\end{array}$} \\
\hline \multirow{2}{*}{\multicolumn{2}{|c|}{$\begin{array}{l}\text { Case } 1 \text { (One Bedroom - Single C } \\
\text { Time zone }\end{array}$}} & \multirow{3}{*}{$\begin{array}{l}\text { ple without kid, } \\
\text { Working Days } \\
0.1\end{array}$} & \multirow{3}{*}{$\begin{array}{l}\text { horks } \\
\text { oliday } \\
0.1\end{array}$} & \multicolumn{4}{|c|}{ Case 2 (One Bedroom - Single Couple without kid, one work from home) } & \multicolumn{4}{|c|}{ Case 3 (Two Bedroom - Couple with kids, both work outside) } & \multicolumn{4}{|c|}{ Case 4 (Two Bedroom - Couple with kids, one work home) } & \multirow{2}{*}{\multicolumn{2}{|c|}{$\begin{array}{l}\text { Case } 5 \text { (Three bedrooms } \\
\text { Time zone }\end{array}$}} & \multirow{2}{*}{\multicolumn{2}{|c|}{$\begin{array}{l}\text {-three students apartment) } \\
\text { Working Days } \\
\text { Holiday }\end{array}$}} \\
\hline & & & & & & Working Days & Holiday & & & Working Days & Holiday & & & Working $\mathrm{D}$ & Holiday & & & & \\
\hline $0: 00$ & 7:00 & & & $0: 00$ & $7: 00$ & 0.1 & 0.1 & 0.00 & 7:00 & 0.1 & 0.1 & 0:00 & 7:00 & 0.1 & 0.1 & $0: 00$ & 7:00 & 0.25 & 0.25 \\
\hline $7: 01$ & $9: 00$ & 0.05 & 0.15 & 7:01 & $9: 00$ & 0.05 & 0.15 & $7: 01$ & $9: 00$ & 0.05 & 0.1 & 7:01 & $9: 00$ & 0.05 & 0.1 & 7:01 & $9: 00$ & 0.2 & 0.15 \\
\hline 9:01 & 18:00 & 0.1 & 0.5 & 9:01 & 18:00 & 0.4 & 0.5 & $9: 01$ & 18:00 & 0.15 & 0.55 & 9:01 & 18:00 & 0.45 & 0.55 & 9:01 & 18:00 & 0.15 & 0.65 \\
\hline 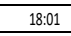 & 22:00 & 0.5 & 0.6 & $\begin{array}{l}18: 11 \\
\end{array}$ & 22:00 & 0.45 & 0.6 & 18:01 & $22: 00$ & 0.55 & 0.6 & $18: 01$ & 22:100 & 0.5 & 0.6 & $18: 01$ & 22:00 & 0.7 & 0.75 \\
\hline 22:01 & 23:59 & 0.15 & 0.25 & 22:01 & 23:59 & 0.15 & 0.25 & $22: 01$ & 23:59 & 0.1 & 0.2 & 22:01 & $23: 59$ & 0.15 & 0.2 & 22:01 & $23: 59$ & 0.5 & 0.6 \\
\hline
\end{tabular}

Restroom (Aroma Lamp, Electric Shaver, Hair Dryer, Hair Iron, Exhaust Fan)

\begin{tabular}{|c|c|c|c|c|c|c|c|c|c|c|c|c|c|c|c|c|c|c|c|}
\hline \multicolumn{20}{|c|}{ Restroom (Aroma Lamp, Electric Shaver, Hair Dryer, Hair Iron, Exhaust Fan) } \\
\hline \multicolumn{20}{|c|}{ Restroom } \\
\hline \multicolumn{4}{|c|}{ Case 1 (One Bedroom - Single Couple without kid, both works) } & \multicolumn{4}{|c|}{ Case 2 (One Bedroom - Single Couple without kid, one work from home) } & \multicolumn{4}{|c|}{ Case 3 (Two Bedroom - Couple with kids, both work outside) } & \multicolumn{4}{|c|}{ Case 4 (Two Bedroom - Couple with kids, one work home) } & \multicolumn{4}{|c|}{ Case 5 (Three bedrooms - three students apartment) } \\
\hline & & Working Days & Holiday & & & Working Days & Holiday & & & Working Days & Holiday & & & Working Day: & Holiday & & & Working Days & Holiday \\
\hline $0: 00$ & 7:00 & 0.05 & 0.05 & $0: 00$ & 7:00 & 0.05 & 0.05 & $0: 00$ & $7: 00$ & 0.05 & 0.05 & $0: 00$ & 7:00 & 0.05 & 0.05 & $0: 00$ & $7: 00$ & 0.05 & 0.05 \\
\hline 7:01 & 9:00 & 0.25 & 0.15 & 7:01 & 9:00 & 0.2 & 0.15 & 7:01 & 9:00 & 0.3 & 0.2 & 7:01 & 9:00 & 0.25 & 0.2 & 7:01 & 9:00 & 0.25 & 0.1 \\
\hline 9:01 & $16: 00$ & 0.05 & 0.15 & 9:01 & 16:00 & 0.15 & 0.1 & $\begin{array}{l}9: 01 \\
\end{array}$ & 16:00 & 0.1 & 0.15 & 9:01 & $16: 00$ & 0.15 & 0.15 & $9: 01$ & $16: 00$ & 0.05 & 0.15 \\
\hline 16:01 & 22:00 & 0.15 & 0.2 & $16: 01$ & 22:00 & 0.15 & 0.15 & $16: 01$ & 22:00 & 0.15 & 0.2 & $16: 01$ & 22:00 & 0.15 & 0.2 & $16: 01$ & 22:00 & 0.15 & 0.2 \\
\hline 22:01 & $23: 59$ & $\begin{array}{l}0.1 \\
0.1\end{array}$ & 0.1 & $22: 01$ & 23:59 & 0.1 & 0.1 & 22:01 & 23:59 & 0.1 & 0.1 & 22:01 & 23:59 & 0.1 & 0.1 & 22:01 & 23:55 & 0.1 & 0.1 \\
\hline
\end{tabular}

Kitchen/Restroom (Water Heater)

\begin{tabular}{|c|c|c|c|c|c|c|c|c|c|c|c|c|c|c|c|c|c|c|c|}
\hline \multicolumn{20}{|c|}{ Kitchen/Restroom (Water Heater ) } \\
\hline \multicolumn{4}{|c|}{ Case 1 (One Bedroom - Single Couple without kid, both works) } & \multicolumn{4}{|c|}{ Case 2 (One Bedroom - Single Couple without kid, one work from home) } & \multicolumn{4}{|c|}{ Case 3 (Two Bedroom - Couple with kids, both work outside) } & \multicolumn{4}{|c|}{ Case 4 (Two Bedroom - Couple with kids, one work home) } & \multicolumn{4}{|c|}{ Case 5 (Three bedrooms - three students apartment) } \\
\hline \multicolumn{2}{|c|}{ Time zone } & \multirow{2}{*}{$\begin{array}{c}\text { Working Days } \\
0.1\end{array}$} & \multirow{2}{*}{$\begin{array}{c}\text { Holiday } \\
0.1\end{array}$} & \multicolumn{2}{|c|}{ Time zone } & \multirow{2}{*}{$\begin{array}{c}\text { Working Days } \\
0.1\end{array}$} & \multirow{2}{*}{$\begin{array}{c}\text { Holiday } \\
0.1\end{array}$} & \multicolumn{2}{|c|}{ Time zone } & \multirow{2}{*}{$\begin{array}{c}\text { Working Days } \\
0.1\end{array}$} & \multirow{2}{*}{$\begin{array}{c}\text { Holiday } \\
0.1\end{array}$} & \multicolumn{2}{|c|}{ Time zone } & \multirow{2}{*}{$\begin{array}{l}\text { Working Day: } \\
0.1\end{array}$} & \multirow{2}{*}{$\begin{array}{c}\text { Holiday } \\
0.1\end{array}$} & \multicolumn{2}{|c|}{ Time zone } & \multirow{2}{*}{$\begin{array}{c}\text { Working Days } \\
0.1\end{array}$} & \multirow{2}{*}{$\begin{array}{c}\text { Holiday } \\
0.1\end{array}$} \\
\hline $0: 00$ & 7:00 & & & $0: 00$ & 7:00 & & & 0:00 & 7:00 & & & $0: 00$ & 7:00 & & & $0: 00$ & 7:00 & & \\
\hline 7:01 & 8:00 & 0.3 & 0.1 & 7:01 & 9:00 & 0.2 & 0.1 & 7:01 & 9:00 & 0.35 & 0.15 & 7:01 & 9:00 & 0.3 & 0.15 & 7:01 & 9:00 & 0.35 & 0.1 \\
\hline 9:01 & $16: 00$ & 0.05 & 0.2 & $9: 01$ & 16:00 & 0.15 & 0.2 & $9: 01$ & $16: 00$ & 0.05 & 0.25 & 9:01 & 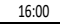 & 0.2 & 0.25 & 9:01 & $16: 00$ & 0.05 & 0.3 \\
\hline $\begin{array}{ll}13 \\
\end{array}$ & 22:00 & 0.25 & 0.25 & 16:01 & 22:00 & 0.2 & 0.25 & 16:01 & 222:00 & 0.3 & 0.3 & 13: & $22: 00$ & 0.25 & 0.3 & 13: & 22:00 & 0.35 & 0.35 \\
\hline 22:01 & 23:59 & 0.1 & 0.15 & 22:01 & $23: 59$ & 0.1 & 0.15 & 22:01 & $23: 59$ & 0.15 & 0.2 & 22:01 & 23:59 & 0.15 & 0.2 & 22:01 & 23:59 & 0.2 & 0.25 \\
\hline
\end{tabular}

\begin{tabular}{|c|c|c|c|c|c|c|c|c|c|c|c|c|c|c|c|c|c|c|c|}
\hline \multicolumn{20}{|c|}{ Livingroom/Bedroom Appliance Probability (Phone Charger, Celling Fan, Space Heater, Humidifier) } \\
\hline \multicolumn{20}{|c|}{ Bed Room } \\
\hline \multirow{2}{*}{\multicolumn{2}{|c|}{$\begin{array}{l}\text { Case } 1 \text { (One Bedroom - Sin } \\
\text { Time zone }\end{array}$}} & \multirow{3}{*}{\begin{tabular}{|c|} 
Couple without \\
Working Days \\
0.5 \\
\end{tabular}} & both works ) & \multicolumn{4}{|c|}{ Case 2 (One Bedroom - Single Couple without kid, one work from home) } & \multicolumn{4}{|c|}{ Case 3 (Two Bedroom - Couple with kids, both work outside) } & \multicolumn{4}{|c|}{ Case 4 (Two Bedroom - Couple with kids, one work home) } & \multicolumn{4}{|c|}{ Case 5 (Three bedrooms - three students apartment } \\
\hline & & & \multirow{2}{*}{$\begin{array}{l}\text { Holidarks } \\
0.5\end{array}$} & & & Working Days & Holiday & & & Working Days & Holiday & & & Working Days & Holiday & & & Working Days & Holiday \\
\hline $0: 00$ & $7: 00$ & & & $0: 00$ & 7:00 & 0.5 & 0.5 & $0: 00$ & 7:00 & 0.65 & 0.65 & $0: 00$ & $7: 00$ & 0.65 & 0.65 & $0: 00$ & $7: 00$ & 0.5 & 0.5 \\
\hline 7:01 & $8: 00$ & 0.3 & 0.45 & 7:01 & $8: 00$ & 0.4 & 0.45 & $7: 01$ & $8: 00$ & 0.45 & 0.5 & & & 0.4 & 0.5 & & $8: 00$ & 0.25 & 0.35 \\
\hline $8: 01$ & 20:00 & 0.1 & 0.15 & $8: 01$ & $\begin{array}{l}20: 00 \\
\end{array}$ & 0.25 & 0.15 & $8: 01$ & $\begin{array}{l}20: 00 \\
\end{array}$ & 0.2 & 0.25 & $8: 01$ & 20:00 & 0.3 & 0.25 & $8: 01$ & 20:00 & 0.1 & 0.2 \\
\hline 20:01 & 22:00 & 0.15 & $\begin{array}{ll}0.1 \\
\end{array}$ & 20:01 & 22:00 & 0.15 & 0.1 & 20:01 & 22:00 & 0.5 & 0.5 & 20:01 & 22:00 & 0.45 & 0.4 & 20:01 & 22:00 & 0.3 & 0.2 \\
\hline 22:01 & 23:59 & 0.3 & 0.15 & 22:01 & 23:59 & 0.3 & 0.15 & 22:01 & 23:59 & 0.55 & 0.55 & 22:01 & 23:59 & 0.55 & 0.55 & 22:01 & 23:59 & 0.5 & 0.5 \\
\hline
\end{tabular}

\begin{tabular}{|c|c|c|c|c|c|c|c|c|c|c|c|c|c|c|c|c|c|c|c|}
\hline \multicolumn{20}{|c|}{ Living Room } \\
\hline \multirow{2}{*}{\multicolumn{2}{|c|}{$\begin{array}{l}\text { Case } 1 \text { (One Bedroom - Sir } \\
\text { Time zone }\end{array}$}} & \multirow{3}{*}{\begin{tabular}{|c|} 
Couple wothout \\
Working Days \\
0.1 \\
\end{tabular}} & both works ) & \multicolumn{4}{|c|}{ Case 2 (One Bedroom - Single Couple without kid, one work from home) } & \multirow{2}{*}{\multicolumn{4}{|c|}{ Case 3 (Two Bedroom - Couple with kids, both work outside) }} & \multicolumn{4}{|c|}{ Case 4 (Two Bedroom - Couple with kids, one work home) } & \multicolumn{4}{|c|}{ Case 5 (Three bedrooms - three students apartment) } \\
\hline & & & \multirow{2}{*}{$\begin{array}{c}\text { Holiday } \\
0.1\end{array}$} & & & Working Days & Holiday & & & & Holiday & & & Working Days & Holiday & & & Working Days & Holiday \\
\hline $0: 00$ & 7:00 & & & $0: 00$ & 7:00 & 0.1 & 0.1 & $0: 00$ & 7:00 & 0.25 & 0.25 & $0: 00$ & 7:00 & 0.25 & 0.25 & $0: 00$ & 7:00 & 0.15 & 0.15 \\
\hline 7:01 & $8: 00$ & 0.2 & 0.1 & 7:01 & $8: 00$ & 0.25 & 0.1 & 7:01 & $8: 00$ & 0.35 & 0.3 & 7:01 & $8: 00$ & 0.34 & 0.3 & $7: 01$ & 8:00 & 0.35 & 0.1 \\
\hline 8:01 & 19:00 & 0.1 & 0.25 & $8: 01$ & 19:00 & 0.25 & 0.25 & 8:01 & 19:00 & 0.15 & 0.25 & $8: 01$ & 19:00 & 0.25 & 0.25 & 8:01 & 19:00 & 0.15 & 0.25 \\
\hline 19:01 & 22:00 & 0.3 & 0.4 & $\begin{array}{ll}19: 01 \\
\end{array}$ & 22:00 & 0.3 & 0.4 & \begin{tabular}{ll|}
$19: 01$ \\
\end{tabular} & 22:00 & 0.35 & 0.4 & 19:01 & 22:00 & 0.35 & 0.4 & 19:01 & $22: 00$ & 0.5 & 0.4 \\
\hline 22:01 & 23:59 & 0.1 & 0.25 & $22 \cdot 01$ & 23.59 & 0.2 & 0.25 & $22: 0$ & 23.59 & 0.3 & 0.35 & $22 \cdot 01$ & 23:59 & 0.25 & 0.35 & 22:01 & $23: 59$ & 0.3 & $\frac{0.4}{0.4}$ \\
\hline
\end{tabular}

Figure 5: Other appliances usage probability chart for five cases 

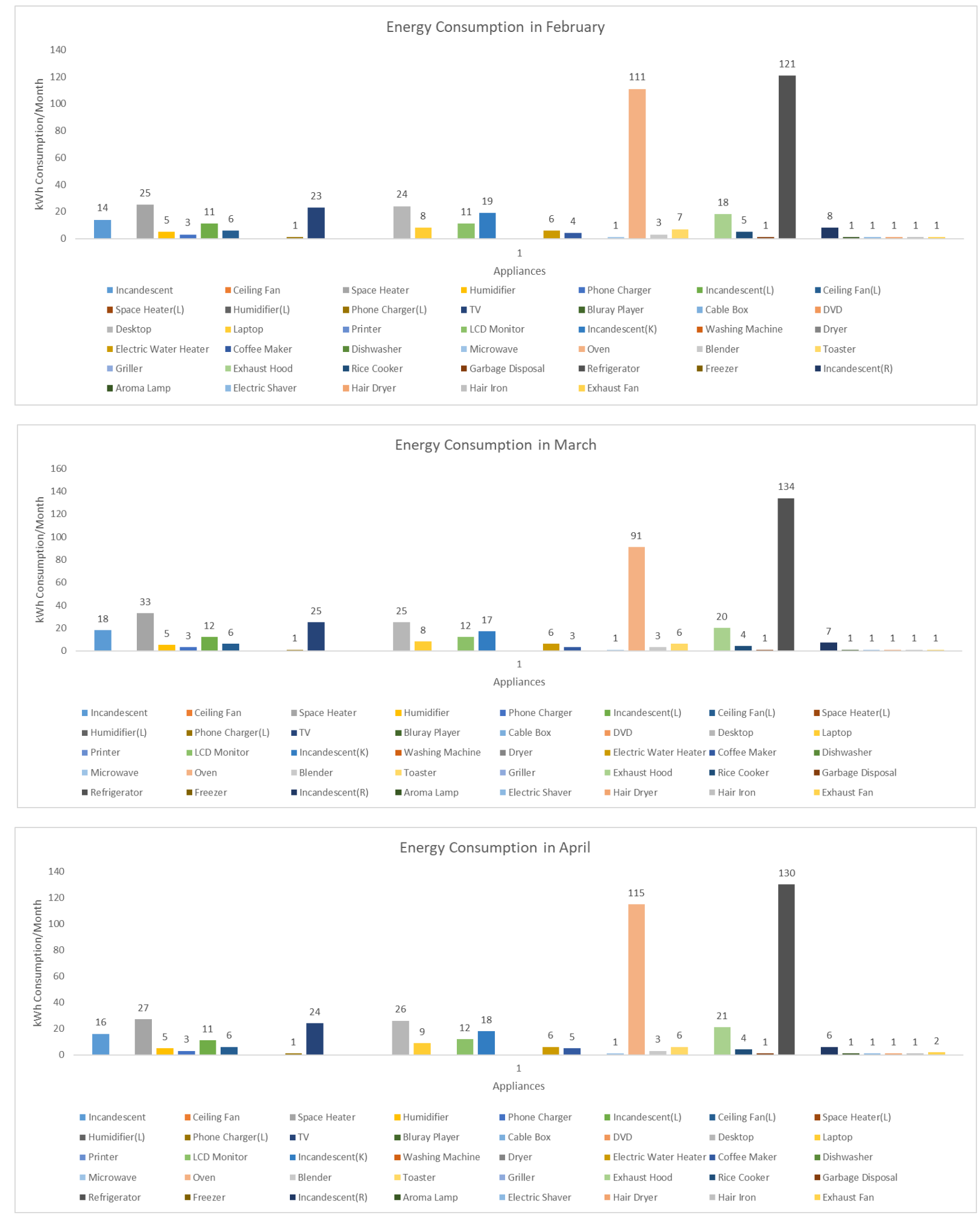

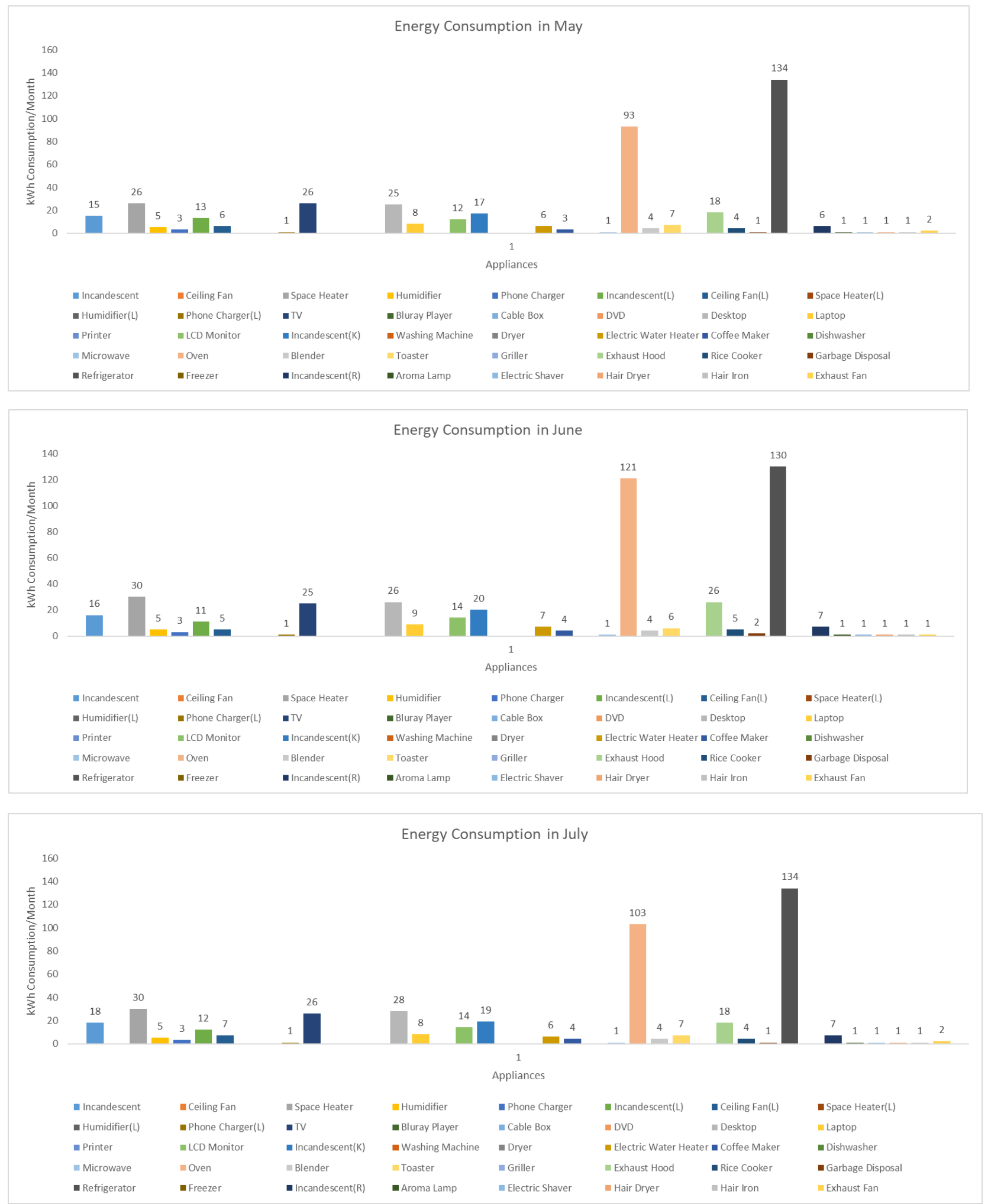

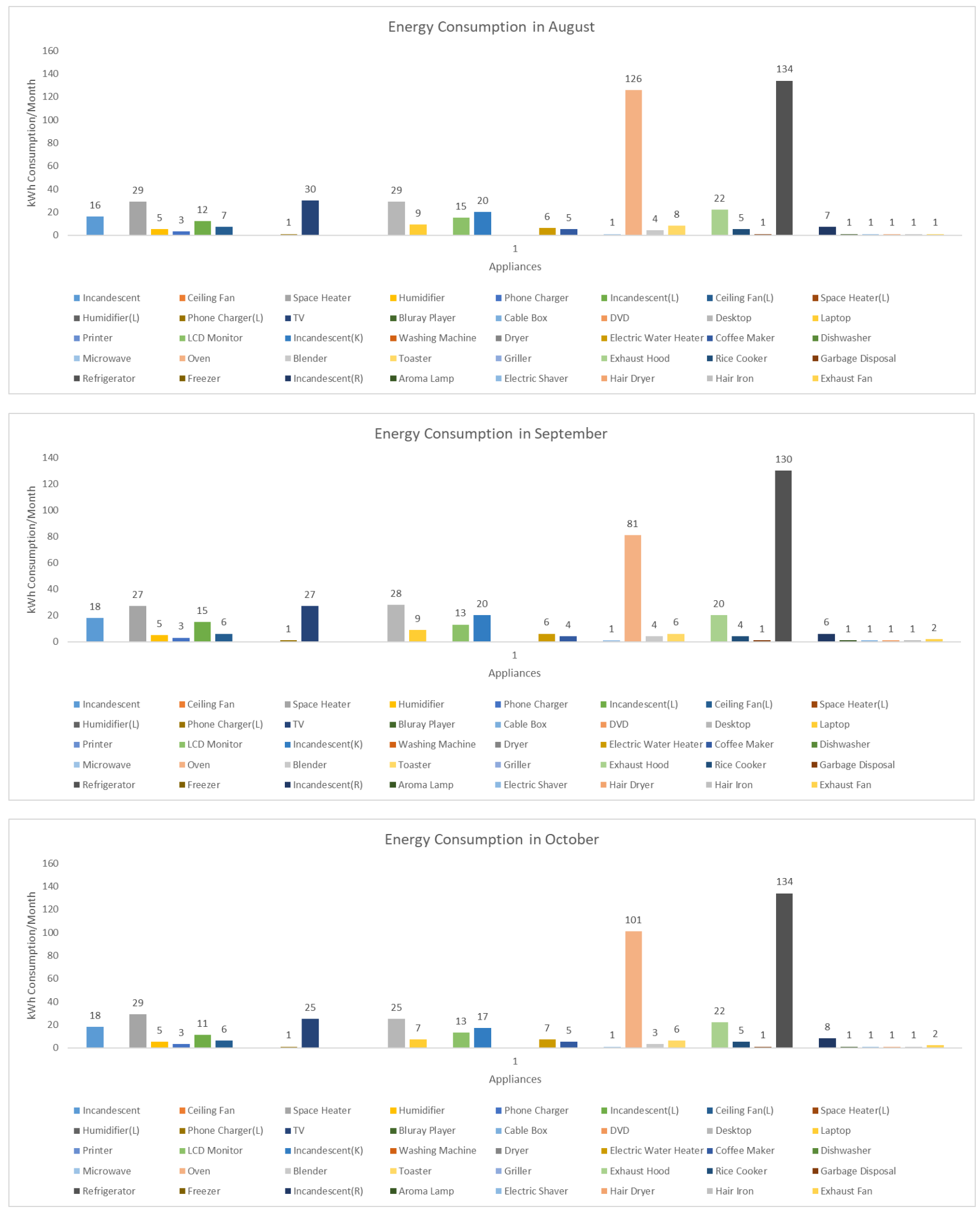

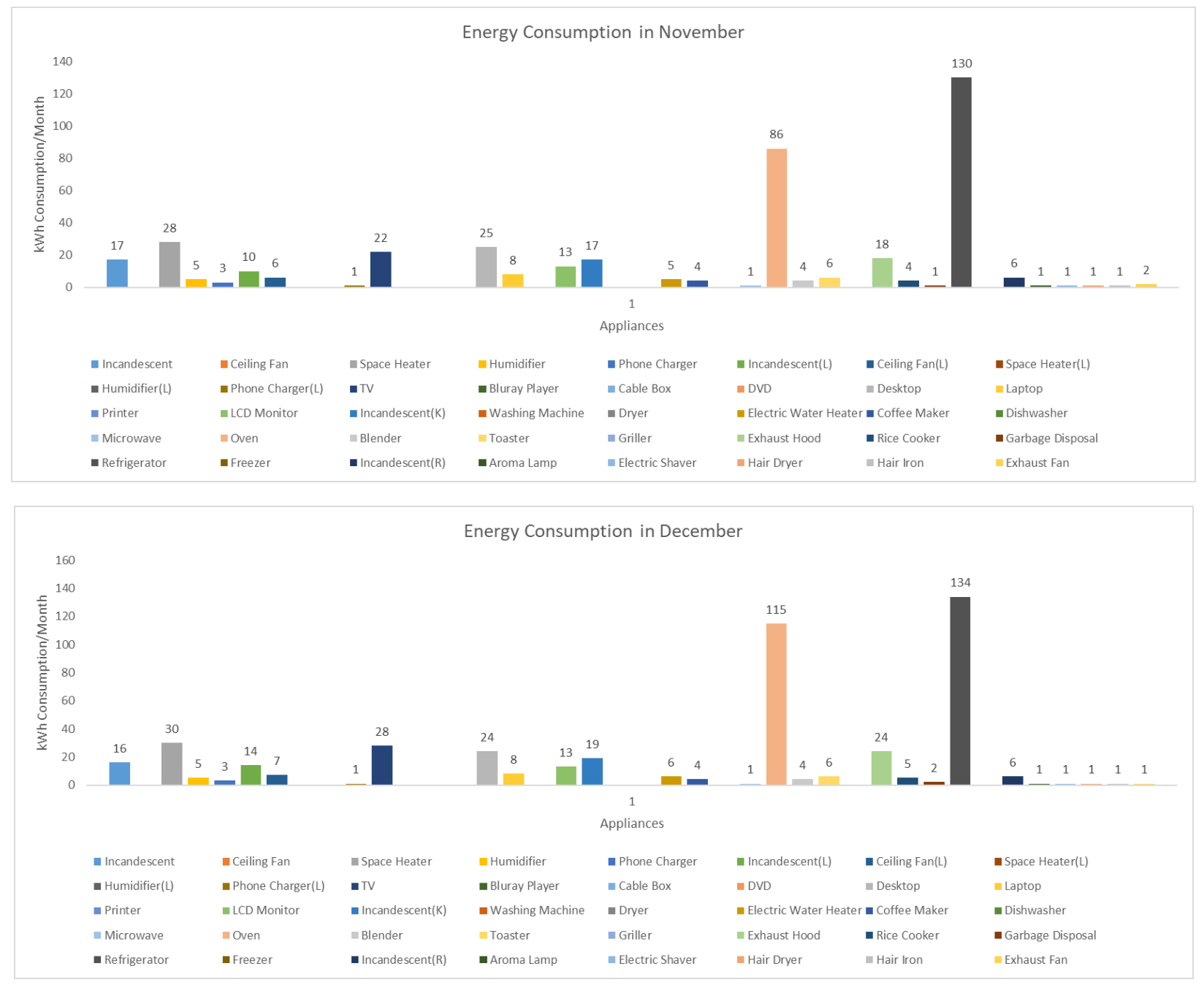

Figure 6: Appliances energy consumption for eleven months for case 1 


\section{$\underline{\text { Reference }}$}

[1] G. Palmer, "A road map for digital forensic research," in Proceedings of the Digital Forensic Research Conference, DFRWS 2001 USA, 2001, pp. iii-42.

[2] A. Almeida and G. Azkune, "Predicting Human Behaviour with Recurrent Neural Networks," Appl. Sci., vol. 8, no. 2, p. 305, Feb. 2018.

[3] A. A. Chaaraoui, J. R. Padilla-López, F. J. Ferrández-Pastor, M. Nieto-Hidalgo, and F. Flórez-Revuelta, "A vision-based system for intelligent monitoring: Human behaviour analysis and privacy by context," Sensors (Switzerland), vol. 14, no. 5, pp. 8895-8925, 2014.

[4] A. Pentland and A. Liu, "Modeling and Prediction of Human Behavior," Neural Comput., vol. 11, no. 1, pp. 229-242, Jan. 1999.

[5] Q. Sun et al., "A Comprehensive Review of Smart Energy Meters in Intelligent Energy Networks," IEEE Internet Things J., vol. 3, no. 4, pp. 464-479, Aug. 2016.

[6] H. Farhangi, "The path of the smart grid," IEEE Power Energy Mag., vol. 8, no. 1, pp. 1828, Jan. 2010.

[7] S. S. S. R. Depuru, L. Wang, V. Devabhaktuni, and N. Gudi, "Smart meters for power grid \&\#x2014; Challenges, issues, advantages and status," in 2011 IEEE/PES Power Systems Conference and Exposition, 2011, pp. 1-7.

[8] A. Mey and S. Hoff, "Nearly half of all U.S. electricity customers have smart meters," U.S. Energy Information Administration. [Online]. Available: https://www.eia.gov/todayinenergy/detail.php?id=34012\#.

[9] N. Fumo and M. A. Rafe Biswas, "Regression analysis for prediction of residential energy consumption," Renew. Sustain. Energy Rev., vol. 47, pp. 332-343, 2015.

[10] J. Min, Z. Hausfather, and Q. F. Lin, "A high-resolution statistical model of residential energy end use characteristics for the United States," J. Ind. Ecol., vol. 14, no. 5, pp. 791$807,2010$.

[11] Z. Yu, F. Haghighat, B. C. M. Fung, and H. Yoshino, "A decision tree method for building energy demand modeling," Energy Build., vol. 42, no. 10, pp. 1637-1646, Oct. 2010.

[12] E. Hoşgör and P. S. Fischbeck, "Virtual home energy auditing at scale: Predicting residential energy efficiency using publicly available data," Energy Build., vol. 92, pp. 6780, 2015.

[13] K. E. Westergren, H. Högberg, and U. Norlén, "Monitoring energy consumption in singlefamily houses," Energy Build., vol. 29, no. 3, pp. 247-257, 1999.

[14] T. Catalina, J. Virgone, and E. Blanco, "Development and validation of regression models to predict monthly heating demand for residential buildings," Energy Build., vol. 40, no. 
10, pp. 1825-1832, 2008.

[15] B. Soldo, P. Potočnik, G. Šimunović, T. Šarić, and E. Govekar, "Improving the residential natural gas consumption forecasting models by using solar radiation," Energy Build., vol. 69, pp. 498-506, Feb. 2014.

[16] N. Elsawaf, T. Abdel-Salam, and L. Pagliari, "Evaluation of heat pumps usage and energy savings in residential buildings," Int. J. Energy Environ., vol. 3, no. 3, pp. 399-408, 2012.

[17] H. Nie and R. Kemp, "Index decomposition analysis of residential energy consumption in China: 2002-2010," Appl. Energy, vol. 121, pp. 10-19, May 2014.

[18] V. Bianco, O. Manca, and S. Nardini, "Linear Regression Models to Forecast Electricity Consumption in Italy," Energy Sources, Part B Econ. Planning, Policy, vol. 8, no. 1, pp. 8693, Jan. 2013.

[19] J. Chen, X. Wang, and K. Steemers, "A statistical analysis of a residential energy consumption survey study in Hangzhou, China," Energy Build., vol. 66, pp. 193-202, Nov. 2013.

[20] W. Gans, A. Alberini, and A. Longo, "Smart meter devices and the effect of feedback on residential electricity consumption: Evidence from a natural experiment in Northern Ireland," Energy Econ., vol. 36, pp. 729-743, 2013.

[21] G. Raffio, O. Isambert, G. Mertz, C. Schreier, and K. Kissock, "Targeting residential energy assistance," Proc. Energy Sustain. Conf. 2007, pp. 489-496, 2007.

[22] M. K. Mattinen, J. Heljo, J. Vihola, A. Kurvinen, S. Lehtoranta, and A. Nissinen, "Modeling and visualization of residential sector energy consumption and greenhouse gas emissions," J. Clean. Prod., vol. 81, pp. 70-80, Oct. 2014.

[23] A. Mastrucci, O. Baume, F. Stazi, and U. Leopold, "Estimating energy savings for the residential building stock of an entire city: A GIS-based statistical downscaling approach applied to Rotterdam," Energy Build., vol. 75, pp. 358-367, Jun. 2014.

[24] J. Schleich, M. Klobasa, S. Gölz, and M. Brunner, "Effects of feedback on residential electricity demand-Findings from a field trial in Austria," Energy Policy, vol. 61, pp. 1097-1106, Oct. 2013.

[25] D. Ndiaye and K. Gabriel, "Principal component analysis of the electricity consumption in residential dwellings," Energy Build., vol. 43, no. 2-3, pp. 446-453, Feb. 2011.

[26] R. Bartels, D. G. Fiebig, M. Garben, and R. Lumsdaine, "An end-use electricity load simulation model. Delmod," Util. Policy, vol. 2, no. 1, pp. 71-82, 1992.

[27] G. Chicco, "Overview and performance assessment of the clustering methods for electrical load pattern grouping," Energy, vol. 42, no. 1, pp. 68-80, 2012.

[28] J. D. Rhodes, W. J. Cole, C. R. Upshaw, T. F. Edgar, and M. E. Webber, "Clustering analysis of residential electricity demand profiles," Appl. Energy, vol. 135, pp. 461-471, 2014. 
[29] A. Al-Wakeel and J. Wu, "K-means based cluster analysis of residential smart meter measurements," Energy Procedia, vol. 88, pp. 754-760, 2016.

[30] K. Zhou, S. Yang, and Z. Shao, "Household monthly electricity consumption pattern mining: A fuzzy clustering-based model and a case study," J. Clean. Prod., vol. 141, pp. 900-908, 2017.

[31] J. P. Gouveia and J. Seixas, "Unraveling electricity consumption profiles in households through clusters: Combining smart meters and door-to-door surveys," Energy Build., vol. 116, pp. 666-676, 2016.

[32] T. Yang, M. Ren, and K. Zhou, "Identifying household electricity consumption patterns: A case study of Kunshan, China," Renew. Sustain. Energy Rev., vol. 91, no. March 2017, pp. 861-868, 2018.

[33] M. Beaudin and H. Zareipour, "Home energy management systems: A review of modelling and complexity," Renew. Sustain. Energy Rev., vol. 45, pp. 318-335, May 2015.

[34] B. Yildiz, J. I. Bilbao, J. Dore, and A. B. Sproul, "Recent advances in the analysis of residential electricity consumption and applications of smart meter data," Appl. Energy, vol. 208, no. October, pp. 402-427, 2017.

[35] L. Poznaka, I. Laicane, D. Blumberga, A. Blumberga, and M. Rosa, "Analysis of Electricity User Behavior: Case Study Based on Results from Extended Household Survey," Energy Procedia, vol. 72, pp. 79-86, 2015.

[36] M. A. Lisovich, D. K. Mulligan, and S. B. Wicker, "Inferring Personal Information from Demand-Response Systems," IEEE Secur. Priv. Mag., vol. 8, no. 1, pp. 11-20, Jan. 2010.

[37] J. I. LERNER and D. K. MULLIGAN, "Taking the 'Long View' on the Fourth Amendment : Stored Records and the Sanctity of the Home," STAN. TECH. L. REV. 3, 2008.

[38] E. McKenna, I. Richardson, and M. Thomson, "Smart meter data: Balancing consumer privacy concerns with legitimate applications," Energy Policy, vol. 41, pp. 807-814, 2012.

[39] E. Zio, The Monte Carlo Simulation Method for System Reliability and Risk Analysis. London: Springer London, 2013.

[40] K. Mandlem, "Abstract Energy Efficiency Effectiveness of Smart Thermostat Based BEMS Koushik Mandlem." West Virginia University, 2018.

[41] Liton Biswas, "What Should Be Standard Size of Rooms in Residential Building? - A Civil Engineer." .

[42] "Degree-Days - Energy Explained, Your Guide to Understanding Energy." Information Publication, US Energy Information Administration, 2017.

[43] “How Much Power Do Your Appliances Use?" [Online]. Available: https://www.wholesalesolar.com/solar-information/power-table.

[44] B. L. Capehart, W. C. Turner, and W. J. Kennedy, Guide to Energy Management, Eighth 
Edition, 8th Editio. Fairmont Press. 